\title{
Emotional Intelligence and Deans: Exploring the Nature of the Emotional Intelligence of Community College Deans in the Southeastern Region of the United States
}

Irene Kasungwa Maundu

West Virginia University

Follow this and additional works at: https://researchrepository.wvu.edu/etd

\section{Recommended Citation}

Maundu, Irene Kasungwa, "Emotional Intelligence and Deans: Exploring the Nature of the Emotional Intelligence of Community College Deans in the Southeastern Region of the United States" (2013). Graduate Theses, Dissertations, and Problem Reports. 3635.

https://researchrepository.wvu.edu/etd/3635

This Dissertation is protected by copyright and/or related rights. It has been brought to you by the The Research Repository @ WVU with permission from the rights-holder(s). You are free to use this Dissertation in any way that is permitted by the copyright and related rights legislation that applies to your use. For other uses you must obtain permission from the rights-holder(s) directly, unless additional rights are indicated by a Creative Commons license in the record and/ or on the work itself. This Dissertation has been accepted for inclusion in WVU Graduate Theses, Dissertations, and Problem Reports collection by an authorized administrator of The Research Repository @ WVU.

For more information, please contact researchrepository@mail.wvu.edu. 
Emotional Intelligence and Deans: Exploring the Nature of the Emotional Intelligence of Community College Deans in the Southeastern Region of the United States

Irene Kasungwa Maundu

Dissertation submitted to College of Education and Human Services at West Virginia University in partial fulfillment of the requirements for the Degree of

Doctor of Education in

Educational Leadership Studies, Higher Education Administration

Reagan P. Curtis, Ph.D, Committee Chair Adriane Williams, Ph.D Helen Hazi, Ph.D Ernest R. Goeres, Ph.D Gerald Blakely, Ph. D

Department of Educational Leadership Studies

Morgantown, West Virginia

2013

Keywords: emotional intelligence, community college deans, leadership Copyright $@$ Irene Kasungwa Maundu 


\section{Abstract \\ Emotional Intelligence and Deans: Exploring the Nature of the Emotional Intelligence of Community College Deans in the Southeastern Region of the United States}

\section{Irene K. Maundu}

Leadership is an essential aspect of community college administration. Community colleges are currently facing numerous challenges such as: above average retirement rates for administrators, funding and limited government support, diverse student populations, changes in technology, shift in teaching to student-centered learning, and steep competition. The purpose of this study was to understand the nature of the emotional intelligence of community college deans within the southeastern region of the United States of America. I used the Mayer-Salovey-Caruso Emotional Intelligence Test (MSCEIT) to measure the emotional intelligence scores of community college deans, and a demographic questionnaire for the demographic variables. Public community college deans from the entire southeastern region of the United States of America were selected for the survey. I sent a total of 323 invitations to community college deans from 294 public community colleges in the southeastern region of the United States. Findings from this study indicated that total emotional intelligence, using emotions, and managing emotions were not statistically significant with any of the demographic characteristics. There was a significant negative relationship between gender, size of institution, level of education, and perceiving emotions. Male participants had low levels of perceiving and understanding emotions when compared with females. Level of education and experience were also significant with understanding emotions. This study provided a snapshot of the nature of the emotional intelligence of community college deans in the southeastern region of the United States, adds to the available information on emotional intelligence in general, and also provides insights for future research. 


\section{Dedication}

This dissertation is dedicated to: My dad, Joseph Maundu, who has been supportive of me throughout my studies, inspiring, encouraging me along my journey, and believing in me even when I had doubts; My Mom, Angelina Katheu, for lending a listening ear and believing in me; My siblings, for putting up with me; and to Hillary and our kids, Carlos, Carla, and Calista. 


\section{Acknowledgements}

Thank you God Almighty, for your mercy and grace. You guided me throughout this journey and I can bear witness of your love. May this degree bring glory and honor to your name. My deepest and sincere gratitude goes to all the wonderful people that the Lord placed into my life through this academic journey.

Thank you to all my advisors: Dr. Reagan Curtis, thank you so very much for your time, support, and encouragement. I would have been lost without your guidance in statistics and data analysis. Your patience has taught me a great deal. I hope to someday become a great teacher and mentor as you. Dr. Adriane Williams, for your constant support and encouragement. You are an amazing and wonderful mentor that I will always look up to. I am honored to have had a chance to work with you. Dr. Helen Hazi, thank you for starting off this chapter of my life with me, leading me in the right direction, and supporting me to the end. Thank you for your inspiration and encouragement. Dr. Earnest Goeres, thank you for going the extra mile and lending a listening ear when things seemed impossible, for staying on the committee even unto retirement. Dr. Gerald Blakely, thank you for your encouragement through this journey.

To my family: my parents Joseph Maundu and Angelina Katheu, for supporting and teaching me the value of education at a young age. Dad, thank you for encouraging and believing in me, even when I didn't have much faith in myself. Mom, for your patience, strength, and love. Through you, I have learned the value of perseverance and forgiveness. Thank you for holding it together when things seemed impossible: to my siblings; Munyiva, Mumo, Ngene, Salima, Mbithi, and Mulendi, thank you for all your support; to my grandma, Beatrice Ngene, for all the sleepless nights you spend watching the kids for me. I can never thank you enough; to Hillary, for your support; to the kids, Carlos Kiptoo, Carla Katheu, and Calista Chebet, for all the events 
and time I spend away from you guys. I love you so very much and I hope to spend more quality time with you guys soon.

Lastly, I acknowledge Jennifer McIntosh, through the office of social justice, for your moral and financial support; Dr. Dooley, for your inspiration and support; and to all my friends who have been with me throughout the years. Thank you all. 


\section{Table of Contents}

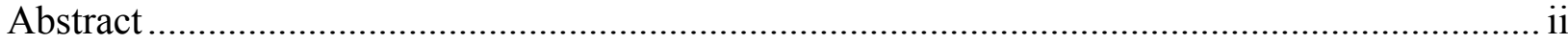

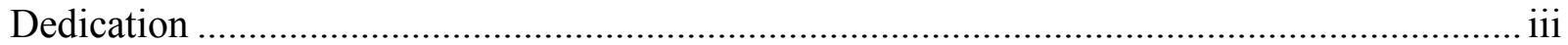

Acknowledgements ...................................................................................................... iv

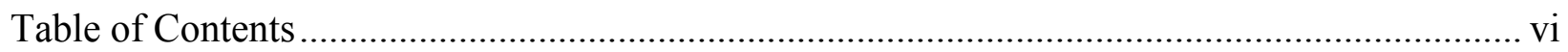

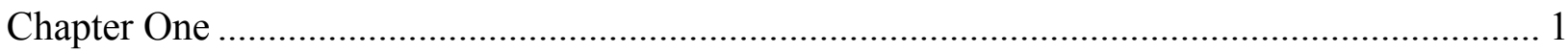

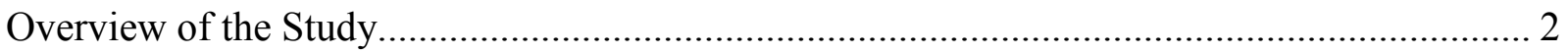

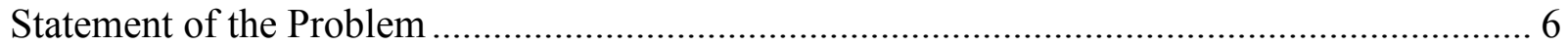

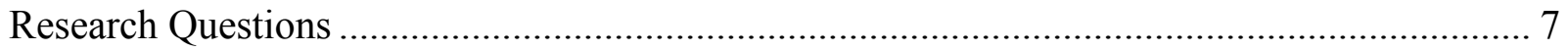

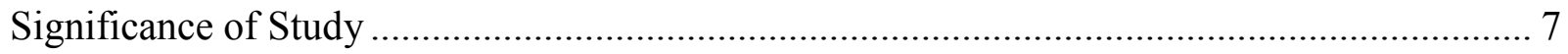

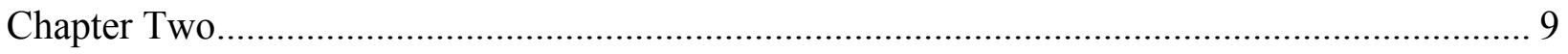

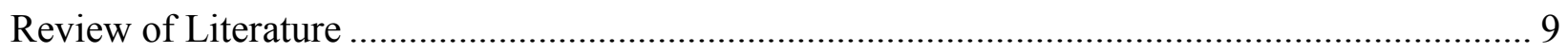

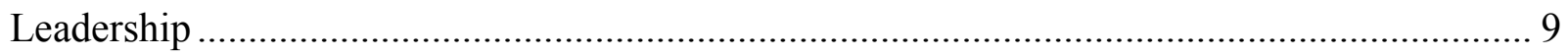

Approaches to the study of leadership................................................................................ 10

Emotional Intelligence ………………………………................................................ 18

Approaches of Emotional Intelligence .................................................................................. 25

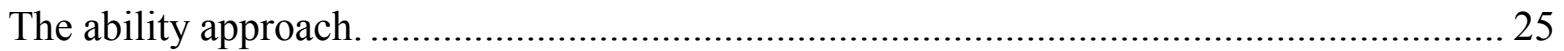

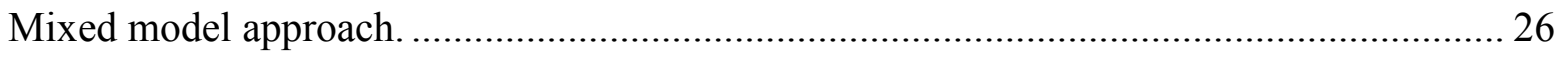

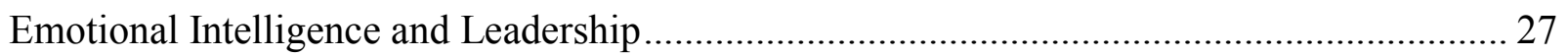

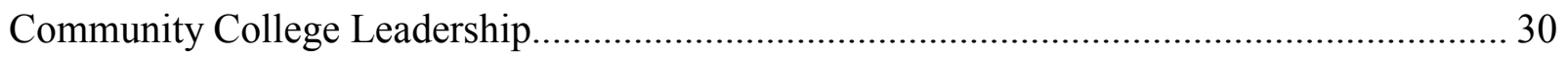

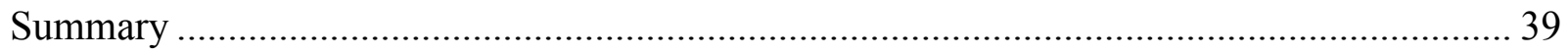

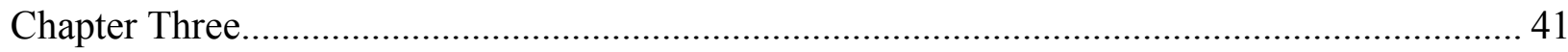

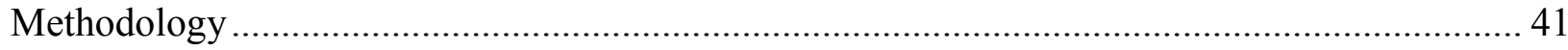

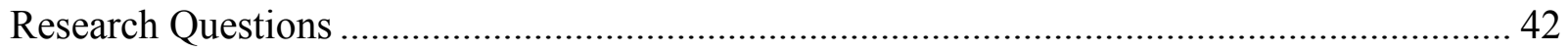

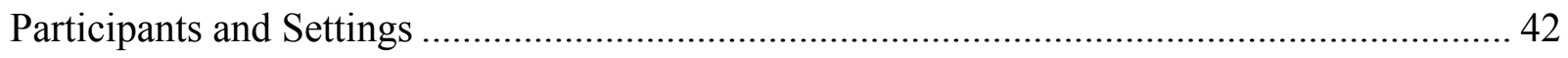




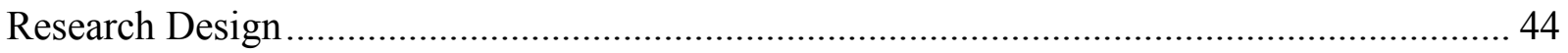

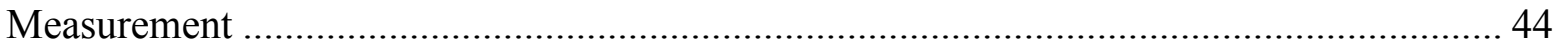

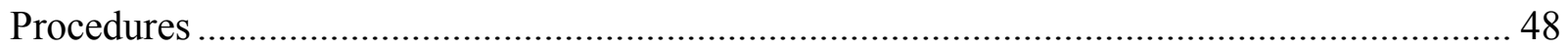

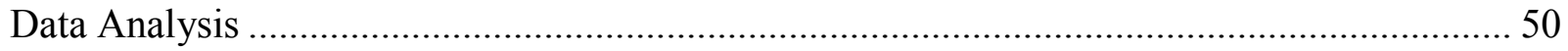

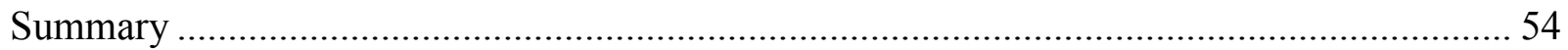

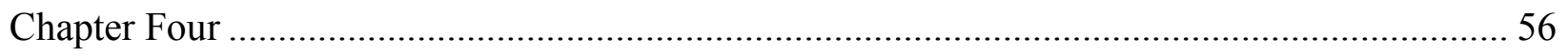

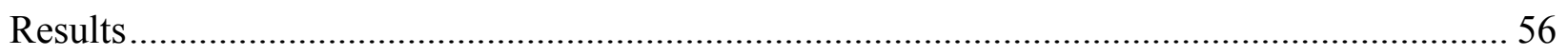

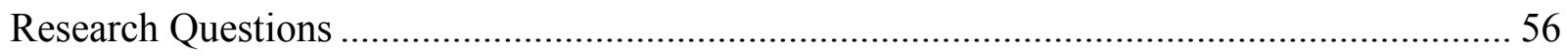

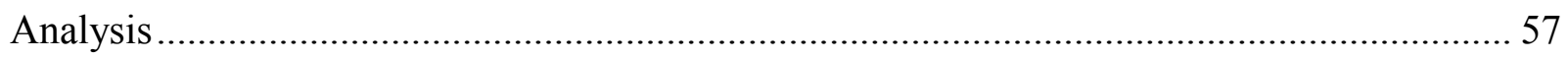

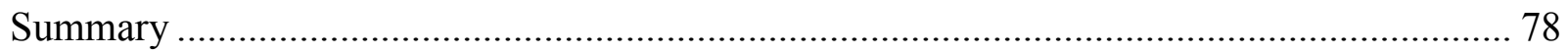

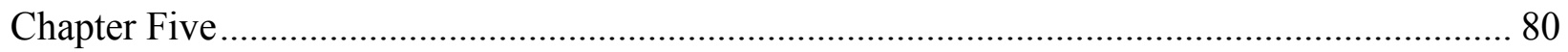

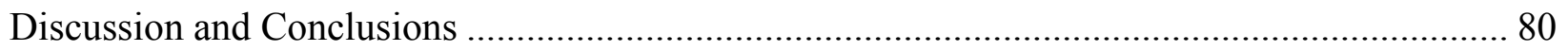

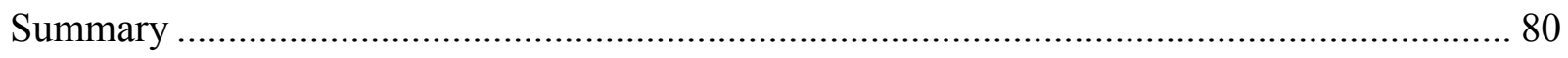

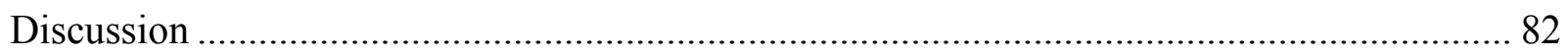

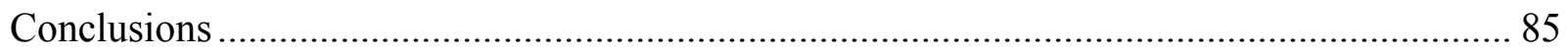

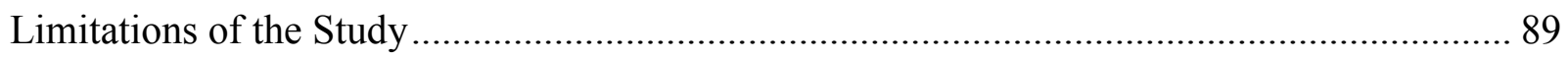

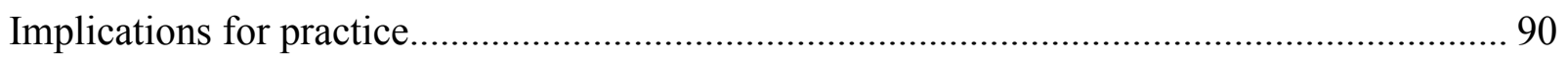

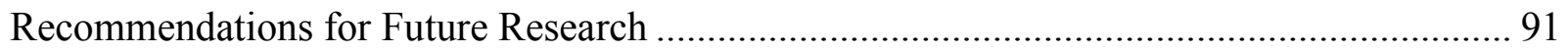

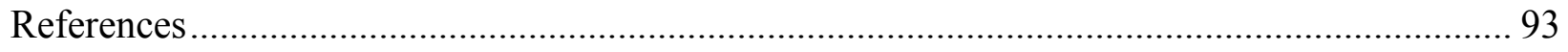

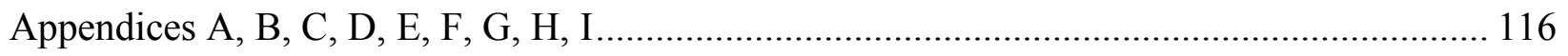

Appendix A: Mayer-Salovey-Caruso Emotional Intelligence Test (MSCEIT) - Request to use

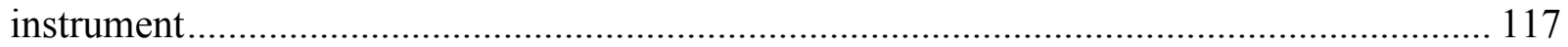

Appendix B: Mayer-Salovey-Caruso Emotional Intelligence Test (MSCEIT) - Permission to

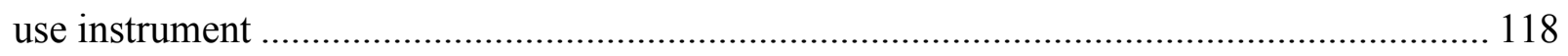

Appendix C: MAYER-SALOVEY-CARUSO EMOTIONAL INTELLIGENCE ................. 119

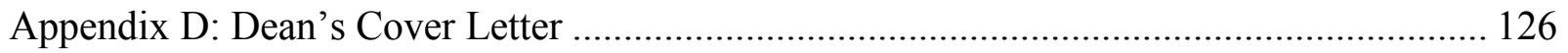




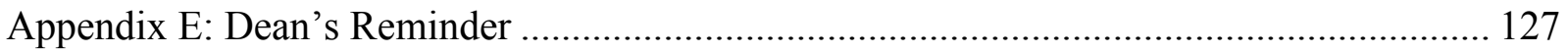

Appendix F: Demographic follow up Questions................................................... 128

Appendix G: Approval to use Table 4.1 from the MSCEIT Manual .................................... 129

Appendix H: Permission to use Table 4.1 from the MSCEIT Manual - Request to use table

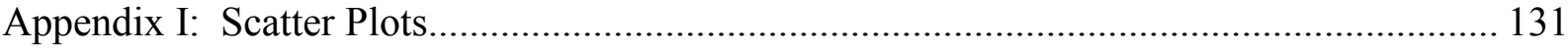




\section{Chapter One}

I have always been fascinated by the numerous roles that leaders play in society, and I have often wondered what I could do to contribute to the available information on leadership. Learning about emotional intelligence and its role in leadership increased my desire to determine if there were any links between one's level of emotional intelligence and demographic characteristics.

The idea of different forms of intelligence is a recent phenomenon introduced within the last few decades. This notion has led to debate around and doubts about the usefulness and effectiveness of relying on the regular cognitive intelligence (IQ) to determine the success or failure of an individual in life. Good leadership requires more than cognitive intelligence (Bennis, 1989; Goleman, 1995). Emotional intelligence plays a significant role in leadership (Goleman, 1995). Leaders in today’s competitive world require numerous skills and competencies in order to be successful. This is especially imperative for community college leaders whose roles are more complicated than in other postsecondary institutions of learning. Community college leaders serve the communities at-large and have diverse student populations. Community colleges must also face numerous retirements in the early to mid- $21^{\text {st }}$ century (Boggs, 2003; Carroll, 2004; Evelyn, 2001; Shults, 2001; Weisman \& Vaughan, 2007). This makes it necessary and important to investigate some of the emotional intelligence competencies that community college deans use and further determine if any relationship exists between these competencies and selected demographics.

The style of a leader in most cases helps determine how effective and successful a leader is (Northouse, 2004). A successful leader relies heavily on the components of emotional intelligence in that leadership revolves around building relationships. I found limited previous 
research on postsecondary institutions of learning about the relationship between emotional intelligence and demographic information. Findings from this study serve to extend the literature base on the importance of emotional intelligence in the academic world of postsecondary education.

Results from this study provide an opportunity for community college deans to explore their own emotional intelligence and provide insight on the importance of emotional intelligence competencies in leadership.

The study contributes to the body of knowledge in understanding important aspects of emotional intelligence that are common to community college deans. It also provides empirical evidence on the relationship between emotional intelligence and demographic information. In addition, findings from the study provide useful information that could be used for future professional development programs.

\section{Overview of the Study}

Multiple intelligences was introduced within the last few decades. The notion of a different kind of intelligence, other than the IQ, has led to increased growth in interest of factors that contribute to the success or failure of individuals in life. Human beings have different capacities and capabilities that help them perform in different areas and functions of their daily life (Gardner, 1992). The use of the IQ as the only measure to determine if a person is intelligent and if they are likely to be successful or experience failures in life is not entirely accurate. This is because being academically bright does not necessarily mean that a person will apply the academic knowledge appropriately in different life situations (Gardner, 1992). The intellectually smart people in society are not necessary the most successful, either in business or personal life (Cooper \& Sawaf, 2007). 
Emotional intelligence consists of competencies that are good predictors of success or failure in life (Goleman, 1998; Mayer, Salovey, \& Caruso, 2000). Goleman (1995) argued that the use of the regular IQ as the sole measure of intelligence is misguided in that one has to learn to control emotions in order to be successful. Other means of intelligence have to be considered when determining the direction that a person is likely to take in life. Rosenthal (1977) discovered that people who were able to recognize emotions in others were more sociable and successful in their work.

Leadership in any organization plays an important role in the daily operations and smooth running of the organization. In some cases, the leaders of a particular group share a common culture and values that are either openly communicated or mutually agreed upon by all members. The success or failure of any organization depends on the leadership of the organization. Many organizations and institutions perish and some become extinct under poor leadership. Community colleges need effective, efficient, and reliable leaders to be successful in today's competitive society (Robillard, 2000).

Good leadership relies heavily on personal and character aspects of the leader (Bass, 1990a; Hersey \& Blanchard, 1993). A great leader is a person with values, temperament, and character and uses his/her personality to influence others towards a common goal (Northouse, 2004). It is essential for a leader to have the right attitude towards his/her job, fellow employees, and staff. It is also important for leaders to look within themselves and understand their own skills, strengths, and competencies in order to be successful (Goleman, 1998; Van Der Zee \& Wabeke, 2004). Leaders who are aware of their capabilities and weaknesses are likely to influence people and situations in an effective way (Goleman, 2006a). This gives others a sense of direction and confidence that they are in the right hands for direction. Moreover, for a leader 
to exercise and exhibit these skills and qualities, one has to rely heavily on other forms of intelligence.

Successful leadership requires more than cognitive intelligence. Successful leaders rely heavily on the components of emotional intelligence in that leadership revolves around building relationships. Being academically smart is an added advantage, although it is not the only aspect that makes good leaders successful (Goleman, 1998; Van Der Zee \& Wabeke, 2004). Essential character elements should not be ignored in creating and striving for successful leadership. Managing our emotions and understanding other people's emotions help people become more productive in their different roles in society. In addition, these areas assist in motivating and influencing others to become productive members of the society.

A good leader exhibits numerous characteristics in the work place and different environments. Compassion and empathy are important aspects of a leader. Being consciously aware of another person's intentions makes it possible to accurately direct empathy and better predict what the other person is likely to do (Goleman, 2006b). Goleman, Boyatzis, and Mckee (2002) asserted that people tend to watch a leader's emotional state by carefully watching how expressively the leaders face, gestures, and voice convey their feelings. Those who are skilled at transmitting emotions are likely to experience more passion and commitment from others. The ability to accurately read other people's emotions can be useful in determining different outcomes. Successful leadership also involves offering support and attention to followers by listening to their concerns prior to offering suggestions. An emotionally intelligent leader is likely to show concern to his employees, which gives followers a feeling that someone really cares and values them. A leader does not necessarily have to agree with followers, but offering a listening ear goes a long way toward maintaining good working relationships. Employees who 
have good relationships with their leader are more productive and loyal. This is an indication that emotional intelligence and a good understanding of human nature and values are essential in developing leadership skills.

It is important for a good leader to connect with his/her followers; failure to connect may render the leader unsuccessful. A leader has to have influence on those being led (French \& Raven, 1959). This is only possible if the leader has an awareness of self and others (Goleman, 2006a). Ability to control and manage emotions makes it possible for a leader to appear composed even in times of extreme pressure. Self-awareness is essential in successful leadership. Failure to recognize an individual's emotions could negatively impact relationships with others (Goleman, 2006a; Mayer, Salovey, \& Caruso, 1998).

Managing one's emotions is essential in managing negative emotions such as anxiety, anger, fear, etc. (Goleman, 1995). This leaves room for strong relationships. Additionally, a good leader should strive to create lasting positive impressions on followers in order to effectively and efficiently accomplish goals (Goleman, 1995). First impressions play a major role in the type of relationships that we are likely to develop. Whatever our brains register at first contact is likely to be imprinted in our brains for a long time (Goleman, 1995; 1998). Followers are likely to relate well and have a sense of respect for their leaders if they are composed and approachable.

Some people have complete control of their emotions in that they are aware of different moods as they experience them and tend to have some sophistication about their emotional lives. Other people become engulfed in their emotions and feel swamped and helpless as different emotions occur (Goleman, 1995; 2006a). Such people often feel overwhelmed and emotionally out of control, which could negatively affect relationships in the work place. Taking charge of one's emotions is important in decision-making. Decisions made by leaders affect all members 
of the organization. It is therefore important to make those decisions while in control. Ability to take charge in different situations calls for composure, self-control, and awareness in a leader (Goleman, 1995).

Leadership in postsecondary education is in dire need of emotionally competent leaders. In the arena of postsecondary education, the use of IQ and knowledge of the academia is essential for successful leadership. However, reliance on the IQ as the only basis of selecting leaders is likely to fail in that one can easily gain promotions and influence through IQ, but sustainability of good leadership is only possible through the utilization of emotional intelligence competences. Goleman (2006a) argues that emotional intelligence matters twice as much for success over technical skills because being an expert in a particular area does not necessarily mean good leadership. Even though the use of cognitive IQ is still important in different spheres of life, a good leader has to be able to handle self and others. In this study I examined the relationship between the emotional intelligence of community college deans and selected demographics.

\section{Statement of the Problem}

There are several factors that influence leadership of community college administration. To provide an opportunity for successful leadership, there is need for scientific and empirical analysis. There was limited available information about community college deans in general. The objective of the study was to gain a sense of the presence and distribution of emotional intelligence among community college deans. The purpose of the study was to understand the nature of the emotional intelligence of community college deans in the southeastern region of the United States and determine the relationship between emotional intelligence and selected demographics. 


\section{Research Questions}

In order to achieve the goals of this investigation, I used the following questions to guide this study:

1. Who are the community college deans in the southeastern region of the United States of America? What are their demographic characteristics?

2. What is the emotional intelligence of the community college deans?

3. Is there any relationship between the emotional intelligence of the community college deans and selected demographics of age, gender, race, experience, institution size, and education level?

\section{Significance of Study}

The study of emotional intelligence and its significance in the work place has evolved within the last couple of decades. There was a substantial amount of previous research available on the importance of emotional intelligence in business organizations and a limited amount of research in reference to educational settings. Review of available literature indicated that emotional intelligence and its relationship to community college leadership warrants further investigation. Most of the available literature was based on logical arguments with few empirical findings to support the arguments.

Results from this research can be valuable to community college deans who seek to enhance their understanding of emotional intelligence in leadership. Information from this research may be utilized in future professional development programs. Researchers may also find the results of this study useful in future research. Community college deans play an important role in administration and this research provides useful information for the general improvement of deanship. 
This study provides important information on the emotional intelligence of community college deans. It also provides empirical evidence on the relationship between emotional intelligence and the selected demographics of age, gender, race, education level, size of institution, and experience. Understanding the relationship between emotional intelligence and these demographic characteristics may assist current and future community college deans in successfully performing different administrative roles.

For this study, data was collected to explore the emotional intelligence of community college deans and the selected demographics. This provided an opportunity for community college deans to explore their own emotional intelligence and provided insight as to its impact on leadership. The questionnaire provided an opportunity for community college deans to identify areas of emotional intelligence that are important or lacking in their leadership.

The study contributes to the body of knowledge in understanding important aspects of emotional intelligence that are common to community college deans. It also serves to extend the literature base on the importance of emotional intelligence in postsecondary education. 


\section{Chapter Two}

\section{Review of Literature}

Emotional intelligence plays a major role in the success or failure of leaders. Goleman (1995) argues that it is important for individuals to learn different ways of controlling and understanding their emotions in order to relate well with others. According to Goleman (1995), emotional intelligence refers to human abilities that include self-control, zeal, persistence, and self-motivation.

In this chapter, I present the literature on leadership in general, emotional intelligence, approaches of emotional intelligence, emotional intelligence and leadership, and community college leadership.

\section{Leadership}

Leadership in any organization determines the success or failure and the direction the organization takes (Batten, 1989). Different institutions and organizations require different types of leaders based on individual institutional characteristics (Yukl, 1999). Emotional intelligence is an important skill in a leader's response to different situations (Snuggs, 2006).

There has been a significant growth of interest in leadership over the years (Astin \& Astin, 2000; Bagshaw \& Bagshaw, 1999; Bensimon, 1989; Bennis \& Nanus, 1985; Bowen \& Shapiro, 1998; Chaudry, 2000; Davis, 2003; Goffee \& Jones, 2000; Hackman \& Johnson, 2000; Higgs, 2002; Kouzes \& Posner, 1995). Despite the growth in interest, there is still little that effectively defines the nature of successful leadership (Birnbaum, 1992; Davis, 2003; Eddy \& Van Der Linden, 2006; Green, 1997; Kets De Vries, 1994; Rost, 1991). In his review on leadership, Stogdill (1974) concluded; "there are almost as many definitions of leadership as there are persons who have attempted to define it" (p. 259). This statement properly characterizes 
the current situation on leadership. Levinson (1996) also made the following observation on leadership; “...leadership is like beauty, it is hard to define but you know it when you see it" (p.158).

With the confusion on the definition of leadership, Chemers (1993) suggested the need for the integration of different leadership theories and approaches to provide a unified definition of leadership. His suggestion was contested by many researchers who felt that the term leadership was too broad and could not be conceptualized into a unified definition (Bass, 1990; Birnbaum, 1992; Hersey \& Blanchard, 1993; Rost, 1993).

The inability to identify a unified definition creates challenges in leadership development (Birnbaum, 1992; Rost, 1991; 1993). Some of the challenges created by a failed unified definition include the constantly changing nature of personality characteristics (traits) and the contingent nature of leadership (Bass, 1990; Hersey \& Blanchard, 1993; Rost, 1993). Leslie and Van Velsor (1996) tried to identify some of the characteristics that are associated with successful leadership. They conducted interviews of executive managers and found that interpersonal skills, technical cognitive skills, emotional stability, and composure were some of the key factors.

\section{Approaches to the study of leadership.}

There are numerous aspects of leadership theories that are closely linked to emotional intelligence. In trying to understand the connection between leadership and emotional intelligence, one has to consider different aspects of leadership and their influence on the success or failure of a leader. To address some of the challenges, I will focus on several approaches that are associated with leadership. 


\section{Traits approach.}

The traits approach to leadership is based on the great man theory that was prominent in the early $20^{\text {th }}$ century. The Great man theory postulated that leaders are born and not made (Burns, 1978; Johnson, 2005; Stogdill, 1974). Leadership traits refer to the things that people see in the people they consider leaders (Stogdill, 1948). Most trait theories examine inherent personality characteristics that distinguish leaders from followers (Hersey \& Blanchard, 1993; Howell \& Costley, 2001; Stogdill, 1948; Rost, 1993). Northouse (2004) defined leadership traits as the personal characteristics and skills that leaders use as part of his/her behavior or character. These traits could be physical characteristics such as decisiveness, charisma, confidence, and empathy.

Some theorists believe that some people are born with the natural traits of a leader, while other people develop leadership skills through learning, experience, and training (Hersey \& Blanchard, 1993; Stogdill, 1948). Stogdill (1948) examined different studies on traits and personal factors related to leadership. He identified several characteristics that could be associated with successful leadership. Some of these traits include:

- Strong drive for responsibility

- Persistence in completion of tasks

- Self confidence

- Sense of personal identity

- Willingness to accept consequences of decisions made

- Ability to be patient

- Originality in problem solving

- Self confidence 
In his analysis, Stogdill (1948) asserted that in most cases, followers identified leaders through their ability to get things done in an effective way. From his review, Stogdill (1948) concluded that "a person does not become a leader by virtue of possession of some combination of traits, but the pattern of personal characteristics of the leader must bear some relevant relationship to the characteristics, activities, and goals of the followers" (p. 64). Another study conducted by Stogdill (1974) in which 163 trait studies were reviewed found that successful leaders were adaptable to different situations, alert to their social environment, decisive, energetic, self-confident, tolerant to stress, and cooperative (Yulk, 1981).

The emphasis on different traits has been criticized by numerous researchers who claim that reliance on personal qualities ignores other important aspects of leadership such as knowledge, skills, education, and situation (Hersey \& Blanchard, 1993; Howell \& Costley, 2001; Yulk, 1981). This has led to variations in the different characteristics that identify leaders and has led to confusion and lack of agreed upon set of traits. Some researchers have adopted a balanced point of view and suggest that successful leadership is impacted by factors such as personal traits, situation, and relationship between leaders and followers (Green, 1997; Hersey \& Blanchard, 1993; Kelley, 1998).

The leadership traits identified by Stogdill and others fall under emotional intelligence in that the ability to interact well with others and effectively manage one's emotions eventually lead to the development of other leadership attributes, which in turn result in effective and successful leaders.

\section{Leadership style approach.}

Kurt Lewin and Associates at the University of Iowa first developed this approach in the mid-1930s (Lewin, 1935). They conducted studies focused on the leadership style of the 
manager. This was a shift from the trait theories that had focused on the traits of a leader to an approach focused on the behavior of the leader.

The style approach is divided into two areas of behaviors which include task behavior and relationship behaviors (Bass, 1990a). This approach focuses on the actions of the leader but not on their personalities, or who they actually are as human beings. Researchers at Ohio State developed a style questionnaire, The Leader Behavior Description Questionnaire (LBDQ) and asked subordinates to identify the number of times that the leader engaged in certain behaviors (Hemphill \& Coons, 1957). The results from the study identified two areas of leader behavior that were important in leadership. These areas included initiating structure and consideration.

Initiating structure is when the leader identifies clear forms and channels of communication by defining the different roles of the leader and those of the subordinates. Initiating consideration is when the leader cares about the subordinates and creates a warm, friendly, and supportive environment. The Ohio study found the two behaviors to be completely independent in that a leader could choose to exhibit varying degrees of initiating structure and consideration at the same time or different times in leadership. A similar study at Michigan that was focused on identifying relationships among group process, group performance, and leader behavior identified employee oriented and production oriented as key leader behaviors (Yulk, 1981). Initiating structure was found to correspond to the production oriented perspective, while consideration dimension was similar to employee orientation (Hersey \& Blanchard, 1984).

The style approach to successful leadership is influenced by emotional intelligence in that leaders have to show emotion and signs of concern for others. This influences the way they interact and relate with the followers. Their actions are dictated by their ability to control their emotions and relate with others (Goleman, 1998; 2000; Mayer, Salovey, \& Caruso, 1998). The 
choice of a leader to use a particular leadership style is influenced by the nature of organization, followers, and a leader's level of expertise (Northouse, 2004).

\section{Situational approach.}

Halpin (1955) suggested that leaders exhibit numerous behavior traits when faced with different leadership situations. The situational approach to leadership was developed based on a 3-dimensional-leadership style theory (Reddin, 1967). A later version of the situational approach by Hersey and Blanchard (1969) suggests that a leader ought to be flexible and able to use different styles when relating with different people.

Most situational approach models of leadership are based on the assumption that leadership success and effectiveness can be increased through training, education, and development (Hersey \& Blanchard, 1993; Howell \& Costley, 2001). The theory urged the use of different approaches for different situations and considered leadership as a process with emphasis on the behavior of the leaders and followers (Blanchard \& Zigarmi, 1985; Hershey \& Blanchard, 1993; Howell \& Costley, 2001). This approach to leadership requires the leader to adjust his/her leadership style after analyzing the situation.

\section{Power and leadership theories.}

The power and leadership theories focus on the use of power to influence followers. French and Raven (1959) identified different types and bases of power, social influence, and their impact on different organizations. They pointed out the importance for organizations to identify the best type of power that is appropriate depending on the nature of activities and organizational goals. It has been noted that power and influence go hand in hand and one can hardly be effective without the other (French \& Raven, 1959). Most researchers have identified

two main aspects of power: a) social power and b) social exchange. Bass (1990b) defined social 
power as the ability to take charge through influence. Bensimon (1989) defined social exchange as the process through which both the leaders and the followers gained through a mutual relationship. Social influence takes place after an intentional act on the part of the leader, which could lead to either a positive influence or negative influence (French \& Raven, 1959). Positive influence is when the reaction is what the leader expected of the followers while negative influence is when the intended behavior is not achieved after influence has been exerted.

French and Raven (1959) identified different sources of power that include coercion, legitimating, rewarding, expertise, and symbolic. Coercive power is based on the leader's ability to manipulate the followers to meet organizational goals and objectives. Followers conform to the leaders influence because they believe that dire consequences could follow if they do not follow orders or perform as expected. Legitimate power stems from internalized values in the followers about their leader. These values dictate that the leader has a legitimate right to influence the followers and the followers have an obligation to accept and obey this influence. Reward power is based on the ability to give rewards to followers. The followers believe that the leader has the ability to mediate towards them. Expert power comes from one's knowledge in a specific area. Followers think that the leader is knowledgeable and trusts his/her judgment. Finally, symbolic power is derived from the leader's association or identification with the followers. The followers identify with the ideals for which the leader stands (French \& Raven, 1959). All these sources of power could be used alternately in different educational settings. The ability to influence followers in a successful way leads to increase in productivity and creation of harmony in the work place. It is important for leaders to exert expert and referent power in order to be considered reliable and trustworthy (Bensimon, 1987). For any leader to be successful, he or she has to have some form of power over others (French \& Raven, 1959). 
However, for any source of power to be effective, the leader has to have good mastery of his emotional intelligence in order to relate with others, build and maintain relationships, and exert influence (Birnbaum, 1988; Hollander, 1995). One has to have strong communication skills and a clear grasp of his emotions in order to be a successful leader. Most of the aspects and factors that lead to successful leadership focus on creating healthy and meaningful relationships with others in order to create a balance between personal and organizational goals.

Transactional, transformational, and laissez faire leadership approaches.

Burns (1978) introduced the concept of transactional and transformational leadership. He distinguished the two leadership styles on the basis of what leaders and followers had to offer one another (Judge \& Piccolo, 2004). Burns argued that transactional and transformational leaderships represented opposites in a single continuum, with transformational leadership on the one end, transactional leadership in the middle, and laissez faire on the other end. Transformational leadership is focused on intrinsic needs while transactional leadership is focused on exchange of resources. Bass (1985) based his arguments on Burn's conceptualization of transformational and transactional leadership. He argued that the two leadership styles were not opposites, but rather different concepts.

Avolio and Bass (1988) identified four dimensions of transformational and three dimensions of transactional leaderships. The transformational dimensions include idealized influence, inspirational motivation, intellectual stimulation, and individualized consideration. Idealized influence refers to behaviors from the leader which helps develop trust. The followers view the leader as a role model and try to emulate him. Inspirational motivation refers to behaviors that inspire followers through setting high standards and expectations. The leader communicates expectations. Intellectual stimulation is when the leader encourages creativity, 
solicits ideas from the followers, and offer support. Lastly, individualized consideration is when the leaders make followers feel valued, accepted, and unique. The leader helps develop selfesteem and promotes personal development of the followers (Bass \& Avolio, 1993; Bass, 2002).

The three dimensions of transactional leadership include contingent reward, management by exception-active, and management by exception-passive. Contingent reward refers to when the leader sets up goals and expectations and outlines the rewards that the followers will receive after completion of tasks. Management by exception-active and management by exceptionpassive are based on the time when the leader decides to intervene. Active leaders closely monitor the behavior of the followers and take action before behaviors develop into chaos or serious problems, while passive leaders do not pay attention to the followers and do not take action until behaviors cause problems to the organization (Bass \& Avolio, 1993).

Transactional leadership has been associated with the exchange of incentives for performance and compliance. Transformational leadership is based on empowerment of the followers and encouraging them to achieve their maximum potential. Transformational leaders are likely to be creative, visionary, passionate, and empowering (Hackman \& Jonson, 2000). They can convert followers into leaders themselves. Laissez faire leaders tend to be absent when needed and avoid making decisions when possible (Avolio, Waldman, \& Einstein, 1988; McClelland, 1975).

Transformational leadership has been closely linked to emotional intelligence. Burns (1978) suggested that in transformational leaders, followers were able to develop a sense of trust and admiration for the leader. Transactional leadership on the other hand involved bargaining processes that eventually lead to development of values such as fairness, honesty, and trust. Bass 
(1985) concluded that successful leaders used a combination of both transactional and transformational approaches.

\section{Emotional Intelligence}

Originally, most research on intelligence was focused on cognitive aspects, such as mathematical problem solving. Wechsler (1958) was among the earlier researchers to recognize that non-cognitive aspects of intelligence were also important. Wechsler (1958) defined intelligence as "...the aggregate or global capacity of the individual to act purposefully, to think rationally, and to deal effectively with his environment" (p.7).

Emotional intelligence is being recognized as a significant factor in academics and general life experiences (Cooper \& Sawaf, 1997; Min, 2010). Goleman (1995) argued that IQ accounted for approximately $20 \%$ of the factors that were associated with success in life, while emotional intelligence accounted for the remaining factors. In his study, Goleman (1995) questioned the over reliance of IQ in his arguments;

...what factors are at play...when people of high IQ flounder and those of modest IQ do surprisingly well? I would argue that the difference quite often lies in the abilities called here emotional intelligence, which includes self-control, zeal, persistence, and the ability to motivate oneself. p.12

Emotional intelligence plays a great role in everyday life (Cooper \& Sawaf, 1997). Cooper and Sawaf (1997) asserted that "modern science is proving every day that it is emotional intelligence, not IQ or raw brain power alone, that underpins many of the best decisions, the most dynamic and profitable organizations, and the most satisfying and successful lives" (p. 12).

Since the popularity of emotional intelligence, researchers have found that emotional intelligence is associated with numerous positive outcomes in different environments. Emotional 
intelligence has been found to have positive outcomes in relation to leadership, work attitude, resistance to stress, creativity, career achievement, job satisfaction, and performance (Bar-On, Brown, Kirkcaldy, \& Thorn, 2000; Cooper \& Sawaf, 1997; Goleman, 1995; Higgs \& Dulewitz, 1999; Min, 2010). The application of emotional intelligence in organizations makes a difference in critical success factors such as leadership, open communication, decision making, loyalty, creativity, innovation, and strategic technical breakthroughs (Cooper \& Sawaf, 1997). The ability to control emotions is likely to lead to success in life (Feist \& Barron, 1996; Goleman, 1995; Salovey, Bedell, Detweiler, \& Mayer, 1999).

Several researchers have attempted to define emotional intelligence. Salovey and Mayer (1990) coined the term emotional intelligence and defined it as "a form of intelligence that involves the ability to monitor one's own and others' feelings and emotions, to discriminate among them, and to use this information to guide one's thinking and action" (p. 189). Higgs and Dulewitz (1999) used the personal capabilities approach and defined emotional intelligence in the following way: “...achieving one's goals through the ability to manage one's own feelings and emotions, to be sensitive to, and influence other key people, and to balance one's motives and drives with conscientious and ethical behavior" (p. 20). Cooper and Sawaf (1997) defined emotional intelligence as "....the ability to sense, understand, and effectively apply the power and acumen of emotions as a source of human energy, information, connection and influence" (p. 13). Initially, Goleman (1995) defined emotional intelligence as consisting of: abilities such as being able to motivate oneself and persist in the face of frustrations, to control impulses and delay gratification, to regulate one's moods and keep distress from swamping the ability to think, empathize and to hope. p. 34. 
Several years later, Goleman (1998), defined emotional intelligence as "the capacity for recognizing our own feelings and those of others, for motivating ourselves, and for managing emotions well in ourselves and in our relationships" (p. 318). Goleman (1998) also noted that, “emotional intelligence determines our potential for learning the practical skills that are based on five elements: self-awareness, motivation, self-regulation, empathy, and adeptness in relationships" (p. 24). Bar-On (1997) also defined emotional intelligence as, "an array of noncognitive abilities, capabilities, and skills that influence one's capacity to succeed and to cope with environmental demands and pressures" (p.3).

Salovey and Mayer (1990) identified five domains of emotional intelligence. These domains include knowing one's emotions, managing emotions, motivating oneself, recognizing emotions in others, and handling relationships. Knowing one's emotions (know thy self) refers to the ability to recognize feelings as they occur. Goleman (1995) argued that the ability for individuals to monitor feelings from moment to moment made it possible to control their reaction to emotions. Some people have complete control of their emotions in that they are aware of the different moods as they experience them and tend to have some sophistication about their emotional lives, while other people get engulfed in their emotions and feel swamped and helpless as different emotions occur. Such people often feel overwhelmed and emotionally out of control. Good leaders ought to have some control of their emotions in order to successfully and efficiently relate with others.

Managing emotions refers to the ability to handle emotions appropriately. It is the capacity to sooth oneself, shake off rampant anxiety, and unpleasant emotions. People who are good at managing their emotions are likely to bounce back quickly from unpleasantness and life's ups and downs. Motivating oneself is the ability to delay gratification and impulsiveness. It 
is also the ability to channel emotions towards productive means by motivating oneself to persist in completing tasks even in times of great difficulties (Goleman, 1995).

Recognizing emotions in others refers to the ability to understand the feelings of other people through empathy. Empathy builds on self-awareness. People who are emphatic are attuned to the social signals that indicate the emotional state of others and are likely to come up with ways of helping and effortlessly relating with others. Lastly, handling relationships refers to managing emotions of other people. It is the ability to be sensitive to other people's emotions in a manner that maintains positive relationships (Goleman, 1995).

Different people have different aspects and degrees of the five domains, with some people being able to control and manage their emotions, yet being very poor in relating and understanding others (Goleman, 1995). Successful leaders should strive to create some form of balance between the domains depending on their goals.

The reliance on cognitive intelligence (IQ) as a determiner of success or failure of an individual in life has been typical in the past; however, several studies on the limitations of the IQ have proved that one needs more than IQ to be successful in life. The Summerville study, in which 450 participants (boys) were involved in a 40-year longitudinal investigation to determine factors that contribute to social mobility found intellectualization to be a major factor in determining success (Snarey \& Vaillant, 1985). The participants in the study came from different cultural, social, and economic backgrounds. One third of the participants had IQs of below 90. Seven percent of the participants with IQs below 80 and IQs over 100 were unemployed for over ten years. This was an indication that IQ had little to do with their success or failures in life (Snarey \& Vaillant, 1985). The study found that differences in emotional intelligence abilities (such as the ability to handle frustrations, control emotions, and get along with others) played a 
major role in the participants' success. It turned out that the ability to manage and control emotions played a significant role in their lives "...the fact that they did not get angry made them easier to work with and more socially acceptable" (p. 907).

Psychology researchers at Stanford University conducted a longitudinal study that started in the 1960 s to investigate the relationship between self-discipline and success in life. Hungry four year olds were given a marshmallow and promised to receive two if they waited for about ten to fifteen minutes for the researchers to return after running some errands. One third of the children were impatient and ate the marshmallow right after the researchers left, while another third waited for less than ten minutes. Only one third of the children waited for ten to fifteen minutes. About ten years later, (after the children had graduated from high school), the researchers found that the children who had resisted temptation had total SAT scores of 210 points higher than those children who were impatient. The patient children were found to be positive, successful, self-motivated, and able to resist temptation to pursue their goals. The impatient children were found to be impulsive and had difficulty remaining on task (Shoda, Mischel \& Peake, 1990).

Another study of 80 science graduate students who took personality tests, IQ tests, and participated in numerous interviews in 1950 were tracked down forty years later to determine their success. Experts in the different fields reviewed on resumes and evaluations and found that emotional abilities were four times more important that IQ in determining success and prestige in life (Feist \& Barron, 1996). Goleman (2006) supports this notion through his argument that emotional intelligence matters twice as much for success over technical skills because being an expert in a particular area does not necessarily mean an individual possess the skills needed for effective leadership. 
Dulewiz and Higgs (1998) initiated a research program that was aimed to develop valid measures of emotional intelligence. The research was also aimed at exploring the significance of emotional intelligence. In one study, it was found that when a group of people watched an upsetting film, those with a high level of emotional intelligence were able to recover faster (Salovey, Mayer, Goldman, Turvey, \& Palfai, 1995). Another study found that people who scored higher in the ability to perceive accurately, understand, and appraise others' emotions were able to respond faster to changes in their social environments and were also able to build supportive social networks (Salovey, Bedell, Detweiler, \& Mayer, 1999). A study by Rahim (2010) on emotional intelligence and organizational performance found that the emotional intelligence of participants increased as their level of education increased.

Goleman (1995) argued that emotional intelligence increased with age and maturity. Other studies supported the notion that emotional intelligence could be taught to children, leading to an increase in their performance later in life (Bar-On, 1997; Cooper \& Sawaf, 1997; Weisinger, 1998). A report from a survey of parents and teachers indicated that children in today's society were growing lonelier, depressed, unruly, impulsive, and aggressive (Goleman, 1998). Goleman (1998) attributed this to a steady decline of children's emotional intelligence that spanned across all economic groups. Milhoan (2007) conducted a study on the relationship between the emotional intelligence competencies of departmental chairs and the organizational climate perceptions of faculty members. The results indicated that emotional intelligence increased with age and experience.

Cherniss and Adler (2000) cautioned that people entering the work place were likely to have low emotional intelligence competence skills that are necessary for successful job performance. However, Mayer, Salovey, and Caruso (2004) cautioned that there was limited 
available evidence to support the increase of emotional intelligence with age. This makes it necessary to find out if there is any relationship between emotional intelligence and demographic characteristics of community college deans.

Min (2010) conducted a study to explore the relationships between social and work demographic variables with the emotional intelligence of tour guides. Demographic variables in the study were gender, age, education, marital status, work experience, and language .The study consisted of 380 tour guides and found that there were significant differences between individual's emotional intelligence in relation to gender and length of service (Min, 2010). Women participants in the study had high emotional intelligence scores when compared to the men. Tour guides with tenure also had high emotional intelligence scores. The study found that there was no statistically significant difference between emotional intelligence and the demographic characteristics of age, education, marital status, and language used.

Thomas (2007) did a study on the relationship between the emotional intelligence of chief development officers and organizational climate. In the study, demographic characteristics of age, gender, and experience were identified. The results from the study indicated a statistically significant positive relationship between emotional intelligence and organizational climate perceptions. There was no significant relationship between the demographic characteristics and organizational climate.

Many researchers have suggested that gender based differences exist in relation to emotional intelligence. Females tend to have higher emotional intelligence than men (Brackett, Rivers, Shiffman, Lerner, \& Salovey, 2006; Mayer, Caruso, \& Salovey, 1999; Palmer, Monacha, Gignac, \& Stough, 2003). Women have been found to have better people skills than males (Morrison, White \& Velser, 1992; Rutherford, 2001; Sharpe, 2000), leading to the ability to 
manage and understand emotions in self and others (Boyatizs \& Sala, 2004). Palmer et al. (2003) found that women scored higher on interpersonal and self-awareness skills when compared to males. Studies conducted by Bar-On (2002) concluded that gender and age had a significant difference on emotional intelligence.

Alumran and Punamaki (2008) conducted a study on the relationship between gender, age, academic achievement, emotional intelligence, and copying styles in Bahraini adolescents. The study had 312 participants and the Bar-On emotional Quotient Inventory was used to measure emotional intelligence. The results indicated that gender, but not age was significantly correlated with emotional intelligence. Other studies have confirmed that women tend to have higher emotional intelligence when compared to men (Mayer et al, 1999; Palmer et al, 2003; Petrides \& Furnham, 2000). For the purposes of this study, emotional intelligence refers to the ability to reason with and about emotions, through perceiving, using, understanding, and managing emotions (Mayer, Salovey, \& Caruso, 2002).

\section{Approaches of Emotional Intelligence}

The concept of emotional intelligence has increased in popularity in the last few decades. This has led to two main approaches: an ability approach and mixed model approach.

\section{The ability approach.}

This was first conceived by Mayer, Salovey and Caruso (1998). The ability based model perceives emotional intelligence as a form of pure intelligence. Emotional intelligence is perceived as an individual's capacity to reason and process emotion in order to regulate behavior and enhance cognitive process (Mayer \& Salovey, 1993; Min, 2010). The ability approach considers emotional intelligence to be an integrated set of mental abilities and focus on individual aptitudes for processing information in an effective way (Salovey \& Mayer, 1990). 
Proponents of this approach argue that the ability model meets the standards of intelligence in that an individual's thinking grows towards a level of proficiency that is similar to what is espoused by traditional principles of intelligence (Mayer \&, Salovey 1993; Wechsler, 1958). This approach is a hierarchical model comprised of four branches. The fourth branch is the most important. These branches include:

1) Perception, appraisal, and expression of emotion

2) Emotional facilitation

3) Understanding and analyzing emotion and

4) Reflective regulation of emotion

\section{Mixed model approach.}

This model was developed by Bar-On (1997) and Goleman (1995; 1998) and regards emotional intelligence as a mixed form of intelligence consisting of cognitive ability and personal aspects. These models focus on how cognitive and personality factors determine workplace success.

The mixed model of emotional approach has two major proponents; Bar-On $(1997 ; 2004)$ and Goleman (1995; 1998). Goleman expanded on Mayer and Salovey's model to incorporate personal and social competencies. These competencies include self-awareness, self-regulation, motivation, empathy, and social skills.

Bar-On perceived emotional intelligence as a non-cognitive ability involving intrapersonal skills, interpersonal skills, adaptability, stress management, and general mood. These skills are deemed to help people become effective in dealing and coping with daily demands and environmental pressures. The Bar-On model has five factor areas which include intrapersonal skills, interpersonal skills, adaptability, stress management, and general mood. 
Goleman's (1995) model has four domains which include: Self -awareness, self-management, social awareness, and relationship management.

\section{Emotional Intelligence and Leadership}

The world today is faced with many cultural and social changes. These changes have led to competition in the academic and non-academic world (Hagenow, 2001). Chaudry (2000) supported the notion that the changes in today's world demand effective leadership. Community colleges need to equip themselves with competent leaders to lead during these tough and challenging times. The use of IQ as a measurement of competency in leadership is not enough in the current competitive world (Hagenow, 2001). Hagenow argued that it is important for leaders in today's world to have the ability to exercise multiple intelligences during different times of their leadership. He also argued that emotional intelligence is important in making and maintaining fulfilling relationships.

Higgs (2002) conducted a quantitative study to determine the relationship between leadership and emotional intelligence. The study involved 70 managers from different organizations who took both the CLCQ (Change Leadership Competency questionnaire) and the self-assessment EIQ (emotional intelligence questionnaire). The study used the self-assessment managerial version of the EIQ, which has been previously used and demonstrated to have predictive validity and an acceptable reliability (Dulewicz \& Higgs, 1998). Scores from both questionnaires were correlated and the results indicated a significant relationship between leadership and emotional intelligence. The relationship between the emotional intelligence (EI) factor of intuitiveness and the elements of change leadership was statistically insignificant (Higgs, 2002). 
Fleishman and Harris (1962) proposed that leaders who were successful were those who were able to establish friendly and lasting relationships built on trust and respect with members of the same group, which are aspects of emotional intelligence. Goleman (1995) discovered a wealth of literature on emotional intelligence that came from neuropsychology, personality, and social psychology. He discovered that there was a significant connection between the cognitive and non-cognitive abilities. A study of retail managers conducted by Lusch and Serpkenci (1990) found that the ability to manage and handle stress was a good predictor of net profits, sales per employee, sales per square foot, and per dollar of inventory investment.

Several researchers have concluded that emotional intelligence plays a major role in leader success or failure (Bennis \& Nanus, 1985; Chernis, 2000; Goleman, 1998; 2000; Higgs \& Dulewicz, 1999). Bass (1998) argued that leaders needed to possess some emotional intelligence skills in order to be both successful and effective. In addition, Bass (1998) suggested that it was important for leaders to have high moral standards, act as role models, and inspire the followers for successful leadership. Once followers identify with the leader, then leadership is likely to be successful.

Research has shown that emotional intelligence is more important for top-level administrators than low-level administrators (Goleman, Boyatzis, \& Mckee, 2002). Van Der Zee and Wabeke (2004) found that top executives scored higher on emotional intelligence dimensions when compared with the general population of managers. This could be attributed to the nature of their jobs and leadership positions because they have to motivate, communicate with, and inspire their followers (Van Der Zee \& Wabeke, 2004).

Van Der Zee and Wabeke, (2004) in examining the usefulness of emotional intelligence conducted a study in which 1,186 top managers completed the Bar-On EQ-I and the Five Factor 
personality inventory questionnaires through a consulting agency as part of training. They concluded that emotional intelligence played a major role in leadership because the results indicated that the executive managers possessed emotional intelligence (EI) qualities such as managing emotions, agreeability, and autonomy (Van Der Zee \& Wabeke, 2004).

Emotional intelligence provides competencies that are good predictors of success or failure in life (Goleman, 1998; Mayer, Salovey, \& Caruso, 1998). People are more likely to develop the competencies of initiative if they are first able to recognize and regulate their emotions (Chernis, 2000). Rosental, (1977) discovered that people who were able to recognize the emotions in others were more sociable and successful in their work. A study conducted by Pillin and Eroglu (1994) on retail sales buyers found that most sales representatives were valued for their empathy in the work place. Buyers preferred sales representatives who understood and listened to their concerns. This made them feel valued and believed that they were receiving the best service available.

In order to predict performance, it is necessary to identify and measure emotional competencies (Chernis, 2000). Leaders in different organizations require different competencies in the work place depending on the goals, processes, structures, and cultures within the organization (Schneider \& Goldstein, 1985). Hollander (1995) argued that leaders who were opportunists had a tendency to dominate social environments through manipulation. Such leaders lack what would today be termed as emotional intelligence competencies. Community college leaders ought to possess leadership qualities such as accountability, productivity, social, and budgetary skills in order to be influential in their different roles (Andrews, 2000).

Leadership in higher education is complicated and many scholars might be tempted to place less value on emotional intelligence as opposed to IQ. This is because the academy is quite 
competitive and requires more than cognitive skills to be successful. Academic researchers have come to the conclusion that emotional intelligence plays a major role in leadership and should be a consideration in the academic world for leaders. College faculty continues to pay little attention to the development of essential personal qualities that are crucial to successful leadership, and instead emphasize on the acquisition of knowledge in traditional disciplinary fields (Astin \& Astin, 2000). Several studies indicate a strong relationship between emotional intelligence and successful leadership (Cherniss \& Adler, 2000; Cooper \& Sawaf, 1997; Goleman, 1998; Goleman, Boyatzis \& Mackee, 2000).

Bennis (1989) argued that emotional intelligence was a better predictor of leadership than IQ. Goleman (1995) supported the notion that emotional intelligence was more important than IQ in leadership. Simms (2002) suggested the importance of the same sort of skills for both managers and leaders. He postulated that emotional intelligence was important for leaders because their leadership roles involved planning, organizing, and controlling skills which are aspects of emotional intelligence.

Higher education leaders are responsible for a large number of personnel and different departments and need to have a mastery of different competencies to be effective. They ought to have the right social and emotional skills that will be essential in creating harmony between the different departments.

\section{Community College Leadership}

Community college deans perform many functions in the institutions that they serve (Cantu, 1997). These community college deans have been identified by different job titles which include: division director, chair, division chair, and assistant dean (Rosser, Johnsrud, \& Heck, 2003; Sypawka, Mallett, \& McFadden, 2010). Wolverton, Montez, Guillory, and Gmelch, 
(2001) defined community college deans as the middle managers in higher education institutions. Rosser, Jonsrud and Heck, (2003) defined community college deans as professional administrators responsible for coordinating, facilitating, and directing academic institutions towards the success of institutional goals. Community college deans are responsible for the day to day operations of the community colleges and are designated to lead and implement initiatives set forth by the board of trustees and the community college presidents (Moore, 1983; Sypawka et al, 2010). For the purpose of this study, community college dean refers to leaders in community colleges who act as middle managers and are responsible for the day to day operations of the institutions that they serve.

Initially, the sole administrator in institutions of higher education was the president. However, as colleges began to grow, the responsibilities of the president increased and this called for additional administrative assistance (Cantu, 1997; Moore, 1983). The role of the academic dean was to act on behalf of the president and "in his absence, to administer discipline of the college, to handle all petitions from students to faculty, and in general to supervise all clerical and administrative business of the college" (Dill, 1980, p. 262).

The role of the dean has evolved over time and there is no exhaustive definition of the roles and responsibilities of the dean (Singh \& Purohit, 2010). Other scholars have also supported the notion that the role and functions of the dean are not standardized and vary across the board. These variations to the roles and responsibilities depend on several factors such as the size of institution, institutional goals, location, hierarchy, and sponsorship (Dill, 1980; Heck, Johnsrud, \& Rosser, 2000; Montez, Wolverton \& Gmelch, 2002; Moore, 1983; Sypawka et al, 2010). 
Today, deans are frequently entangled in a web of competing agendas that require important leadership skills such as negotiation, courage, integrity, and risk taking (Singh \& Purohit, 2010; Gardner, 1992; Munitz, 1995). Individual institutions usually dictate the scope and magnitude of the dean's responsibilities depending on the needs and goals of the institution. Bragg (2001) identified six core knowledge areas that are essential for deanship. These areas include: assessment and accountability, knowledge of the mission, instructional leadership, information and educational technologies, and administrative preparation.

Community College deans play a major role in the success of community colleges. They are faced with numerous responsibilities and ought to have the necessary knowledge and skills to be successful. Even though the role of the community college dean is still evolving, community college deans play the role of academic managers and are responsible for both instructional and administrative programs at community colleges (Robillard, 2000; Rosser, Johnsrud, \& Heck, 2003).

The premise of leadership is important in different areas of higher education (Sypawka, Mallett, \& McFadden, 2010). Community colleges have numerous challenges to address. Some of the challenges that community colleges are facing include above average retirement rates for administrators, funding and limited government support, diverse student populations, changes in technology, shift in teaching to student-centered learning, and steep competition (Baldwin, 1998; Barr \& Tagg, 1995; Boone, 1992; Eddy \& Van Der Linden, 2006; Hurtado \& Dey, 1997; Johnstone, 1999; Schults, 2001; Weisman \& Vaughan, 2002; 2007; Vaughan, 1995). Academic leadership is complex and demanding (Murphy, 2003), especially in community colleges. This is mainly because community college leaders serve both the institutions and the community at large, and focus on community responsiveness, open access, 
and emphasis on teaching and learning. Community college leaders are in charge of numerous aspects of the institutions because they have few faculty committees. It is important for these leaders to build relationships with the communities they serve. Building relationships relies heavily on emotional competencies that are essential in developing self-awareness, working with others through collaboration, understanding organizational culture, nurturing ethical analysis, and dedicating oneself to teaching and learning (Amey, 2004; Cooper \& Sawaf, 1997).

Growth in student enrollments and the accumulated missions of community colleges make leadership in community colleges more complex (Romero, 2004; Shults, 2001). According to Fields (2004), community colleges educate nearly half of the nation's students enrolled in higher education. Community colleges serve a different student clientele as compared to 4-year colleges and K-12 programs. Community colleges are open admissions and serve everyone or anyone interested in higher education. This calls for leaders with specialized skills in student services in order to cater to the diverse student population (Romero, 2004). Community colleges provide learning opportunities to people who would otherwise lack access to higher education due to financial and demographic reasons among others (Boggs, 2003). This has led to the need for more collaboration among community college leaders, community members, and other institutions of higher education.

The complexity of community college leadership is made more challenging by the many people who question the core values and missions of community colleges. The mission to serve all students, irrespective of their education level, social, and economic backgrounds, guides most community colleges. They have an open door policy in which all students are accepted. This makes the leadership of community college leaders more complex than other institutions of higher education and calls for the need to have leaders who are smart and diligent to defend their 
core values (Boggs, 2003). As Martin, Samels, and Associates, (1997) postulated, "... there is a growing consensus that the position of the dean can no longer be defined by succession of skilled amateurs rotating out of their faculties for short periods of time" (p. 15).

Successful leadership is imperative for the succession of community colleges. Most community college leaders who joined the workforce in the early to late 60s are approaching retirement (Boggs, 2003; Carroll, 2004; Evelyn, 2001; Schults, 2001; Weisman \& Vaughan, 2002; 2007). With more than 75 percent of community college leaders expected to have retired by 2011 , community colleges are in dire need of effective leadership that will see them through to the future (Evelyn, 2001; Schults, 2001; Weisman \& Vaughan, 2007). It is therefore important to understand some of the emotional intelligence competencies common to leaders in community colleges. Due to the rapid changes in the society today, community college leaders ought to have important people skills in order to cope and be successful in their leadership roles. Community colleges require leaders who can connect and relate to the communities that they serve (Boggs, 2003). They ought to be equipped with the right skills in order to be successful.

Since the major role of academic institutions is to foster the development of the human potential (Murphy, 2003), academic institutions require leaders who can appreciate the value of bringing order through organizational and societal priorities. Community college leaders ought to be equipped with knowledge and skills to encourage collaboration both within and outside the institutions (Romero, 2004). There is need for every dean and other leaders to have conflict management skills in order to be effective, especially at times when competing priorities and limited budgets call for unpopular decisions (Romero, 2004). 
Numerous programs have been developed to cater to the needs of leaders, but little has been done to cater to the specific leadership needs of community colleges (Romero, 2004). Cooper and Pagotto (2003) argued that:

....at a time when the responsibilities of community college leaders require a skill set and knowledge base more complex than ever before, when the average age of senior administrators is rising, and when almost half of current presidents expect to retire in the next five years, the number of graduate degrees awarded in community college administration has plummeted... (p. 27).

This is an indication of the great need for efficient community college leaders. Sypawka, Mallet, and McFadden (2010) conducted a study to examine the leadership styles of academic deans in relation to education level, prior business experience, and length of deanship. Surveys were sent to 340 academic deans. There was a 39 percent response rate. The results indicated that community college deans who developed and maintained good relations with others were more successful. These deans made the followers feel valued and took time to recognize efforts made by others (Sypawka et al. 2010).

There has been a decrease in supply of qualified leaders in community colleges (Barwick, 2002; Campbell \& Peek, 2002; Leubsdorf, 2006; Schults, 2001; Snuggs, 2006). With the many difficulties that community colleges are facing, having reliable and qualified leaders is not an easy task. Leadership positions in community colleges are not particularly perceived as attractive positions due to the complex nature of these institutions (Cooper \& Pagotto, 2003). Available research shows that many community college leaders are drawn from faculty ranks (Cantu, 1997; Leubsdorf, 2006; Weisman \& Vaughan, 2001). This is becoming more challenging with limited faculty willing to take up leadership roles (Barwick, 2002). Most deans do not receive any 
formal training on the role of the dean before taking over the responsibilities. This is mainly because "most of the deans ascend to their positions as members of the professorate, rather than as trained administrators" (Cantu; 1997, p. 50).

Community colleges play an important role in higher education and society in general. Boggs (2003) stated that:

...the societal trends indicate that community colleges will be "where the action is" in higher education in the years ahead. Faculty members and leaders who join community colleges will be able to make significant contributions to educational opportunity and to the economic well-being of individuals and communities... p. 17.

Since community college leaders are viewed as community leaders, possession of emotional intelligence attributes is essential in developing and sustaining relationships. It is imperative for community college administrators to effectively use and manage their emotional and IQ competencies for successful leadership.

To better understand academic deans, it is important to look at demographic information. Farmer and Paris (2000) conducted a study on the opinions of community college deans regarding principles of continuous quality improvement and considered demographic characteristics of age, gender, ethnicity, and experience. Purpose of the study was to determine the opinions of academic deans in the North Carolina Community College system with regard to applications of continuous quality improvement principles in academic settings. The study found that majority of the participants were white males aged between 50- 54 with 20 or more years of experience. Results also indicated personal and organizational factors did not affect the perceptions of continuous quality improvement principles. 
Cantu (1997) did a study on the leadership frames of academic deans and looked at the demographics of age, gender, race, and experience. Participants in Cantu's study constituted of randomly selected academic deans from 426 public masters and doctorate -granting institutions across the United States. Results indicated that most academic deans predominantly utilized human resource frames in their leadership orientations

Keim and Murray (2008) conducted a national study on the demographic characteristics of community college deans. A total of 300 community college deans participated in the study. Demographic characteristics of gender and level of education were considered in the study. On highest level of education attained, Keim and Murray (2008) found that $70 \%$ of the study participants held doctoral degrees while $27 \%$ held masters degrees.

Several studies on deanship found the average age of deans to be above 50 (Cantu, 1997; Crawford, 1983; Farmer \& Paris, 2000; Moore 1983). Farmer and Paris (2000) conducted a study on the principles of continuous quality improvement in the North Carolina community college system. Fifty community college deans participated in the study. From the study, results indicated that the average age of the participants was 50-54. A study by Amey, Van Der Linden, and Brown (2002) found that the average age of community college deans was 54 . This makes it important to determine if there is any relationship between the emotional intelligence of community college deans and their age.

Men for the most part seem to out-number women in deanship roles. Several studies have revealed that women are generally grossly underrepresented in administrative roles as compared to their male counterparts (Anderson \& King, 1987; Cantu, 1997; Farmer \& Paris, 2000; Moore, 1983; Snuggs, 2006; Weisman \& Vaughan, 2002). Results from Farmer and Paris (2000) found that of the 50 participants from the study, $78 \%$ were males and $22 \%$ were females. Weisman and 
Vaughan (2002) found that women were underrepresented in administrative roles with $28 \%$ representation of presidency and $21 \%$ deanship positions. Another study on chief academic officer's demographics and educational backgrounds revealed that of the 300 participants from the study, 44\% were females and 56\% were males (Keim \& Murray, 2008).

Studies involving ethnicity have revealed that minorities are underrepresented in deanship and administrative positions in general. Of the 1,293 deans in Moore's (1983) study, only seven percent identified themselves as minorities. Another study conducted by Anderson and King (1987) on the demographic analysis of the dean found that of the 100 participants in the study, only $12 \%$ classified themselves as minorities. Farmer and Paris (2000) found that $90 \%$ (45) of the study participants identified as white, while 10\% (5) identified as minority (African American, Hispanic, Native American, and Other). The studies on ethnicity are more than a decade old and very little research have been conducted in the interim, making it necessary to conduct the current study.

On experience, studies reveal that deans tend to remain in their positions for more than five years (Anderson \& King, 1987; Cantu; 1997; Farmer \& Paris, 2000; Moore 1983). Farmer and Paris (2000) found that $30 \%$ of the deans in the study had 5 years or less of experience, $34 \%$ had 6-20 years of experience, and 36\% had more than 21 years of experience. Anderson and King (1987) found that there was an inverse relationship between years of service as a dean and the size of the institution. In general they argued that, "the length of service as dean at very large institutions is relatively short" (p. 11). This could be attributed to the challenging demands and responsibilities that are common to large institutions.

A study conducted by Snuggs (2006) to explore the relationship between the emotional intelligence, faculty and staff retention of community college presidents in North Carolina found 
no statistically significant relationship between emotional intelligence and retention. The study had 39 participants and yielded a 67.2\% response rate. Demographic characteristics of age, gender, and experience were considered for accuracy and interpretation purposes. Snuggs (2006) found that most of the presidents were male and more than $55 \%$ of the population had been presidents for fewer than two years.

Most of the available literature with regards to the demographic characteristics of community college deanship and leadership in generals is several years old and might not reflect the current demographic representation in academic institutions. This is an indication of a growing need for further investigation on community college leadership.

The literature shows the growing need for successful leaders in community colleges. In this study I identified the relationship between the emotional intelligence of community college deans and selected demographics. This information could be helpful to both current and future community college deans.

\section{Summary}

In this chapter I reviewed some of the available literature pertaining to leadership in general, emotional intelligence, approaches of emotional intelligence, emotional intelligence and leadership, and community college leadership. From the literature review, numerous studies suggest that emotional intelligence plays an important role in leadership. It also suggests that there is some relationship between emotional intelligence and some demographic characteristics.

There are limited current studies conducted in the area of emotional intelligence and community college deans and this study serves to fill some of the missing gaps in the literature and to confirm or reject earlier suggestions. Community college leadership is complex and requires more attention and focus if community colleges are to be successful. Information from 
this study serves to enlighten others on the nature of the emotional intelligence of community college deans. 


\section{Chapter Three}

\section{Methodology}

In this chapter I describe the research design that I employed in the study. I describe the quantitative methods that were used to understand the emotional intelligence of community college deans and the relationship between their emotional intelligence and selected demographics. In the chapter, I include a description of the research questions, participants and settings, research design, measurements, procedures, and data analysis.

While community college deans have myriad responsibilities and duties, now more than any other time in the history of postsecondary education, community colleges have a great need for leaders to effectively compete with societal demands and trends. Emotional intelligence plays a significant role in leadership (Goleman, 1995). A successful leader relies heavily on the components of emotional intelligence in that leadership revolves around building relationships. Emotionally intelligent leaders are able to communicate openly, motivate, encourage, and connect with others in different work situations (Bennis, 1989; Goleman, 2006a). Community colleges will be facing numerous challenges in the near future with the retirements of most of the current leaders (Shults, 2001). This makes it important to investigate some of the emotional intelligence competencies that community college deans use and further determine if any relationship exists between these competencies and selected demographics.

In this study, I provided important information on the emotional intelligence of community college deans. I also aimed to provide empirical evidence on the relationship between emotional intelligence and the selected demographics of age, gender, race, education level, size of institution, and experience. 


\section{Research Questions}

In order to achieve the goals of this investigation, the following questions were used to guide this study;

1. Who are the community college deans in the Southeastern region of the United States of America? What are their demographic characteristics?

2. What is the emotional intelligence of the community college deans?

3. Is there any relationship between the emotional intelligence of the community college deans and selected demographics of age, gender, race, experience, institution size, and education level?

\section{Participants and Settings}

According to the American Association of Community Colleges (2010), as of December 2009 , there were 1,173 community colleges in the US. Of these community colleges, 987 were public community colleges, 155 independent community colleges, and 31 tribal community colleges. For this study, I utilized Carnegie classification of higher education to identify community colleges in the southeastern region of the United States. I evaluated community college deans in public community colleges within the southeastern region of the United States. These community colleges are classified as those public colleges that award at least 2 year associate degrees within the southeastern region of the United States. Students attending these colleges could be non-traditional, part-time or full time students (Carnegie Classification, 2011). In this study, I focused on community college deans from the southeastern region of the United States. A community college dean is the academic manager and is responsible for both instructional and administrative programs at community colleges (Robillard, 2000). According to the Carnegie classification of higher education, there are 12 states in the southeastern region of 
the United States and 294 two year public community colleges as shown on Table 1 (Carnegie, 2010). All 294 community college deans were invited to participate in the survey.

\section{Table 1}

Southeastem states and number of public community colleges

\begin{tabular}{lc}
\hline State & Number of Community Colleges \\
\hline Alabama & 26 \\
Arkansas & 22 \\
Florida & 16 \\
Georgia & 42 \\
Kentucky & 16 \\
Louisiana & 31 \\
Mississippi & 15 \\
North Carolina & 59 \\
South Carolina & 20 \\
Tennessee & 13 \\
Virginia & 24 \\
West Virginia & 10 \\
Total $(N)$ & 294 \\
\hline
\end{tabular}

Table 1 shows the names of the states in the southeastern region of the United States and the number of two year public community colleges in each of the states. North Carolina had the largest number of two year public community colleges (59), while West Virginia had the lowest number of public community colleges (10).

A total of 84 community college deans participated in the survey, yielding a response rate of $27.45 \%$. Thirty two percent of the participants identified as males while sixty five percent 
identified as females. The number of participants who held masters degrees was 44, while 29 participants held doctoral degrees.

\section{Research Design}

This was a descriptive study that utilized available instruments to measure emotional intelligence. There was no manipulation of variables in this study. I employed quantitative research design and statistical tools to understand the nature of the emotional intelligence of community college deans. I assessed the relationship between the emotional intelligence of community college deans and selected demographics.

One of the strengths of this study was the data analysis. The correlation analysis used in this study (multiple regressions) made it possible to examine many variables and explore relationships among them. Another strength of this study was the ability to provide information on the degree to which relationships among variables exist. The MSCEIT self-report measure was selected for this study because it is simple to administer and enabled participants to complete the survey at their own time and convenience. The MSCEIT has also been previously tested for both validity and reliability.

\section{Measurement}

For the emotional intelligence, Mayer-Salovey-Caruso Emotional Intelligence Test (MSCEIT) was used for this study (See A for request to use MSCEIT and Appendix B for permission to use MSCEIT Questionnaire). This test is used to measure four branches of emotional intelligence, which include: perceiving emotions, facilitating thought/using emotions, understanding emotions, and managing emotions. This measure of emotional intelligence was developed from an intelligence testing tradition and was formed through a scientific study of 
emotions. MSCEIT is a performance measure based on the number of correct answers given (See Appendix C for MSCEIT sample). It is used to assess how well an individual solves emotion loaded problems in the four domains of emotional intelligence.

MSCEIT is an ability based scale used to measure emotional intelligence and measures how well people perform tasks and solve emotional problems (Mayer et al., 2002). The MSCEIT responses represent actual abilities to solve problems, and the results are relatively unaffected by emotional state, self-concept, and other confounds (Mayer et al, 2002). MSCEIT consists of 141 items that form an overall emotional intelligence score (Emotional intelligence quotient), two area scores (Experiential Emotional Intelligence Quotient and Strategic Emotional Intelligence Quotient), four branch scores (perceiving emotions, using emotions/facilitating thought, understanding emotions, and managing emotions), and finally eight task scores. According to Mayer et al. (2002), “the branch scores provide information on a respondents' specific emotional abilities and are more reliable" (p.19).

The two area scores were not used for this study because they represent broad areas of emotional intelligence skills. The task scores were also not used in this study because they represent less reliable measures of emotional intelligence and are subject to great variations (Mayer et al, 2002). The total emotional intelligence score and the four branch scores were used in this study because they represent specific emotional intelligence skills (Mayer et al, 2002). For the purpose of this study, the overall emotional intelligence (EI) score and the four branch scores were correlated through multiple regressions with the selected demographics of age, gender, race, education level, size of institution, and experience.

MSCEIT uses both 5-point scales and multiple-choice response format, with a variable rating scale based on task/question (Mayer, Salovey, Caruso \& Sitarenios, 2003). Scores can be 
calculated using either "general consensus" or "expert consensus" scoring methods. According to Mayer, Salovey and Caruso, (2002), the general scoring method uses answers from MSCEIT normative sample to determine the correct answers (population of 5000 people), while the expert scoring method uses answers from 21 emotional intelligence experts to determine the correct answers ( experts from International Society for Research in Emotions). The general scoring method is recommended (Mayer et al, 2002) and was thus used for this study.

The results from MSCEIT are reported in three forms: raw scores, percentiles, and standard scores. The raw scores are usually skewed and are converted to standard scores for ease of interpretation and comparison to other intelligence tests (Mayer et al, 2002). The raw scores are first converted to percentiles, from which the standard scores are derived. The standard scores were used in this study.

The MSCEIT has a mean emotional Intelligent Quotient score of 100 and a standard deviation of 15 . If a respondent obtains a score of 115 , then he is about one standard deviation above the mean or at the $84^{\text {th }}$ percentile. An overall emotional intelligence score of 85 means that they are about one standard deviation below the mean, or at the $16^{\text {th }}$ percentile (Mayer, Salovey, \& Caruso, 2002). The total Emotional intelligence score measures the overall emotional intelligence level of an individual and compares an individual's performance on the MSCEIT to those in the normative sample. Mayer et al. (2002) argues that the total emotional intelligence score is a "good place to start when analyzing a respondents' level of emotional intelligence" (p. $18)$.

MSCEIT has been previously tested for reliability and validly, with a general internal consistency reliability score of 0.93 , and an experiential area reliability score of 0.90 (Brackett \& Mayer, 2003). MSCEIT also has test retest reliability of .86, the four branch scores have a 
reliability of .90 (Perceiving emotions), .76 (Using emotions), .77 (Understanding emotions), and .81 (Managing emotions) (Mayer et al, 2002). MSCEIT is said to have good face validity in that it measures what it was supposed to measure (Brackett \& Salovey, 2006). The different areas that the MSCEIT is used to assess are considered as different aspects of emotional intelligence. It consists of eight different sections, all of which measure different aspects of emotional intelligence. Some of the questions can be easily identified to contain face validity (For example: the faces task in the survey, that requires an individual identify the emotions expressed in a photograph), while others are difficult to determine if they directly measure emotional intelligence. Figure 1 shows emotional intelligence competences and the four branch areas that the MSCEIT measures.

Fig. 1

\section{Emotional Intelligence through MSCEIT}

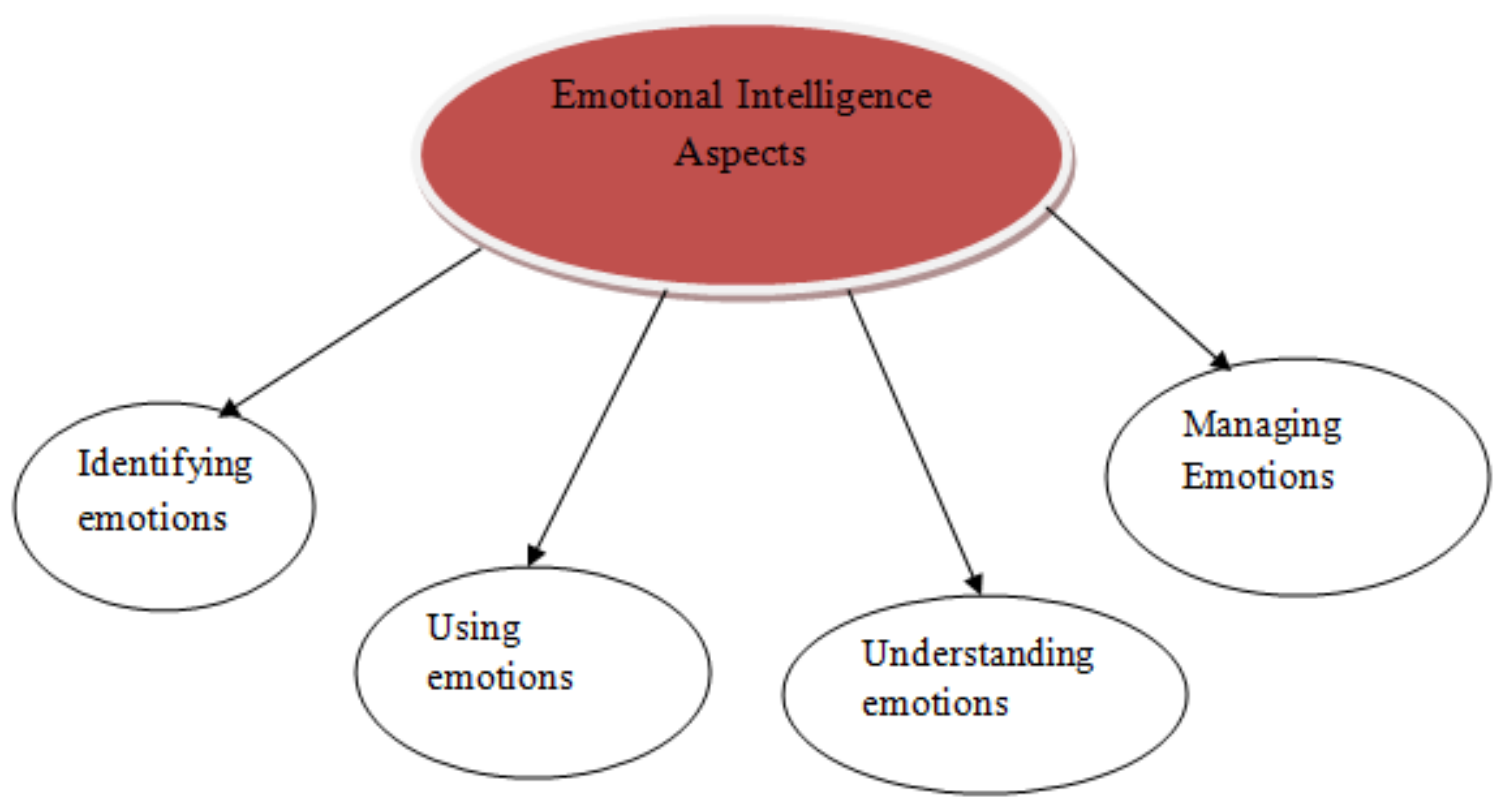


The MSCEIT has been found to contain content validity in that it was operationalized for the ability model of emotional intelligence. It has been found to measure: the ability to identify emotions in persons and objects; ability to generate emotion and use it to solve problems; ability to manage emotions and enhance growth; and the ability to understand emotional causes and complexity. It has also been found to have test retest and discriminant validity (Mayer et al, 2002).

\section{Procedures}

All community college deans from the public community colleges within the southeastern region of the United States were invited to participate in the survey. The study population consisted of community college deans from the region (as categorized by higher education publication, 2011). According to Carnegie classification of higher education, there are 294 public community colleges in the southeastern region of the United States. Some of the community colleges had more than one college dean and all deans were invited to participate in the survey. A total of 323 invitations were sent to community college deans inviting them to participate in the study. Seventeen of the acquired email addresses were reported as undeliverable and hence the number of community college deans who actually received the invitation was 306 . Out of the 306 delivered surveys, twenty two of the deans opted out of the study, while 84 deans completed the study, yielding a response rate of $27.45 \%$. A response rate of $25-36 \%$ is considered sufficient (Keeter, Kennedy, Dimock, Best, \& Craighill, 2006). Ketter et al. (2006) found no significant difference between a survey that yielded a response rate of 50$61 \%$ with one that yielded a response rate of $25-36 \%$. After clearance from the Institutional Review Board (IRB), I purchased the MSCEIT survey instrument, which was then placed on an 
online data collection tool through MHS (Multi-Health Systems). I then sent personalized letters of invitation through electronic mail inviting deans to participate in the study (See Appendix D for dean's letter). The invitation email introduced the researcher, gave a brief description of the study and survey instruments, invited the deans to participate in the survey, and provided a link to the survey instrument.

I obtained community college deans' contact information from the Higher Education Directory (Higher Education Publication, Inc., 2011), which compiles and sells customized databases of educational personnel for research purposes. Contact information included name of institution, email address, and telephone number of participants. Confidentiality was maintained throughout the study.

I collected data over a period of 4 months to give participants ample time to complete the survey. Original email and three follow up email reminders (See Appendix E for deans reminder) were sent to respondents during the same period. Participants completed the MSCEIT online from May 2012 through August 2012. MHS (Multi-Health Systems) Incorporated, the test owner based in the USA, scored the tests. After each participant completed the survey, an email was automatically generated and sent to me, notifying me of the completion of the survey and availability of results to be scored. I sent reminders after every two weeks during that time to those deans who had not completed the survey. I considered results from all participants. The online survey tool remained open until a sufficient number of participants completed the survey. Once all participants completed the MSCEIT, I scored the results using the general scoring option. MHS provided me with the raw data.

I created a follow up questionnaire based on the demographic information. The follow up questionnaire asked participants to identify their level of education, experience, and size of 
institution (Appendix F). I emailed the follow up demographic questions to participants once they completed the MSCEIT. Once I received the responses to the demographic questionnaire, participants were entered into a drawing for a chance to win one of $\$ 50$ gas gift cards. I sent emails to the winners requesting their mailing addresses where the gift cards could be mailed. Of the 84 deans that completed the MSCEIT, 7 of them did not complete the follow up demographic questions.

Demographic data, specifically age, race, gender, education level, work experience, and size of institution were covered through the online survey system. This information was necessary to appropriately score the instrument. The demographic information was also important for data analysis and was correlated with emotional intelligence scores to identify the existence of relationships.

\section{Data Analysis}

I performed appropriate statistical analysis on the data to determine the significance of the results. I particularly aimed to discover the relationship between the various predictive variables (demographic variables) and the emotional intelligence of community college deans. A total of eight predictive variables were utilized for this study. I used SPSS for most of the data analysis and employed a quantitative research design and statistical tools to assess the relationship between the emotional intelligence of community college deans and selected demographics.

The data obtained from this research was analyzed through descriptive statistics and multiple regressions (Fig. 2). Descriptive statistics were used to answer question 1 and 2. The mean, median, and standard deviations of emotional intelligence and demographics were calculated. This made it possible to summarize the data in a clear and understandable way. 
Question 3 was answered through multiple regressions and t-tests. Multiple regressions were used to determine the relationship between the emotional intelligence of community college deans and the selected demographics of age, gender, race, experience, institution size, and education level. T-tests were also computed for gender and ethnicity with the emotional intelligence outcomes. The researcher checked to ensure that all of the regression assumptions were met.

\section{Design Analysis}

Dummy coding was employed for the data analysis. A dummy variable is a vector in which members of a given group are assigned an arbitrary number while all others not belonging to the group are assigned another arbitrary number. The number of vectors required is equal to one less than the number of groups. Each factor or categorical variables are coded using $1 \mathrm{~s}$ and 0s. 1 indicates membership in a group and 0 indicates non-membership. For this study, dummy coding was used for the different demographic variables. Vectors were assigned accordingly.

The sample size in this study was appropriate for a large to medium effect and an alpha of .05. Effect sizes are used to express the importance of a research finding in any given study. Fields (2005) suggests that researchers' should always have a sample size of at least 60 participants for a large or medium effect and up to 20 predictors. Ideally, he suggests that a sample size of 80 for a large effect and about 100 for a medium effect would be more desirable.

In the descriptive and regression analysis, ethnicity and size of institution categories were combined to form 'white' and 'others' in which Asian, Black/African American, and Hispanic categories were grouped together. Size of institution categories were grouped together into; (very small and small), (medium), and (large and very large) to form 3 categories (small, medium, and large). For this study, 84 participants completed the MSCEIT questionnaire; however, responses 
from 69 participants were entered into the regression analysis because of missing data from other participants. Five multiple regressions were conducted for the overall emotional intelligence score and the four area scores with gender, age, race, experience, education level, and size of institution variables to determine if any relations exist. The responses to the survey were stored in an internal database and downloaded into a Microsoft excel spreadsheet format. 
Figure 2 shows the data analysis employed for this study.

Figure 2

Data Analysis 


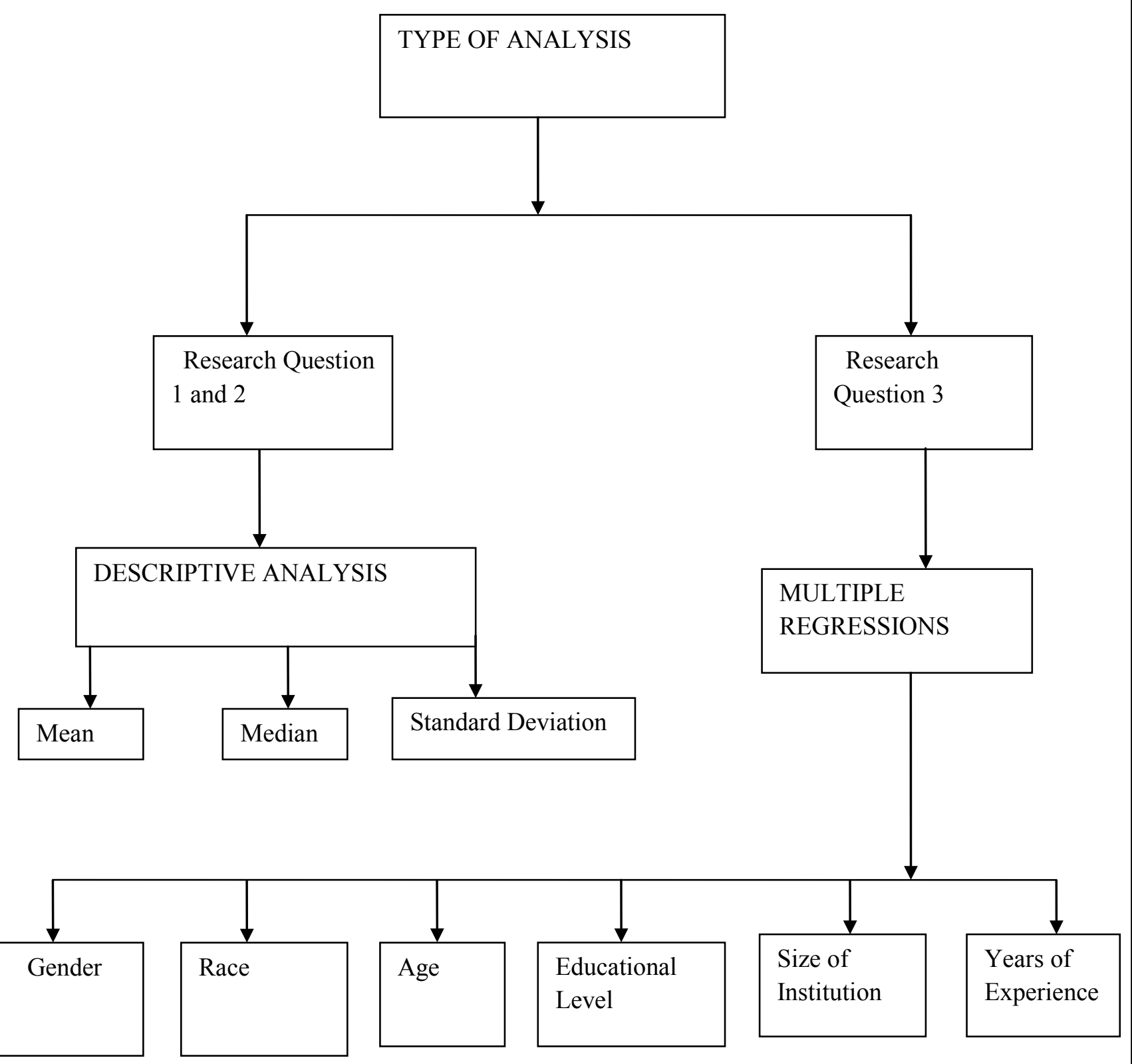

\section{Summary}

The purpose of this study was to understand the nature of the emotional intelligence of community college deans within the southeastern region of the United States and to identify 
relationships with selected demographics. The survey utilized MSCEIT (Mayer-Salovey-Caruso Emotional Intelligence Test) to measure the emotional intelligence of community college deans. Follow up demographic questionnaire was also emailed to participants. Eighty four community college deans completed the survey, yielding a response rate of $27.45 \%$.

The data obtained from this research was analyzed through descriptive statistics and multiple regressions. Multiple regressions were used to determine the relationship between the emotional intelligence of community college deans and the selected demographics of age, gender, race, experience, size of institution, and level of education. 


\section{Chapter Four}

\section{Results}

In this chapter I present the findings from the study. Each question was answered in the order that it was stated in the methodology section. To provide an in-depth analysis of each question, tables and narrative discussion are included.

The purpose of this study was to examine the nature of the emotional intelligence of community college deans in the southeastern region of the United States. The purpose of the study was not to predict the outcomes of one variable over the other or show any causality between variables, but the researcher intended to simply determine existence of relationships between variables. Instruments used in the study were MSCEIT (for emotional intelligence) and demographic questionnaire that addressed experience, educational level, and size of institution. The MSCEIT (see sample on Appendix D) questionnaire addressed demographic variables of age, gender, and ethnicity. This examination led to a better understanding of the nature of the emotional intelligence and selected demographic characteristics of community college deans.

\section{Research Questions}

The following questions were used to guide this study;

1. Who are the community college deans in the southeastern region of the United States of America? What are their demographic characteristics?

2. What is the emotional intelligence of the community college deans?

3. Is there any relationship between the emotional intelligence of the community college deans and selected demographics of age, gender, race, experience, institution size, and education level? 
Descriptive and regression analyses were used to analyze the data. Preliminary analysis involved computing the descriptive data on the demographic variables of age, gender, ethnicity, level of education, size of institution, and experience. T-tests were used to determine and identify significant differences in emotional intelligence branch scores and the selected demographic characteristics.

Multiple regressions were used to determine predictive relationships among total demographic characteristics and emotional intelligence subscales. Variables were inspected and one extreme score was found. Data was run with and without the outlier, and a sizable difference was found. After running the descriptive analysis for the overall data, the outlier was removed and data analysis was run without it. In this study, SPSS 20.0 was used to analyze the data at the alpha 0.05 level. The researcher checked to ensure that the regression assumptions were met.

\section{Analysis}

The data obtained from this research was analyzed through descriptive statistics and multiple regressions. Descriptive statistics were used to answer question 1 and helped summarize the data in a clear and understandable manner. The mean, median, and standard deviations of demographic characteristics were computed to help understand the community college deans.

The second research question was answered through descriptive analysis of the total emotional intelligence scores and the four branch scores (Perceiving emotions, Using emotions, Understanding emotions, and Managing emotions). Multiple regression analysis and Independent t-tests were used to answer question three of the research and to determine the relationship between the emotional intelligence of community college deans and the selected demographics of age, gender, race, experience, institution size, and level of education. 
Dummy coding was employed for variables in the regression analysis. The number of vectors required for dummy coding is usually equal to one less than the number of groups. Each factor or categorical variables were coded using 1's and 0's. 1 indicated membership in a group and 0 indicated non-membership. The dummy codes used were as follows: For size of institution, a dummy variable was created for values medium (1) versus other (0), and large (1) versus other (0); Experience was coded as; 0-4(1) versus other (0), 5-10 (1) versus other (0), and 11 plus (1) versus other (0); Gender was coded as females (0), males (1); and ethnicity was coded as white $(0)$, others (1).

\section{Research Question 1}

Who are the community college deans in the southeastern region of the United States of America? What are their demographic characteristics?

In this section, I present the demographic information of the participants in the study. The demographic information gathered included age, gender, race, size of institution, level of education, and experience.

A total of 306 invitations were delivered to potential participants through email. Eighty four participants completed the MSCEIT survey. Descriptive data on Table 2 indicates the characteristics of the study sample. 
Table 2

Characteristics of the study sample $(n=84)$

\begin{tabular}{|c|c|c|c|}
\hline Characteristics & & $\mathbf{N}$ & $\%$ \\
\hline \multicolumn{4}{|l|}{ Gender } \\
\hline & Male & 27 & 32.1 \\
\hline & Female & 55 & 65.5 \\
\hline & Missing & 2 & 2.4 \\
\hline \multicolumn{4}{|l|}{ Race/Ethnicity } \\
\hline & Asian & 1 & 1.2 \\
\hline & Black/African American & 8 & 9.5 \\
\hline & Hispanic & 1 & 1.2 \\
\hline & White & 72 & 85.7 \\
\hline & Missing & 2 & 2.4 \\
\hline \multicolumn{4}{|c|}{ Size of Institution } \\
\hline & Very Small & 2 & 2.4 \\
\hline & Small & 18 & 21.4 \\
\hline & Medium & 34 & 40.5 \\
\hline & Large & 14 & 16.7 \\
\hline & Very Large & 9 & 10.7 \\
\hline & Missing & 7 & 8.3 \\
\hline \multicolumn{4}{|l|}{ Experience } \\
\hline & 0 to 4 & 30 & 35.7 \\
\hline & 5 to 10 & 29 & 34.5 \\
\hline & 11plus & 18 & 21.5 \\
\hline & Missing & 7 & 8.3 \\
\hline \multicolumn{4}{|c|}{ Level of Education } \\
\hline & Bachelors & 4 & 4.8 \\
\hline & Masters & 44 & 52.4 \\
\hline & Doctorate & 29 & 34.5 \\
\hline & Missing & 7 & 8.3 \\
\hline
\end{tabular}

The number of participants who indicated their gender was 82 , with $65.5 \%$ females and $32.1 \%$ males. Only 1 participant identified themselves as Hispanic (1.2\%), 1 Asian (1.2\%), 8 African American (9.5\%), and a majority of 72 identified as white (85.7\%). This breakdown did not meet the $90 / 10$ split level, so all other ethnic groups were combined together to form $85.7 \%$ white and $11.9 \%$ other. 
Size of institution had $23.8 \%$ small, $40.5 \%$ medium, and $27.4 \%$ large, indicating that most community colleges in the region are of medium size (Full Time Equivalent 2000-4,999). Experience in number of years had $35.7 \%$ of participants with $0-4$ years of experience, $34.5 \%$ had 5-10 years, and 21.5\% had more than 10 years of experience. A majority of the participants had an experience of four years or less. Only $4.8 \%$ of participants had bachelor's degrees as their highest level of education, 52.4\% master's degrees, while $34.5 \%$ had doctoral degrees. The number of participants with bachelor's degrees as the highest level of education was too small and did not meet the 90/10 split level, and was therefore eliminated in the regression analysis.

On the descriptive statistics of age, 80 participants indicated their age and 4 participants did not. The minimum age was 33 years and the maximum age was 72, with a median age of 53 and standard deviation of 9 .

\section{Research Question 2}

What is the emotional intelligence of the community college deans in the southeastern region of the United States?

In this section, I present the data collected through the MSCEIT in terms of overall emotional intelligence and the four branch level scores of emotional intelligence: perceiving emotions, using emotions, understanding emotions, and managing emotions. The MSCEIT consists of 141 items. MSCEIT scores are interpreted on a normal curve with an average score of 100 and a standard deviation of 15 . High and low scores are identified by how close or distant they are from the mean score of 100 . Scores that exceed or fall below the mean by one standard deviation are considered significant (Mayer, Salovey \& Caruso, 2002). Table 3 shows the 
emotional intelligence scores guidelines and their significance (See Appendix G and $\mathrm{H}$ for request and permission to use MSCEIT table).

Table 3

\begin{tabular}{ll}
\multicolumn{2}{l}{ Guidelines for interpreting MSCEIT Scores } \\
\hline EIQ Score & Significance \\
\hline 69 or less & Consider development \\
$70-89$ & Consider improvement \\
$90-99$ & Low average score \\
$100-109$ & High average score \\
$110-119$ & Competent \\
$120-129$ & Strength \\
$130+$ & Significant strength \\
\hline
\end{tabular}

Note. From Mayer-Salovey-Caruso Emotional Intelligence Test MSCEIT: Users' Manual (p. 18), by J. D. Mayer, P. Salovey, and D. R. Caruso, 2002, Toronto, Ontario, Canada: Multi-Health Systems Inc.

Copyright 2002 by Multi-Health Systems Inc. Adapted with permission

Table 4 shows the descriptive statistics of the emotional intelligence scores of all 84 participants.

Table 4

Descriptive Statistics for Emotional Intelligence Variables $(\mathrm{N}=84)$

Mean Std. Deviation

Perceiving Emotions

96.00

Using Emotions

95.92

13.07

Understanding Emotions

100.25

9.01

Managing Emotions

100.55

9.20

$\underline{\text { Total EQ }}$

98.59

12.36 
From the descriptive statistics in Table 4, $(\mathrm{N}=84)$, the results indicated an overall emotional intelligence score mean of 98.59 and a standard deviation of 12.36 . Perceiving emotions had $M=96$ and $S D=14.40$, Using emotions had $M=95.92$ and $S D=13.07$. Understanding emotions $M=100.25$ and $S D=9.01$. Managing emotions had $M=100.55$ and $S D$ $=9.2$. These results indicate that the emotional intelligence scores of most of the participants were within one standard deviation of the population mean. This placed most participants in the low average level of emotional intelligence.

The highest total emotional intelligence score of all the participants was 129.13 and the lowest score was 64.75. Of the four branches of emotional intelligence, perceiving emotions had both the lowest and highest scores of 35.26 and 131.82 respectively.

\section{Research Question 3}

Is there any relationship between the emotional intelligence of the community college deans and selected demographics of age, gender, race, experience, institution size, and education level?

In this section, I present the data collected through the MSCEIT and demographic variables of age, gender, level of education, experience, and size of institution. Data was grouped based on gender. Independent t-tests for gender and ethnicity were also computed. Five different regressions were run with each of the four branch scores (B1 Perceiving emotions, B2 using emotions , B3 Understanding emotions, B4 managing emotions, and the total emotional intelligence score) as the outcome variable. The demographic variables of age, gender, level of education, experience, and size of institution were entered into each of the regression model simultaneously and no variables were removed. 
Before I conducted any statistical analysis, I subjected the data to a number of critical analyses to determine whether the assumptions underlying data analysis procedures were violated. I assessed independent variables for multicollinearity using Tolerance and the Variance Inflation Factor. According to Warner (2008), in order to contribute more useful predictive information, tolerance measures should be $>.20$ and the VIF should be $<4$. All the independent variables met this assumption as shown in table 5 . The assumption of normality is usually tested using Kolgomoriv-Smirnov test and is confirmed if $\mathrm{p}$ value is greater than .05 . Tests of normality were conducted using Kolgomoriv-Smirnov and data was found to be normal for Perceiving emotions, Understanding emotions, Managing emotions, and Total emotional intelligence. The $p$ value for Using emotions was .04, which is borderline. The test for normality is said to be overly sensitive with large samples, thus, the assumption of normality is only broken if there are large departures from normality (Fields, 2005). This value was not too skewed and was found to be on the borderline, therefore was accepted.

The standardized residuals were plotted against the standardized predicted values of the depended variables to determine the relationship between independent and dependent variables to check for curvilinear patterns. From the scatterplots (Appendix I), there were no obvious curvilinear patterns observed, so the assumption of linearity was not violated. Homoscedasticity, a measure used to assess if error variances are equal across all independent variables was also assessed. The scatter plots were found to be free from any clear patterns, an indication that homoscedasticity was met.

Table 5 shows the tolerance and VIF values, while Table 6 shows the results from tests of normality using Kolmogorov- Smirnova. The p value for using emotions was slightly above .05 . 
Table 5

Tolerance and VIF values

\begin{tabular}{lrr}
\hline & \multicolumn{2}{c}{ Collinearity Statistics } \\
\cline { 2 - 3 } & Tolerance & VIF \\
\hline Age & 0.82 & 1.22 \\
Gender & 0.87 & 1.14 \\
Ethnicity & 0.92 & 1.09 \\
Size Medium & 0.57 & 1.77 \\
Size Large & 0.56 & 1.77 \\
Exp5to10 & 0.62 & 1.61 \\
Exp11plus & 0.61 & 1.65 \\
Level of & & \\
Education & 0.78 & 1.29 \\
\hline Tolerance should be $>.20$ & & \\
VIF should be $<.40$ & &
\end{tabular}

Table 6

Testing the Assumptions of Normality

\begin{tabular}{lccc}
\hline & \multicolumn{3}{l}{ Kolmogorov-Smimova } \\
\hline & Statistic & $\mathrm{df}$ & \multicolumn{2}{c}{ Sig. } \\
\cline { 2 - 4 } $\begin{array}{l}\text { Perceiving } \\
\text { Emotions }\end{array}$ & 0.08 & 83 & $0.20^{*}$ \\
Using emotions & 0.10 & 83 & 0.04 \\
$\begin{array}{l}\text { Understanding } \\
\text { Emotions }\end{array}$ & 0.08 & 83 & $0.20^{*}$ \\
Managing & & & \\
Emotions & 0.07 & 83 & $0.20^{*}$ \\
Total EIQ & 0.09 & 83 & 0.09 \\
\hline
\end{tabular}

*. This is a lower bound of the true significance.

Lilliefors Significance

Correction 
Table 7 shows the maximum and minimum scores by gender. For the female participants, total emotional intelligence scores (total EIQ) range from a high score of 129.13 to a low score of 64.75. Male scores range from a high total emotional intelligence score of 118.29 to a low score of 78.33. Female participants scored higher than the male participants in all areas. Female participants had a high score for Perceiving emotions of 131.82, while men had 115.22. It is interesting to note that women participants also had both the highest and lowest scores in almost all areas when compared to male participants.

Table 7

MSCEIT Scores for Males \& Females

\begin{tabular}{lcc}
\hline & Males & Females \\
\hline $\begin{array}{c}\text { Perceiving Emotions } \\
\text { Range of scores }\end{array}$ & $75.52-115.22$ & $35.26-131.82$ \\
$\begin{array}{c}\text { Using Emotions } \\
\text { Range of scores }\end{array}$ & $71.65-124.99$ & $63.56-129.55$ \\
Understanding & & \\
$\begin{array}{l}\text { Emotions } \\
\text { Range of scores }\end{array}$ & $81.37-113.11$ & $81.46-120.12$ \\
$\begin{array}{l}\text { Managing Emotions } \\
\quad \text { Range of scores } \\
\text { Total EIQ } \\
\quad \text { Range of scores }\end{array}$ & $77.43-115.84$ & $74.25-117.33$ \\
\hline
\end{tabular}

From the emotional intelligence scores, one participant had an extremely low score in perceiving emotions. This score was considered an outlier and was therefore eliminated in the reminder of the data analysis. Table 8 shows the means and standard deviations of the emotional intelligence scores after the outlier was removed. 
Table 8

Descriptive Statistics for Emotional Intelligence Variables $(\mathrm{N}=83)$

\begin{tabular}{lcc}
\hline & Mean & Std. Deviation \\
\hline Perceiving Emotions & 96.73 & 12.81 \\
Using Emotions & 96.31 & 12.65 \\
Understanding & 100.37 & 9.00 \\
Emotions & & \\
Managing Emotions & 100.7 & 9.20 \\
Total EIQ & 98.99 & 11.85 \\
\hline
\end{tabular}

For the study sample ( $\mathrm{N}=83)$, the mean for total emotional intelligence (total EIQ) as measured by MSCEIT was 98.99, with a standard deviation of 11.85 , which is within one standard deviation of the population mean. This placed most participants in the low average emotional intelligence range. MSCEIT scores were grouped based on gender as shown in tables 9 and 10. 
Table 9

MSCEIT Scores for Female participants

\begin{tabular}{lllllll}
\hline EIQ Score & Significance & B1 & B2 & B3 & B4 & TOT \\
\hline \multirow{2}{*}{$\begin{array}{l}\text { or less } \\
70-89\end{array}$} & Consider development & 0 & 2 & 0 & 0 & 0 \\
$90-99$ & Consider improvement & 11 & 17 & 5 & 4 & 13 \\
$100-109$ & Low average score & 19 & 12 & 17 & 21 & 14 \\
$110-119$ & High average score & 14 & 13 & 22 & 21 & 12 \\
$120-129$ & Competent & 9 & 7 & 9 & 8 & 13 \\
$130+$ & Strength & 0 & 3 & 1 & 0 & 2 \\
Total Number of Participants & 1 & 0 & 0 & 0 & 0 \\
\hline
\end{tabular}

Note; Perceiving emotions is B1, Using emotions B2, Understanding emotions B3, Managing emotions B4 and TOT is total emotional intelligence score.

Twenty seven (50\%) female participants had total emotional intelligence score below the mean, 12 had scores around the average range, and only 2 female participants had 'strong' emotional intelligence scores. None of the female participants scored in the 'significant strength' range. Table 10 shows the number of male participants in each of the emotional intelligence scales. 
Table 10

MSCEIT Scores for Male participants

\begin{tabular}{lllllll}
\hline EIQ Score & Significance & B1 & B2 & B3 & B4 & TOT \\
\hline 69 or less & Consider development & 0 & 0 & 0 & 0 & 0 \\
$70-89$ & Consider improvement & 14 & 6 & 4 & 2 & 10 \\
$90-99$ & Low average score & 5 & 11 & 13 & 11 & 6 \\
$100-109$ & High average score & 4 & 8 & 9 & 9 & 8 \\
$110-119$ & Competent & 4 & 1 & 1 & 5 & 3 \\
$120-129$ & Strength & 0 & 1 & 0 & 0 & 0 \\
$130+$ & Significant strength & 0 & 0 & 0 & 0 & 0 \\
Total Number of Participants & 27 & 27 & 27 & 27 & 27 \\
\hline
\end{tabular}

Note; Perceiving emotions is B1, Using emotions B2, Understanding emotions B3, Managing emotions B4 and TOT is total emotional intelligence score.

Sixteen male participants had total emotional intelligence score below the mean, 8 male participants had scores around the average range, only 3 male participants had 'strong' emotional intelligence scores. None of the male participants scored in the 'significant strength' range. 
Table 11 shows the descriptive analysis of the emotional intelligence scores by gender, ethnicity, and level of education.

Table 11

Descriptive Of EIQ with gender, race and level of education

\begin{tabular}{llllllll}
\hline \multicolumn{1}{c}{ EIQ } & \multicolumn{2}{c}{ Gender } & \multicolumn{2}{c}{ Ethnicity } & Level of Education \\
\hline & Male & Female & White & Other & Masters & Doctorate \\
\hline Perceiving & & & & & & \\
Emotions & & & & & & \\
$\quad$ Mean & 92.72 & 98.90 & 98.03 & 88.38 & 98.79 & 93.10 \\
SD & 12.21 & 12.88 & 12.35 & 14.21 & 13.07 & 13.07 \\
N & 27 & 54 & 71 & 10 & 44 & 28 \\
Using Emotions & & & & & & \\
Mean & 95.76 & 96.7 & 96.72 & 94.02 & 96.78 & 94.51 \\
SD & 10.88 & 13.69 & 12.38 & 15.77 & 11.07 & 23 \\
N & 27 & 54 & 71 & 10 & 44 & 28 \\
Understanding & & & & & & \\
Mean & 97.17 & 101.64 & 100.87 & 95.08 & 101.94 & 97.97 \\
SD & 7.91 & 8.98 & 8.93 & 6.48 & 7.89 & 9.41 \\
N & 27 & 54 & 71 & 10 & 44 & 28 \\
Managing & & & & & & \\
Emotions & & & & & & \\
Mean & 100.36 & 101.06 & 100.93 & 100.09 & 100.87 & 100.82 \\
SD & 9.6 & 8.68 & 8.74 & 10.45 & 8.4 & 9.02 \\
N & 27 & 54 & 71 & 10 & 44 & 28 \\
Total EIQ & & & & & & \\
Mean & 95.99 & 100.63 & 100.03 & 92.39 & 100.65 & 95.68 \\
SD & 11.2 & 12.98 & 11.64 & 12.91 & 11.37 & 11.57 \\
N & 27 & 54 & 71 & 10 & 44 & 28 \\
\hline
\end{tabular}

Note: The $N$ value represents the number of participants who responded to the corresponding demographic characteristic.

Female participants had high average scores when compared to the male participants.

Females had a total emotional intelligence score (total EIQ) $M=100.63, S D=12.98$, while males had an overall emotional intelligence score (total EIQ) $M=95.11$ and $S D=11.20$. Females' mean was higher than the mean of the overall sample by 1.64, while the mean for males was lower 
than that of the overall study sample by 3.00. Participants who identified themselves as whites scored higher than others. Whites had an overall emotional intelligence score (total EIQ) $M=100.03, S D=11.64$, While the category of 'other' had a mean emotional intelligence score (total EIQ) of $M=92.39$ and $S D=12.91$.

Participants who had doctoral degrees had lower scores than those participants who had master's degrees. Participants with master's degrees had scores of perceiving emotions of $M=98.79, S D=13.07$; using emotion scores of $M=96.78, S D=11.07$; understanding emotion scores of $M=101.94, S D=7.79$; managing emotion scores of $M=100.87, \mathrm{SD}=8.4$; and total emotional intelligence scores of $M=100.65, S D=11.37$. Participants who had doctoral degrees had perceiving emotions scores of $M=93.10, S D=13.07$; using emotion scores of $M=94.51$, $S D=15.23$; understanding emotion scores $M=97.97, S D=9.41$; managing emotion scores of $M=100.82, S D=9.02$; and total emotional intelligence scores of $M=95.68, S D=11.57$.

T-tests were conducted for gender and ethnicity. Levene's test of equality of variance for all dependent variables was not significant, indicating that equal variance assumption for t-test was not violated.

The independent samples test for gender indicated that there was a significant difference in the mean score of perceiving emotions and understanding emotions by gender as shown in Table 12. There was a relationship between gender and perceiving emotions, with females scoring higher than the male participants by 6.18 . There was also a difference in using emotions by gender with females scoring higher than males by 4.46 . 
Table 12

\begin{tabular}{|c|c|c|c|c|c|c|}
\hline & \multirow[b]{2}{*}{$\mathrm{t}$} & \multirow[b]{2}{*}{$\mathrm{df}$} & \multirow[b]{2}{*}{$\mathrm{p}$ value } & \multirow[b]{2}{*}{$\begin{array}{l}\text { Mean } \\
\text { Difference }\end{array}$} & \multicolumn{2}{|c|}{$\begin{array}{l}95 \% \text { Confidence Interval of the } \\
\text { Difference }\end{array}$} \\
\hline & & & & & Lower & Upper \\
\hline \multicolumn{7}{|l|}{ Perceiving Emotions } \\
\hline $\begin{array}{l}\text { Equal variances } \\
\text { assumed }\end{array}$ & 2.07 & 79 & 0.04 & 6.18 & 0.25 & 12.11 \\
\hline \multicolumn{7}{|l|}{ Using Emotions } \\
\hline $\begin{array}{l}\text { Equal variances } \\
\text { assumed }\end{array}$ & 0.31 & 79 & 0.76 & 0.94 & -5.08 & 6.96 \\
\hline \multicolumn{7}{|l|}{ Understanding } \\
\hline \multicolumn{7}{|l|}{ Emotions } \\
\hline $\begin{array}{l}\text { Equal variances } \\
\text { assumed }\end{array}$ & 2.09 & 79 & 0.03 & 4.46 & 0.41 & 8.52 \\
\hline \multicolumn{7}{|l|}{ Managing Emotions } \\
\hline $\begin{array}{l}\text { Equal variances } \\
\text { assumed }\end{array}$ & 0.31 & 79 & 0.74 & 0.69 & -3.51 & 4.89 \\
\hline
\end{tabular}

$>$ T-TEST GROUPS $=$ Gender2( $(01)$

${ }^{*}$ Correlation is significant at the 0.05

level (2-tailed).

There was a difference in the mean scores of perceiving emotions and understanding emotions by ethnicity (Table 13). Whites scored higher than 'others' by 9.66 for perceiving emotions, and by 5.78 for understanding emotions. 
Table 13

Independent t-test for Equality of Means for Ethnicity

\begin{tabular}{|c|c|c|c|c|c|c|}
\hline & \multirow[b]{2}{*}{$\mathrm{t}$} & \multirow[b]{2}{*}{$\mathrm{df}$} & \multirow[b]{2}{*}{$p$ value } & \multirow[b]{2}{*}{$\begin{array}{l}\text { Mean } \\
\text { Difference }\end{array}$} & \multicolumn{2}{|c|}{$\begin{array}{l}95 \% \text { Confidence Interval of the } \\
\text { Difference }\end{array}$} \\
\hline & & & & & Lower & Upper \\
\hline \multicolumn{7}{|l|}{ Perceiving Emotions } \\
\hline $\begin{array}{l}\text { Equal variances } \\
\text { assumed }\end{array}$ & 2.27 & 79 & 0.03 & 9.66 & 1.20 & 18.11 \\
\hline \multicolumn{7}{|l|}{ Using Emotions } \\
\hline $\begin{array}{l}\text { Equal variances } \\
\text { assumed }\end{array}$ & 0.62 & 79 & 0.54 & 2.70 & -5.91 & 11.31 \\
\hline \multicolumn{7}{|l|}{$\begin{array}{l}\text { Understanding } \\
\text { Emotions }\end{array}$} \\
\hline $\begin{array}{l}\text { Equal variances } \\
\text { assumed }\end{array}$ & 1.97 & 79 & 0.05 & 5.78 & -0.06 & 11.62 \\
\hline \multicolumn{7}{|l|}{ Managing Emotions } \\
\hline $\begin{array}{l}\text { Equal variances } \\
\text { assumed }\end{array}$ & 0.28 & 79 & 0.78 & 0.84 & -5.18 & 6.86 \\
\hline
\end{tabular}

A number of variables were significantly correlated at the .05 level as shown in Table 14 . Gender was significantly correlated with perceiving emotions, using emotions and total emotional intelligence; experience was significantly correlated with perceiving emotions and understanding emotions; and level of education was significantly correlated with perceiving emotions, understanding emotions, and total emotional intelligence. 
Table 14

Correlation between dependent and independent variables $(\mathrm{N}=69)$

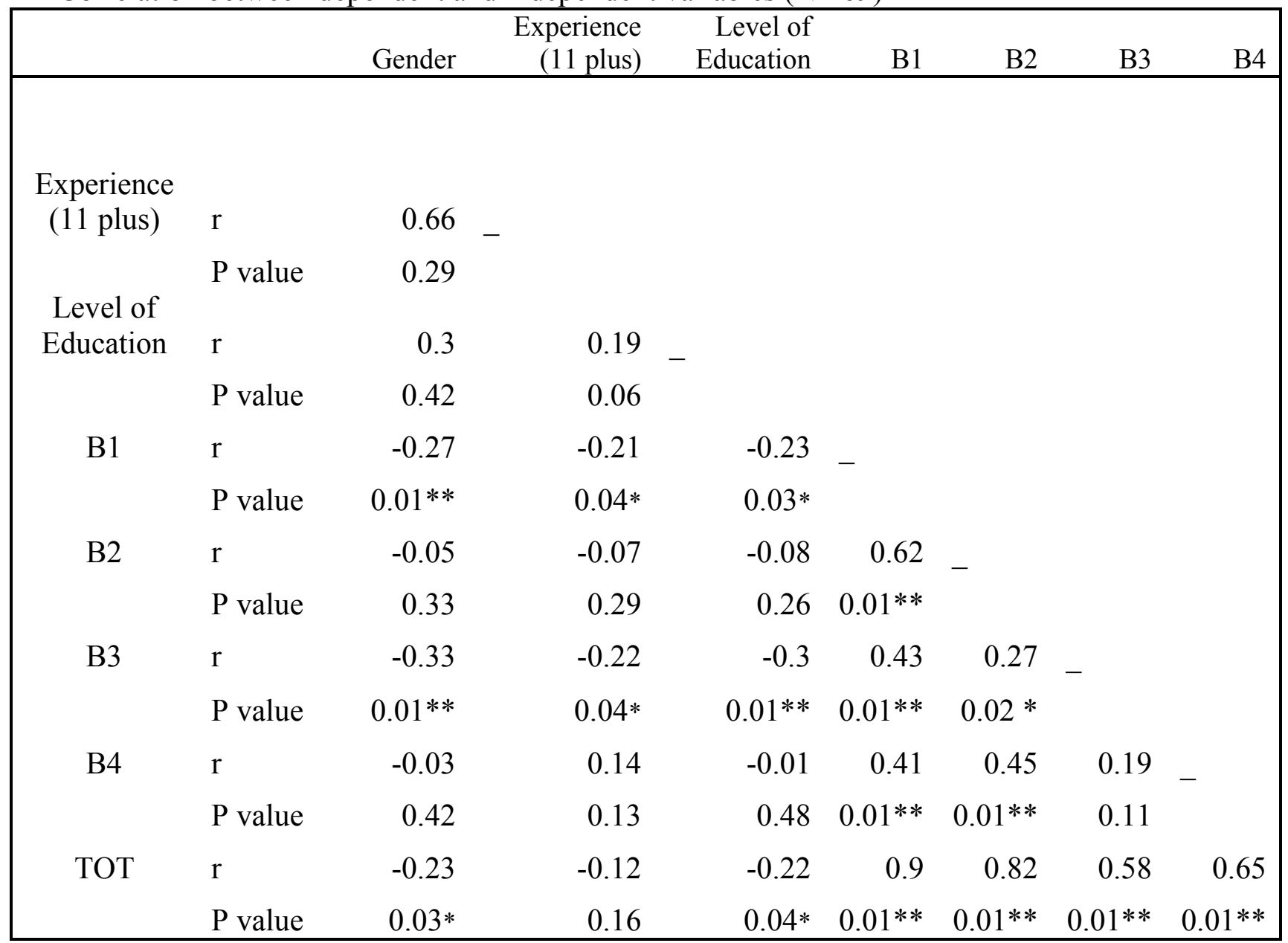

Note

**Correlation is significant at the 0.01 level (2-tailed).

*Correlation is significant at the 0.05 level (2-tailed).

B1 (Perceiving Emotions), B2 (Using Emotions), B3 (Understanding Emotions), B4 (Managing Emotions), TOT (Total Emotional Intelligence)

From the correlations, perceiving emotions was significantly negatively correlated with gender (females), experience (11plus), and level of education. Gender had $[r(67)=-0.27, p=$ $0.01]$, experience of more than 11 years had $[r(67)=-0.21, p=0.04]$ while level of education 
had $[r(67)=-0.23, p=0.03]$. None of the other demographic characteristics were significantly correlated with perceiving emotions.

None of the independent variables were significantly correlated with using emotions. Understanding emotions was significantly correlated with gender, experience (11plus), and level of education. Gender had $[r(67)=-0.33, p=0.00]$, experience of more than 11 years had $[r(67)$ $=-0.22, p=0.04]$, while level of education had $[r(67)=-0.30, p=0.01]$. None of the other demographic characteristics were significantly correlated with perceiving emotions.

Total emotional intelligence was significantly correlated with gender and level of education. Gender had $[r(67)=-0.23, p=0.03]$, while level of education had $[r(67)=-0.22, p=$ 0.04].

Table 15 shows the $\mathrm{R}$ square and adjusted $\mathrm{R}$ values of each of the five regressions, only two of them were significant, and even the ones that were significant, the effect size was moderate. The relationships between the demographic predictors and emotional intelligence outcomes were moderate.

Table 15

Regression Summary

\begin{tabular}{lcccc}
\hline Variables & $\mathrm{R}$ & $\mathrm{R}$ Square & $\begin{array}{l}\text { Adjusted R } \\
\text { Square }\end{array}$ & $\mathrm{Sig}$ \\
\hline Perceiving Emotions & 0.52 & 0.27 & 0.17 & 0.01 \\
Using Emotions & 0.2 & 0.04 & -0.09 & 0.96 \\
Understanding Emotions & 0.53 & 0.28 & 0.18 & 0.01 \\
Managing Emotions & 0.18 & 0.03 & -0.1 & 0.98 \\
Total EIQ & 0.36 & 0.13 & -0.02 & 0.36 \\
\hline
\end{tabular}


Perceiving emotions had a significant negative relationship with gender, size of institution, and level of education. Dummy coding was assigned for the variables. For size of institution, a dummy variable was created for values medium (1) versus other (0), and large (1) versus other (0); Experience was coded as; 0-4(1) versus other (0), 5-10 (1) versus other (0), and 11 plus (1) versus other (0); Gender was coded as females (0), males (1); and ethnicity was coded as white (0), others (1).

Perceiving emotions (B1) had a moderately high multiple regression coefficient R at .52. The $\mathrm{R}^{2}$ value was .27 , while the adjusted $\mathrm{R}^{2}$ value was .17 . Adjusting for the number of cases $(\mathrm{N}=69)$ and the number of predictor variables $(8)$, the proportion of variability accounted for by the model remained moderate at.17. This means that the predictor variables were accounting for $17 \%$ of the total variability in perceiving emotions.

Using all 8 variables in the model, the ANOVA indicated that the model predicted a significant level of the variability in the dependent variable, perceiving emotions. With F $(8,69=$ 2.72), the model was significant, $(p=.01)$. Male participants had lower levels of perceiving emotions than female participants. On average, males had a 6.96 lower ability to perceive emotions than females when controlling for other variables (Table 16). This means that men's ability to perceive emotions was almost half a standard deviation lower than females.

In terms of education, participants with doctoral degrees had a lower ability to perceive emotions than those with masters' degrees. Those who had a doctorate showed a lower ability to perceive emotions by 7.14 than those with master's degrees. Level of education had a Beta value of -.29 (Table 16). An increase in level of education by one standard deviation would result in a decrease in perceiving emotions by .29 . Medium size institution had a B value of - .7 .34 and a $p$ value of 0.05 , while large size institutions had a B value of -4.46 and $p$ value of 0.25 . This means 
that participants from small size institutions had a higher ability to perceive emotions 7.34 . In reviewing the standardized coefficients, size of institution was the strongest predictor of perceiving emotions at -.30 , followed by level of education at -.29 .

Table 16

Perceiving Emotions Coefficients

\begin{tabular}{|c|c|c|c|c|c|}
\hline \multirow[t]{2}{*}{ Model } & $\begin{array}{r}\text { Unstanda } \\
\text { Coefficients }\end{array}$ & dized & $\begin{array}{l}\text { Standardized } \\
\text { Coefficients }\end{array}$ & \multirow[b]{2}{*}{$\mathrm{t}$} & \multirow[b]{2}{*}{ sig } \\
\hline & B & Std. Error & Beta & & \\
\hline (Constant) & 93.72 & 9.57 & & 9.79 & 0 \\
\hline Ethnicity2 & -4.60 & 5.41 & -0.10 & -0.85 & 0.40 \\
\hline Gender2 & -6.96 & 3.09 & -0.27 & -2.26 & 0.03 \\
\hline Level of Education & -7.14 & 3.13 & -0.29 & -2.29 & 0.03 \\
\hline SizeMedium & -7.34 & 3.61 & -0.30 & -2.04 & 0.05 \\
\hline SizeLarge & -4.46 & 3.80 & -0.17 & -1.18 & 0.25 \\
\hline Exp5to 10 & 4.97 & 3.50 & 0.20 & 1.42 & 0.16 \\
\hline Exp11plus & -2.44 & 4.10 & -0.09 & -0.60 & 0.55 \\
\hline Age & 0.22 & 0.17 & 0.15 & 1.29 & 0.21 \\
\hline
\end{tabular}

None of the demographic characteristics were significant with using emotions (B3). Understanding emotions had a significant relationship with gender, level of education, and experience. Understanding emotions (B3) had a moderate multiple regression coefficient R at .53 . The $\mathrm{R}^{2}$ value was .28 , and the adjusted $\mathrm{R}^{2}$ value was .18 . Adjusting for the number of cases and the number of predictor variables, the proportion of variability accounted for by the model remained moderate at .18 . This means that the demographic characteristics in the model accounted for $18 \%$ of total variability in understanding emotions, which could be considered moderate.

Using all 8 variables in the model, the ANOVA indicated that the model was predicting a significant level of the variability in the dependent variable, understanding emotions. With F (8, 
$69)=2.91$, the model was highly significant, $(p=.01)$. Male participants had lower levels of understanding emotions than female participants. On average, males had a 7.34 lower level of understanding emotions than females when controlling for other variables (Table 17). This means that men's ability to understand emotions was almost half a standard deviation lower than that of females.

In terms of education, participants with doctorates had lower levels of understanding emotions than those with masters' degrees. Those who had a doctorate showed a lower level of understanding emotions by 6.37. Level of education had a Beta value of -.36 (Table 17). An increase in level of education by one standard deviation would result in a decrease of understanding emotions by .36. Experience (5-10) had a B value of 5.42 and a p value of 0.03 , while Experience (11plus) had a B value of .93 and p value of 0.75 . This means that participants with 0-4 years of experience had a higher level of understanding emotions by 5.41, while those with more experience (more than 10 years) had a level of understanding emotions by 0.93 and a $\mathrm{p}$ value of 0.75 . Five to ten years of experience had a Beta value of .30 , an indication that with an increase in experience by one standard deviation would result in an increase of understanding emotions by .30 standard deviations. In reviewing the standardized coefficients, gender was the strongest predictor of understanding emotions at -.39 , followed by level of education at -.36. None of the demographic characteristics was significant with managing emotions. 
Table 17

\begin{tabular}{|c|c|c|c|c|c|}
\hline \multirow[t]{2}{*}{ Model } & \multicolumn{2}{|c|}{$\begin{array}{l}\text { Unstandardized } \\
\text { Coefficients }\end{array}$} & \multirow{2}{*}{\begin{tabular}{|r|}
$\begin{array}{l}\text { Standardized } \\
\text { Coefficients }\end{array}$ \\
Beta \\
\end{tabular}} & \multirow[b]{2}{*}{$\mathrm{t}$} & \multirow[b]{2}{*}{ sig } \\
\hline & $\mathrm{B}$ & Std. Error & & & \\
\hline & 109.86 & & & 16.10 & \\
\hline (Constant) & 7 & 6.824 & & 1 & 0 \\
\hline Ethnicity2 & -1.482 & 3.855 & -0.044 & -0.384 & 0.702 \\
\hline Gender2 & -7.337 & 2.199 & -0.391 & -3.336 & 0.001 \\
\hline $\begin{array}{l}\text { Level of } \\
\text { Education }\end{array}$ & -6.369 & 2.228 & -0.355 & -2.858 & 0.006 \\
\hline SizeMedium & -0.944 & 2.571 & -0.054 & -0.367 & 0.715 \\
\hline SizeLarge & 0.487 & 2.708 & 0.026 & 0.18 & 0.858 \\
\hline Exp5to 10 & 5.415 & 2.494 & 0.302 & 2.171 & 0.034 \\
\hline Exp11plus & 0.926 & 2.919 & 0.045 & 0.317 & 0.752 \\
\hline Age & -0.125 & 0.122 & -0.125 & -1.029 & 0.307 \\
\hline
\end{tabular}

None of the demographic characteristics was significant with managing emotions, and total emotional intelligence.

\section{Summary}

In this chapter, I presented the findings of the research questions explored in this study to understand the nature of the emotional intelligence of community college deans in the southeastern region of the United States. I used SPSS 20 for the data analysis and a significance level of 0.05 .

The research yielded 84 responses for an overall response rate of $27.5 \%$. Data analysis for the demographic characteristics of age, gender, ethnicity, size of institution, level of education, and experience were explored with the total emotional intelligence score and four branch areas (perceiving emotions, using emotions, understanding emotions and managing 
emotions). Total emotional intelligence, using emotions, and managing emotions were not statistically significant with any of the demographic characteristics. There was a significant negative relationship between gender, size of institution, level of education and perceiving emotions. Male participants had low levels of perceiving and understanding emotions when compared with females. Level of education and experience were also significant with understanding emotions.

This study provided a snapshot of the nature of the emotional intelligence of community college deans in the southeastern region of the United States. It adds to the available information on emotional intelligence in general and provides insights for future research. 


\section{Chapter Five}

\section{Discussion and Conclusions}

This chapter is divided into summary, discussion, conclusions, implications, and recommendations. In the first section, I present summaries of the purpose of the study, research questions, review of literature, research methodology, and study findings. In the second section, I present the discussion and conclusions drawn from the study. In the third section I present the implications of the study, and in the last section I present recommendations for future research.

\section{Summary}

The purpose of this study was to examine the nature of the emotional intelligence of community college deans in the southeastern region of the United States. Emotional intelligence has become an important element in leadership and everyday aspects of life in today's world. The idea of different forms of intelligence is a recent phenomenon introduced within the last few decades. This notion has led to debate around and doubts about the usefulness and effectiveness of relying on the regular cognitive intelligence (IQ) to determine the success or failure of an individual in life. Good leadership requires more than cognitive intelligence (Bennis, 1989; Goleman, 1995). A recent study by Kent (2006) revealed that $85 \%$ of high performing leaders have high levels of emotional intelligence, while $15 \%$ have high levels of IQ. This is an indication of the importance of understanding emotional intelligence and its different aspects. Leaders in today's competitive world require numerous skills and competencies in order to be successful, especially community college leaders whose roles are more complicated than in other postsecondary institutions of learning. There is limited available information about community college deans in general. The objective of the study is to gain a sense of the presence and distribution of emotional intelligence among community college deans. 
The study sample of this research consisted of community college deans from the southeastern region of the United States. Participants were invited to participate in the study through email. Of the 323 invitations sent, 84 participants completed the survey, yielding a response rate of $27.45 \%$. Follow up emails were send to participants requesting them to complete the demographic questionnaire. Community college deans were selected for this study because of the challenging nature of their leadership roles, while community colleges were selected because of the numerous challenges that they face and because of the complexity of leadership in these institutions. Community colleges have loose departmental structures due to the lack of internal oversight committees, rely heavily on part-time and adjunct faculty, nature close ties to their communities, and have limited faculty self-governance (Franke, 2006). These factors make leadership roles in community colleges more challenging and complex in nature.

The literature review found very little specific research on the emotional intelligence and demographic characteristics of community college deans. The gap in research served as the main basis for this study. Quantitative design was used for the methodology of this study. Data for emotional intelligence was collected using Mayer-Salovey-Caruso Emotional Intelligence Test (MSCEIT). The MSCEIT is an ability-based test that is used to measure four branches of emotional intelligence, which include perceiving emotions, using emotions, understanding emotions, and managing emotions. It consists of 141 items divided between eight task areas (two for each of the four domains) and yields an overall score, two area scores, four branch scores, and eight task scores (Mayer, Salovey, \& Caruso, 1999b). For this study, the overall emotional intelligence score and the four branch scores were used for this study. Follow up demographic questions were send to participants through emails. Once all data was collected, data was analyzed through descriptive statistics, t-tests, and multiple regressions. The intention of this 
research was to gain a sense of the presence and distribution of emotional intelligence among community college deans in the southeastern region of the United States.

The following research questions were used to guide this study.

1. Who are the community college deans in the Southeastern region of the United States of America? What are their demographic characteristics?

2. What is the emotional intelligence of the community college deans?

3. Is there any relationship between the emotional intelligence of the community college deans and selected demographics of age, gender, race, experience, institution size, and education level?

\section{Discussion}

The results revealed that of the 84 participants in the study, $65.5 \%$ were females while $32.1 \%$ were males. The number of participants who did not indicate their gender was $2.4 \%$ of the study sample. This study found that more females than males hold administrative positions. This finding is in contrast to studies that have found women to be under-represented in administrative roles (Anderson \& King 1987; Cantu, 1997; Farmer \& Paris, 2000; Moore, 1983; Snuggs, 2006).

Most of the participants in this study had served in their current positions for fewer than 4 years $(35.7 \%)$, while $34.5 \%$ had served in their current positions for 10 years. Twenty-one percent had more than 10 years of experience. On the demographic characteristic of ethnicity, the study participants identified themselves as Hispanic (1.2\%), Asian (1.2\%), African American $(9.5 \%)$, and white $(85.7 \%)$. From this study, participants from minority groups were grossly underrepresented. This is consistent with previous studies (Anderson \& King, 1987; Farmer \& Paris, 2000; Moore, 1983), which found that few minorities held administrative positions. Even 
though the previous studies noted were conducted over a decade ago, the current study revealed similar results.

On the demographic characteristic of age, the average age was 53 , minimum age of 33 , and maximum age of 72. Several studies on deanship found the average age of deans to be above 50 (Amey, Van Der Linden, \& Brown 2002; Cantu, 1997; Crawford, 1983; \& Moore 1983). This is consistent with previous studies. This study also found that of the total number of participants who indicated their highest education level, majority held a master's degree (52.4\%), while $35.4 \%$ held doctoral degrees. Only $4.8 \%$ held bachelor's degrees as their highest level of education. This finding is consistent with a study by Sypawka (2008), whose study on division deans in Carolina Community college system revealed that $63.6 \%$ of the deans from his sample of 132 participants held masters degrees, $26.5 \%$ doctoral degrees, while only $3.8 \%$ held bachelor's degrees.

In this study 23 of the community college deans had total emotional intelligence scores that were below average (below 89), 40 community college deans had average total emotional intelligence scores (90-109), while 18 participants had above average scores (109 and above). Previous studies have shown that emotional intelligence plays a major role in leadership and have suggested that leaders need to develop their emotional intelligence competencies in order to successfully lead and compete in today's challenging environment (Chernis, 2000; Higgs, 2002; Snuggs, 2006; Van Der Zee \& Wabeke, 2004).

The current study found that female participants had high average total emotional intelligence scores $M=100.63, S D=12.98$ when compared to the male participants $M=95.11$, $S D=11.20$. The independent samples test for gender also indicated that there was a difference in the mean score of perceiving emotions, understanding emotions, and using emotions by gender, 
with female participants scoring higher than the male participants. This finding is consistent with numerous studies which have suggested that gender differences exist with regards to emotional intelligence and gender, with females scoring higher than males (Alumran \& Punamaki, 2008; Brackett, Rivers, Shiffman, Lerner, \& Salovey, 2006; Mayer, Caruso, \& Salovey, 1999; Palmer, Monacha, Gignac, \& Stough, 2003; Petrides \& Furnham, 2000).

This study also found no significant difference with age. This is not consistent with some findings that suggest that emotional intelligence is likely to increase as people get older (BarOn,2002; Goleman ,1995). Studies by Bar-on (2002) found relatively small significant differences with regards to age, with older members scoring higher. However, other studies have found no significance between emotional intelligence and age (Alumran \& Punamaki, 2008; Min 2010).

Participants who identified themselves as White scored higher than others. Whites had an overall emotional intelligence score (total EIQ) $\mathrm{M}=100.03, S D=11.64$, While the category of 'other' had a mean (total EIQ) score of 92.39 and $S D=12.91$. Previous studies by (Bar-On, 2006; Mayer et al, 1999 ;) found no significant difference between emotional intelligence and race. Other studies on intelligence (cognitive) have suggested the existence of significance differences between various racial groups (Suzuki \& Valencia, 1997).

The findings from this study were somewhat significant in nature in terms of level of education. This study revealed that participants who had doctorates had lower scores than those participants who had master's degrees as the highest level of education. Correlations revealed that level of education was significantly negatively correlated with perceiving emotions, understanding emotions, and total emotional intelligence. This study found that an increase in level of education resulted in a decrease in perceiving and understanding emotions. Study by 
Min (2010) found no significant relationship between the level of education of tour guides and their emotional intelligent scores. A study by Rahim (2010) on emotional intelligence and organizational performance found that the emotional intelligence scores of participants increased as level of education increased.

Size of institution was significant with perceiving emotions. Regression analysis indicated that medium size institution had a B value of -. 7.34 and a $p$ value of 0.05 , while large size institutions had a $B$ value of -4.46 and $p$ value of 0.25 . This means that participants from small size institutions had a higher ability to perceive emotions when compared to those from medium and large institutions.

Experience was found to be significant with understanding emotions. Participants with more experience had higher levels of understanding emotions. An increase in experience from 0 4 years to 5-10 years would lead to an increase in understanding emotions by 5.41 . Five to ten years of experience had a Beta value of .30, an indication that an increase in experience by one standard deviation would result in an increase in understanding emotions by .30 standard deviations. A study on tour guides contacted by Min (2010) found that those tour guides who had tenure had higher levels of emotional intelligence when compared to others.

\section{Conclusions}

The following research questions were used to guide this study.

1. Who are the community college deans in the southeastern region of the United States of America? What are their demographic characteristics?

More females than males participated in this study. The findings from this study could have resulted due to several reasons which include small sample size, lengthy nature of the MSCEIT questionnaire, and the willingness of more female participants to complete the study as compared 
to the males. The results could also be an indication that more females than males hold administrative positions in community colleges. It is important to note that in regards to the sample size, I received feedback from some potential participants indicating that the survey was too long; this combined with the fact that participants had to complete the survey in one sitting discouraged many potential participants. Due to these factors, this finding is not conclusive and might not reflect the entire region. Further research would be useful to either confirm or reject these findings.

The minimum age was 33 years and the maximum age was 72 , with a median age of 53 and standard deviation of 9 . This is an indication of the aging administrators in community colleges today. Community colleges should strive to train current faculty on numerous leadership roles because literature shows that most administrators and deans in community colleges are drawn from faculty ranks (Barwick, 2002; Cantu, 1997; Leubsdorf, 2006; Weisman \& Vaughan, 2001). This could make the leadership transition easier on both the institutions and community at large.

Majority of the participants in this study held a master's degree (52.4\%), while $35.4 \%$ held doctoral degrees as the highest level of education. Only $4.8 \%$ held bachelor's degrees as their highest level of education. Even though this finding is consistent with a study by Sypawka (2008), there is still very limited available information on the level of education of community college deans. Further research would be useful to add to the available information on the education levels of community college deans.

Most participants in the study had served in their deanship roles for over 10 years. This finding could be an indication of more retirements in the community colleges and/or new hires to meet the need. These results are consistent with several studies which have indicated that most 
community college deans are bound to retire or to have retired by the end of 2011 ( Boggs, 2003; Carroll, 2004; Evelyn, 2001;Schults, 2001; Weisman \& Vaughan, 2002; 2007), opening up positions that needed to be filled through either promotions, or new hires.

The current study revealed that minority groups are underrepresented in deanship roles. The ethnicity disparity could be an indication of a serious weighting toward those who are not minority members. Community colleges may need to re-examine their equal employment and promotion practices to close the gap.

2. What is the emotional intelligence of the community college deans?

The findings from this research showed that 23 of the community college deans had total emotional intelligence scores that were below average (below 89), 40 community college deans had average total emotional intelligence scores (90-109), while 18 participants had above average scores (109 and above). This finding could be an indication of a need for community colleges to embrace emotional intelligence and educate its members on the role that emotional intelligence plays in leadership. Previous studies have shown that emotional intelligence plays a major role in leadership (Chernis, 2000; Snuggs, 2006; Van Der Zee \& Wabeke, 2004). As leaders of community colleges, it is important for community colleges to take measures and train its leaders with the goal of empowering them with necessary emotional intelligence competences necessary for successful leadership.

3. Is there any relationship between the emotional intelligence of the community college deans and selected demographics of age, gender, race, experience, institution size, and education level? 
Female participants in this study had high average total emotional intelligence scores when compared to the male participants. The independent samples test for gender also indicated that female participants scored higher than the male participants. The finding in gender disparity is not conclusive and more research could be useful particularly on community college deans to add to the available literature.

This study found no significance difference with age. The findings from this study are not conclusive and require more research into the area of emotional intelligence and age, since it is interesting to note that according to Wechsler (1958), cognitive intelligence usually develops until late adolescence and starts to decline as people get older.

Participants who identified themselves as White scored higher than other minority groups. Even though previous studies on intelligence (Cognitive) found significance differences between various racial groups (Suzuki \& Valencia, 1997), emotional intelligence studies have found no significant difference between emotional intelligence and ethnicity (Bar-On, 2006; Mayer et al, 1999;). However, based on these finding alone, we cannot draw any significant conclusions except that White participants scored higher than other racial groups.

The findings from this study were somewhat significant in nature in terms of level of education with participants who had doctoral degrees scoring lower than those participants who had master's degrees. Further research would be useful to either confirm or reject findings from this study.

Participants from small size institutions had higher scores than those participants from large institutions. This finding could be attributed to the fact that participants in small size institutions have a smaller population of students to deal with and thus are likely to develop and 
form some relationships unlike in large institutions where building relationships could be challenging.

In conclusion, results from the present study indicate that there is some relationship between emotional intelligence branch scores of perceiving emotions with age, gender, and level

of education. Results also indicate that there are some relations between understanding emotions, gender, and level of education.

It is important to note that due to the limited nature of available information on emotional intelligence and community college deans and leadership in educational institutions in general, the recommendations given are tentative given the limitations. More research ought to be conducted on the area of emotional intelligence and community college deans to further enrich the available literature.

\section{Limitations of the Study}

There were several limitations in this study which were beyond my control. The measurement instrument used for the study was a self-report measure, which has some limitations such as being subjective in nature, and the possibility of response distortions. Due to the self-report nature of the surveys, there was no way for me to verify the truthfulness of the information provided, which may lead to inaccurate results.

Completion of the MSCEIT required participants to spend between 30-45 minutes of their time in one sitting. This was a major challenge for participants and some of the deans were reluctant to complete the lengthy survey instrument. It was also not possible to identify the causal connections from the results. This made it difficult to determine what caused a leader's emotional intelligence to be one way or another (high/low). 
The survey focused on community college deans from public community colleges in the southeastern region of the United States which limits the generalization of the results to all community college deans in the country.

\section{Implications for practice}

Emotional intelligence plays an important role not only in leadership but also in everyday life. Mayer, Salovey, and Caruso (2004) asserted that emotions were absolutely necessary in guiding people to make good decisions, succeed, cope, and solve problems. It is therefore important for community college deans to:

1. Be more informed on the importance and role of emotional intelligence in the work place due to the challenging nature of the leadership roles of community college deans

2. Continue to develop their emotional intelligence skills through training and practice

3. Identify different emotional intelligence competencies that are more important in the leadership roles and strive to improve them

4. Get trained through workshops and seminars to help improve their emotional intelligence scores. This training could be particularly important for male deans because this study found that male community college deans scored lower than their female counterparts

5. Utilize emotional intelligence testing in the screening process for new deanship hires 


\section{Recommendations for Future Research}

1. The results of this study should be further tested using a larger population sample to further the understanding of the emotional intelligence of community college deans and to provide more diversity and widespread generalizability

2. Further research should be conducted using a different measure of emotional intelligence and compare with results from this study

3. A replica study should also be done on private community colleges to find out if there are significant differences associated with type of institution.

4. The study should be replicated and administered to four-year institutions in the southeastern region of the United States to find out if there are significant similarities or differences between the studies. This knowledge will add to the understanding of emotional intelligence, demographic characteristics, and size of institution

5. A similar study should be conducted using a different region and check for any similarities and/or differences

6. Further research should be done on the same region and check for relationship between emotional intelligence and different leadership styles. This will provide useful information on the relationship between particular leadership styles and emotional intelligence

7. Further research should be done to investigate the nature of the emotional intelligence of community college deans in specific departments and check for differences and similarities

8. Further research should be conducted to determine the relationship between different emotional intelligence and leadership effectiveness. This would lead to an understanding 
of the relationship, if any, between a dean's level of emotional intelligence and his/her leadership effectiveness 


\section{References}

Alumran, J. A., \& Punamäki, R. (2008). Relationship between gender, age, academic achievement, emotional intelligence, and coping styles in Bahraini Adolescents. Individual Differences Research, 6(2), 104-119.

Amey, M. (2004). Learning leadership in today’s community colleges. Community College Journal, 74(4), 6-9.

Amey, M. J., Van Der Linden, K. E., \& Brown, D. F. (2002). Perspectives on community college leadership: Twenty years in the making. Community College Journal of Research \& Practice, 26, 573-589.

Anderson, D. G., \& King, J.P. (1987). The dean of education: A demographic analysis. Journal of Teacher Education, 38(5), 9-12.

Andrews, H. A. (2000). The dean and the faculty. New Directions for Community Colleges, 2000(109), 19.

Astin, A., \& Astin, H. (2000). Leadership reconsidered. Battle Creek, MI: Kellogg Foundation. (ED 444437).

Avolio, B., \& Bass, B. (1988). Transformational leadership, charisma, and beyond. In J. Hunt, B. Baliga, H. Dachler, \& C. Schriesheim (Eds.), Emerging leadership vistas. Lexington, MA: Lexington Books.

Avolio, B. J., Waldman, D. A., \& Einstein, W. O. (1988). Transformational leadership in management game simulation. Group and Organizational Management 13(1), 59-80.

Bailey, J. M. (2008). Work and life balance: Community college occupational deans. Community College Journal of Research \& Practice, 32(10), 778-792. 
Bagshaw, M. \& Bagshaw, C. (1999). Leadership in the twenty-first century. Industrial and Commercial Training, 31(6), 236-240.

Baldwin, R. G. (1998). Technology's impact on faculty life and work. In K. H. Gillespie (Ed.), The impact on technology on faculty development, life, and work (pp. 7-21). San Francisco: Jossey-Bass.

Bar-On, R. (1997). The emotional intelligence inventory (EQ-I). Technical Manual. Toronto: Multi-Health Systems.

Bar-On, R. (2002). BarOn Emotional Quotient Inventory Short (EQ-i: S): Technical Manual. Toronto, ON: Multi-Health Systems

Bar-On, R. (2004). The Bar-On Emotional Quotient Inventory (EQ-i): Rationale, description, and summary of psychometric properties. In G. Geher (Ed.), Measuring emotional intelligence: common ground and controversy. Hauppauge, NY: Nova Science Publishers, pp. 111- 142

Bar-On, R., Brown, J. M., Kirkcaldy, B.D, Thorn, E. P. (2000). Emotional expression and implications for occupational stress: An application of the Emotional Quotient Inventory (EQ-i). Personality and Individual Differences. 28(6),1107-1118.

Barr, R. B., \& Tagg, J. (1995). From teaching to learning: A new paradigm for undergraduate education. Change, 27(5), 12-25.

Barsade, S. G. (2002). The ripple effect: Emotional contagion and its influence on group behavior. Administrative Science Quarterly, 47(4), 644-675.

Barwick, J. T. (2002). Pathways to presidency. Community College Journal, 73(1), 6-11. Bass, B. M. (1985). Leadership and performance beyond expectations, New York: Free Press. 
Bass, B. M. (1990a). Bass \& Stogdill's handbook of leadership: Theory, research and managerial applications. New York: Free Press.

Bass, B. M. (1990b). From transformational to transactional leadership: Learning to share the vision. Organizational Dynamics, 18(3), 19-31.

Bass, B. M. (1998). Transformational leadership: Industry, military, and educational impact. Mahwah, NJ: Erlbaum.

Bass, B. M. (2002). Cognitive, social, and emotional intelligence of transformational leaders. In Riggio, R., Murphy, S., \& Pirozzolo, F. (Eds.), Multiple intelligences and leadership (pp. 105-118). Mahwah, NJ: Lawrence Erlbaum Associate Publishers.

Bass, B. M., \& Avolio, B. J. (1993). Transformational leadership: A response to critiques. In M. M. Chemers \& R. Ayman (Eds.), Leadership theory and research: Perspectives and directions: 49-80. San Diego: Academic Press

Batten, J. D. (1989). Tough minded leadership. New York: American Management Associates.

Beehler, M. C. (1992). The changing role of the community college president in washington state. Seattle University). ProQuest Dissertations and Theses, , 257-257 p. Retrieved from http://search.proquest.com/docview/304026004?accountid=2837. (304026004).

Bennis, W. (1989). On becoming a leader. London: Hutchinson

Bennis, W., \& Nanus, B., (1985). Leaders: The strategies for taking charge. New York: Harper \& Row.

Bensimon, E. M. (1987). The meaning of "good presidential leadership": A frame analysis. Paper presented at the ASHE annual meeting paper. Retrieved from ERIC database. (ED 292416) 
Bensimon, E. M. (1989). The meaning of "good presidential leadership": A frame analysis. The Review of Higher Education, 12(2), 107-123.

Birnbaum, R. (1988). How colleges work: The cybernetics of academic organization and leadership. San Francisco: Jossey-Bass.

Birnbaum, R. (1992). How academic leadership works: Understanding success and failure in the college presidency. San Francisco: Jossey-Bass.

Blanchard, K., Zigarmi, P., \& Zigarmi, D. (1985). Leadership and the one-minute manager: Increasing effectiveness through situational leadership. New York: William Morrow

Boggs, G. (2003). Leadership context for the twenty-first century. New Directions for Community Colleges, (123), 15-25.

Bolman, L. G., \& Deal, T. E. (1991). Leadership and management effectiveness: A multi-frame, multi-sector analysis. Human Resource Management, 30, 509-534.

Boone, E. J. (1992). Community-based programming: An opportunity and imperative for the community college. Community College Review, 20(3), 8-20

Bowen, W. \& Shapiro, H. (1998). Universities and their leadership. Princeton, NJ: Princeton University Press.

Boyatzis, R. E. (1994). Stimulating self-directed learning through the Managerial Assessment and Development Course. Journal of Management Education, 18(3), 304-323.

Boyatzis, R. E. \& Sala, F. (2004), Assessing emotional intelligence competencies. In Geher, G. (Ed.), The Measurement of Emotional Intelligence (pp. 147-180). Hauppauge, NY: Nova Science Publishers. 
Brackett, M. A., \& Mayer, J. D. (2003). Convergent, discriminant, and incremental validity of competing measures of emotional intelligence. Personality and Social Psychology Bulletin, 29(9), 1-12.

Brackett, M. A., Rivers, S. E., Shiffman, S., Lerner, N., \& Salovey, P. (2006). Relating emotional abilities to social functioning: A comparison of self-report and performance measures of emotional intelligence. Journal of Personality and Social Psychology, 91(4), 780-795.

Brackett, M. A., \& Salovey, P. (2006). Measuring emotional intelligence with the MayerSalovey-Caruso-Emotional intelligence Test (MSCEIT). Psicothema, 18, 33-41.

Bragg, D. D. (2001). The new vocationalism in community colleges. San Francisco: Jossey-Bass

Briody, M. E. (2005). Emotional intelligence: Personality, gender and cultural factors. Fairleigh Dickinson University). ProQuest Dissertations and Theses, , 133-133 p. Retrieved from http://search.proquest.com/docview/305396384?accountid=2837. (305396384).

Burns, J. M. (1978). Leadership. New York, NY: Harper \& Row.

Campbell, D. F. \& Peek, R. (2002). Trends reshaping colleges. Community College Journal of Research and Practice, 26(9), 695-700.

Cantu, D. A. (1997). The leadership frames of academic deans randomly selected and nominated as exceptionally effective at public colleges and universities. Arkansas State University). ProQuest Dissertations and Theses, , 170-170 p. Retrieved from http://search.proquest.com/docview/304446077?accountid=2837. (304446077).

Carroll, C. (2004). Succession planning: Developing leaders for the future of the organization. Leadership Abstracts, 17(2), 1-2.

Carnegie, F. (2010). The Carnegie foundation for the advancement of teaching. 
Retrieved from

http://classifications.carnegiefoundation.org/lookup_listings/institution.php

Cartwright, S., \& Pappas, C. (2008). Emotional intelligence, its measurement and implications for the workplace. International Journal of Management Reviews, 10(2), 149-171.

Caruso, D. R., \& Salovey, P. (2004). The emotionally intelligent manager: How to develop and use four key emotional skills of leadership. San Francisco: Jossey-Bass.

Chaudry, S. (2000). Management 21C. London: Pearson Education

Chemers, M. (1993). An integrative theory of leadership. In M. M. Chemers and R. Ayman, (Eds.), Leadership theory and research: Perspectives and directions (pp. 293-319). San Diego, CA: Academic Press

Chernis, C. (2000). Emotional Intelligence: What it is and why it Matters. Paper presented at the Annual Meeting of the Society for Industrial and Organizational Psychology, New Orleans, April 15.

Cherniss, C. \& Adler, M. (2000). Promoting emotional intelligence in organizations. Alexandria, VA: American Society for Training \& Development

Cherniss, C., \& Goleman, D. (2001). The emotionally intelligent workplace. San Francisco, CA: Jossey-Bass.

Cooper, J., \& Pagotto, L. (2003). Developing Community College Faculty as Leaders. New Directions for Community Colleges, (123), 27-37.

Cooper, R. K. \& Sawaf, A. (1997). Executive EQ: Emotional intelligence in leadership and organizations. New York, NY: Grosset/Putman. 
Crawford, A. L. (1983). Skills perceived to lead to success in higher education administration. Paper presented at the Annual Meeting of the American Educational Research Association, Montreal, Canada.

Davis, J. (2003). Learning to lead. Westport, CT: American Council on Education/Praeger.

Dill, W. R. (1980). The deanship: An unstable craft. In E. Griffiths \& D. J. McCarty (Eds.), The dilemma of the deanship (pp. 261-284). Danville, IL: Interstate Publishers

Downey, J. (2008). Hierarchy and Happiness: The Influence of Emotion on Administrative Job Satisfaction. Community College Journal of Research \& Practice, 32(8), 597-606.

Dulewicz, V., \& Higgs, M. (1998). Emotional intelligence: Can it be measured reliably and validly using competency data? Competency, 6(1),28-37.

Dulewicz, V., \& Higgs, M. (2000). Emotional intelligence: A review and evaluation study, Journal of Managerial Psychology, 15(4),341-368.

Dulewicz, V., \& Higgs, M. (2003). Leadership at the top: The need for emotional intelligence in Organizations. The International Journal Of Organizational Analysis, 11(3), 192-210.

Eddy, P., \& Van Der Linden, K. (2006). Emerging Definitions of Leadership in Higher Education. Community College Review, 34(1), 5-26.

Erwin, J. (2000). The Dean as Chief Academic Officer. New Directions for Community Colleges, 2000(109), 9-17.

Evelyn, J. (2001). Community colleges face a crisis of leadership. Chronicle of Higher Education, 36(31), A36.

Farmer, E. \& Paris, H. (2000). Opinions of community college dean's principles of continuous quality improvement. Community College Journal of Research and Practice, 24, 399408. 
Feist, G. J., \& Barron, F. (1996). Emotional intelligence and academic intelligence in career and life success. Paper presented at the Annual Convention of the American Psychological Society, San Francisco, CA.

Feyerabend, R. O. (2009). The relationship of emotional intelligence, demographic characteristics, and job satisfaction to indian call center agents' intentions to stay on the job. University of Maryland University College). ProQuest Dissertations and Theses, , 137. Retrieved from http://search.proquest.com/docview/305169306? accountid=2837. (305169306).

Fields, A. P. (2005). Discovering statistics using SPSS ( $2^{\text {nd }}$ ed.). London: Sage.

Fields, C. (2004). Troubling times for community colleges. Change, pp. 4-5.

Fleishman, E., \& Harris, E. F. (1962). Patterns of leadership behavior related to employee grievances and turnover. Personnel Psychology, 15, 43-56.

Franke, A. H. (2006). How strong is academic freedom in community colleges? Chronicle Of Higher Education, 53(10), B19-B20.

French, J. R. P., \& Raven, B. (1959). The bases of social power. In D. Cartwright (Ed.), Studies in social power (pp. 150-167). Ann Arbor, MI: Institute for Social Research.

Friedel, J. (2010). University-based community college leadership programs: Where future community college leaders are prepared. New Directions for Community Colleges, 2010 (149), 51-58.

Fulton-Calkins, P. \& Milling, C. (2005). Community college leadership: An art to be practiced: 2010 and beyond. Community College Journal of Research and Practice, 29(3), 233-250.

Gall, J. P., Gall, M. D., \& Borg, W. R. (2004). Applying educational research: A practical guide (5th ed.). White Plains, NY: Allyn-Bacon. 
Gardner, H. (1992). New horizons: Multiple intelligences, New York: Basic Books.

Gardner, H. (1999). Intelligence reframed: Multiple intelligences for the $21^{\text {st }}$ century. New York: Basic Books.

Gardner, W. E. (1992). Once a dean: Some reflections. Journal of Teacher Education, 43(5), 357-366.

Goffee, R. \& Jones, G. (2000). Why should anyone be led by you? Harvard Business Review, Sept-Oct, 63-70.

Goleman, D. (1995): Emotional Intelligence: Why it can matter more than IQ. New York, N.Y.: Bantam Books.

Goleman, D. (1998) Emotional intelligence that Lead to Success, EI 2, pp. 9-42.

Goleman, D. (2000). Leadership that gets results. Harvard Business Review, March -April, 7891.

Goleman, D. (2006a). Social Intelligence: The new science of human relationships. New York: Bantam Books.

Goleman, D. (2006b). The socially intelligent leader. Educational Leadership, 64(1), 76-81.

Goleman, D., Boyatzis, R., \& Mckee, A. (2002). Primal leadership: Realizing the power of emotional intelligence. Boston, MA: Harvard Business School Press.

Green, M. (1997). No time for heroes. Trusteeship, 5(2), 6-11.

Hackman, M., \& Johnson, C. (2000). Leadership a communication perspective. (3rd ed.). Illinois: Waveland Press, Inc.

Hagenow, N. R. (2001). Care executives: Organizational intelligence for these times. Nursing Administration Quarterly, 25(4), 30-35. 
Halpin, A. W. (1955). The leader behavior and leadership ideology of educational administrators and aircraft commanders. Harvard Educational Review, 15, 18-32.

Hartley, D. (2004). Management, leadership and the emotional order of the school. Journal of Education Policy, 19(5), 583-594.

Heck, R. H., Johnsrud, L. K., \& Rosser, V. J. (2000). Administrative Effectiveness in higher education. Research in Higher Education, 41(6), 663-684.

Hemphill, J. K. (1959). Job descriptions for executives. Harvard Business Review, 37, 55-67.

Hemphill, J. K., \& Coons, A. E. (1957). Development of the Leader Behavior Description Questionnaire. In R. M. Stodgill, \& A. E. Coons (Eds.), Leader behavior: Its description and behavior and measurement, (pp. 42-53). Columbus: Ohio State University.

Hersey, P., \& Blanchard, K. H. (1969). Life-cycle theory of leadership. Training and Development Journal, 23, 26-34.

Hersey, P., \& Blanchard, K. H. (1984). The management of organizational behavior. Englewood Cliffs, NJ: Prentice Hall.

Hersey, P., \& Blanchard, K. H. (1993). Management of organizational behavior: Utilizing human resources. Englewood Cliffs, NJ: Prentice Hall.

Hersey, P., Blanchard, K. H., \& Johnson, D. E. (1996). Management of organization behavior: Utilizing human resources (7th ed.). Upper Saddle River, NJ: Prentice Hall.

Higgs, M. (2002). Do leaders need emotional intelligence? A study of the relationship between emotional intelligence and leadership change. International Journal of Organizational Behavior, 5(6), 195-212.

Higgs, M. (2003). Developments in leadership thinking. Organizational Development and Leadership Journal, 24(5), 273-284. 
Higgs, M., \& Aitken, P. (2003). An exploration of the relationship between emotional intelligence and leadership potential. Journal of Managerial Psychology, 18(8), 814-823.

Higgs, M., \& Dulewicz, S. V. D. (1999). Making sense of emotional intelligence. Windsor: NFER-Nelson.

Higgs, M., \& Dulewicz, V. (2002). Making sense of emotional intelligence. Windsor: NFERNelson.

Higgs, M., \& Rowland, D. (2001). Developing change leadership capability the impact of a development intervention. Henley Working Paper Series, HWP 0104.

Higher Education Publications, I. (2011). The Higher Education directory. Retrieved from http://www.hepinc.com/index.php

Hollander, E. P. (1995). Ethical challenges in the leader-follower relationship. Business Ethics Quarterly, 5(1), 55-65.

Howell, J. P., \& Costley. D. L. (2001). Understanding behaviors for effective leadership. Saddle River, NJ: Prentice-Hall.

Hurtado, S., \& Dey, E. L. (1997). Achieving the goals of multiculturalism and diversity. In M. Peterson, D. D. Dill, L. Mets, \& Associates (Eds.), Planning and management for a changing environment (pp. 405-431). San Francisco: Jossey-Bass.

Jeandron, C., \& American Association of Community Colleges, W. (2006). Growing your own leaders: Community colleges step up. A Leading Forward Report. American Association of Community Colleges.

Jerome, K. L. (2009). An examination of the relationship between emotional intelligence and the leadership styles of early childhood professionals. The University of Oklahoma). ProQuest 
Dissertations and Theses, , 117. Retrieved from

http://search.proquest.com/docview/304975128?accountid=2837. (304975128).

Johnson, C. (2005). Meeting the ethical challenges of leadership. Thousand Oaks, CA: Sage

Johnstone, D. B. (1999). The challenge of planning in public. Planning for Higher Education, 28(2), 57-64.

Judge, T. A., \& Piccolo, R. F. (2004). Transformational and transactional leadership: A metaanalytic test of their relative validity. Journal of Applied Psychology, 89(5), 755-768.

Kamm-Larew, D., Stanford, J., Greene, R., Heacox, C., \& Hodge, W. (2008). Leadership style in the deaf community: An exploratory case study of a university president. American Annals of the Deaf, 153(4), 357-367.

Keeter, S., Kennedy, C., Dimock, M., Best, J., \& Craighill, P. (2006). Gauging the impact of growing non-response on estimates from a national RDD telephone survey.

Public Opinion Quarterly, 70(5), 759-779

Keim, M. C., \& Murray, J. P. (2008). Chief academic officers' demographics and educational backgrounds. Community College Review 36(2), 116-132.

Kelley, R. E. (1998). In praise of followers. In W. Rosenbach \& R. L. Taylor (Eds.), Contemporary issues in leadership (4th ed.) (pp. 96-106). Boulder, CO: Westview.

Kets de Vries, M. F. R. (1994). The leadership mystique. Academy of Management Executive, 8(3), 73-5.

Kent, T.W. (2006). Leadership and emotions in health care organizations, Journal of Health Organization and Management, 20(1) 49 - 66

Kouzes, J. M., \& Posner, B. Z. (1995). The leadership challenge: How to get extraordinary things done in organizations. San Francisco: Jossey-Bass. 
Kuhnert, K. W., \& Lewis, P. (1987). Transactional and transformational leadership: A constructive/developmental analysis. Academy of Management Review, 12(4), 648-657.

Land, P. (2003). From the other side of the academy to academic leadership roles: Crossing the great divide. New Directions for Higher Education, (124), 13-20.

Leslie, J. G., \& Van Velsor, E. (1996). A look at derailment today: North America and Europe. Greensboro, NC: Center for Creative Leadership.

Leubsdorf, B. (2006). Boomers' retirement may create talent squeeze. Chronicle of Higher Education, 53(2), 51.

Levinson, H. (1996). The leader as analyzer. Harvard Business Review, January/February, pp. $63-70$.

Lewin, K. (1935). A dynamic theory of personality. New York: McGraw-Hill.

Lusch, R. F., \& Serpkenci, R. R. (1990). Personal differences, job tension, job outcomes, and store performance: A study of retail managers. Journal of Marketing, 54(1), 85-101.

Mandell, B., \& Pherwani, S. (2003). Relationship between emotional intelligence and transformational leadership style: A gender comparison. Journal of Business and Psychology, 17(3), 387-404

Martin, J., Samels, J. E., \& Associates. (Eds.), (1997). First among equals: The role of the chief academic officer. Baltimore, MD: Johns Hopkins University Press.

Maulding, W. S. (2002). Emotional intelligence and successful leadership. Paper presented at the Annual Meeting of Southern Regional Council on Educational Administration, Kansas City. Retrieved from www.csa.com

Mayer, J. D., Caruso, D. R., \& Salovey, P. (1999). Emotional intelligence meets traditional standards for an intelligence. Intelligence, 27(4), 267-298. 
Mayer, J. D., \& Geher, G. (1996). Emotional intelligence and identification of emotion. Intelligence, 22, 89-113.

Mayer, J. D., \& Salovey, P. (1993). The intelligence of emotional intelligence. Intelligence, 17, $443-450$.

Mayer, J. D., \& Salovey, P. (1997). What is emotional intelligence? In P. Salovey, \& D. J. Sluyter (Eds.), Emotional development and emotional intelligence: Educational implications (pp. 3-34). New York: Basic.

Mayer, J. D., Salovey, P., \& Caruso, D. (1998). Competing models of emotional intelligence. In R. J. Sternberg (Ed.), Handbook of human intelligence (pp. 396 -420). Cambridge: Cambridge University Press.

Mayer, J. D., Salovey, P., \& Caruso, D. R. (2000). Emotional intelligence as zeitgeist, as personality, and as a mental ability. In R. Bar-On \& J. D. A. Parker (Eds). The handbook of emotional intelligence (pp. 92-117). San Francisco: Jossey -Bass

Mayer, J. D., Salovey, P., and Caruso, D. R. (2002) Mayer-Salovey-Caruso emotional intelligence test (msceit) user manual MHS, Toronto, Canada.

Mayer, J. D., Salovey, P., \& Caruso, D. R. (2004). Emotional intelligence: Theory, findings, and implications, Psychological Inquiry, 15, 197-215.

Mayer, J. D., Salovey, P., Caruso, D. R., \& Sitarenios, G. (2003). Measuring emotional intelligence with the MSCEIT V2.0. Emotion, 3(1), 97-105.

McClelland, D. (1975). Power: The inner experience. New York: Irvington.

McNair, D. (2010). Preparing community college leaders: The AACC core competencies for effective leadership \& doctoral education. Community College Journal of Research and Practice, 34(1-2), 199-217. 
Mills, R. (2006). Leadership in higher education and the second half of life. Education, 127(2), 294-302.

Milhoan, P. L. (2007). Emotional intelligence competencies of department chairs in the west virginia state community college system and their faculty members' perceptions of organizational climate. West Virginia University). ProQuest Dissertations and Theses, , 140. Retrieved from http://search.proquest.com/docview/304804139?accountid=2837. (304804139).

Min, J. C. H. (2010). Tour guides' emotional intelligence in relation to demographic characteristics. African Journal of Business Management. 4(15), 3730-3737

Montez, J. M., Wolverton, M., \& Gmelch, W. H. (2002). The roles and challenges of deans. The Review of Higher Education, 26(2), 241-266. Retrieved from http://muse.jhu.edu/journals/review_of_higher_education/v026/26.2montez.pdf

Moore, K. M., Salimbene,A. M., Marlier, J. D., \& Bragg S. M. (1983). The structure of presidents' and deans' careers. The Journal of Higher Education. 54(5), 500-515 .

Moore, K. M. (1983). The top line: A report on presidents', provosts', and deans' careers. Leaders in transition; A national study of higher education administrators (Report No. CSHE-83-711). University Park, PA: Pennsylvania State University

Morrison, A. M., White, R. P., \& Van Velsor, E. (1992). Breaking the glass ceiling: Can women reach the top of America's largest corporations? MA: Addison-Wesley

Munitz, B. (1995). Wanted: New leadership for higher education. Planning for higher Education, 24(1), 9-15.

Murphy, C. (2003). The rewards of academic leadership. New Directions for Higher Education, (124), 87-93. 
Murray, J. P., Murray, J. I., \& Summar, C. (2000). The propensity of community college chief academic officers to leave an institution. Community College Review, 28(3), 22-36.

Myran, G., Myran, S., \& Galant, R. (2004). The spiritual dimension of leadership: How leaders ignite the spirit of the community college. Community College Journal, 74(4), 10-13.

Noble, J. E. (2006). The dean in california community colleges: The expectation of emotional intelligence. Capella University). ProQuest Dissertations and Theses, , 150-150 p. Retrieved from http://search.proquest.com/docview/304909562? accountid=2837. (304909562).

Northouse, P. G. (2004) Leadership: Theory and practice. London, UK: Sage Publications.

O'Banion, T. (2006). Crisis and calamity in the community college. Community College Journal, 77(3), 44-47.

Palmer, B. R., Monacha, R., Gignac, G., \& Stough, C. (2003). Examining the factor structure of the Bar-On Emotional Quotient Inventory with an Australian general population sample. Personality and Individual Differences, 35(5), 1191-1211.

Perrakis, A., Campbell, D., \& Antonaros, M. (2009). Diversifying the community college CEO pipeline. Community College Enterprise, 15(1), 7-19.

Petrides, K. V., \& Furnham, A. (2001). Traits emotional intelligence: Psychometric investigation with reference to established trait taxonomies. European Journal of Personality, 15, 425448.

Petrides, K. V., \& Furnham, A. (2000). On the dimensional structure of emotional intelligence. Personality and Individual Differences, 29(2), 313-320.

Piland, W. E., \& Wolf, D. B. (2003). In-House Leadership Development: Placing the Colleges Squarely in the Middle. New Directions For Community Colleges, (123), 93-99. 
Pilling, B. K., \& Eroglu, S. (1994). An empirical examination of the impact of salesperson empathy and professionalism and merchandise salability on retail buyer's evaluations. Journal of Personal Selling and Sales Management, 14(1), 55-58.

Rahim, M. S. (2010). An optimal score fusion strategy for a multimodal biometric authentication system for mobile device. University of Windsor (Canada)). ProQuest Dissertations and Theses, , 88. Retrieved from http://search.proquest.com/docview/869642983?accountid=2837. (869642983).

Reddin, W. J. (1967). The 3-D Management Style Theory. Training \& Development Journal, 21(4), 8-17.

Reille, A., \& Kezar, A. (2010). Balancing the pros and cons of community college "Grow-YourOwn" leadership programs. Community College Review, 38(1), 59-81

Rilling, C., \& Jordan, D. (2007). Important co-leader skills and traits on extended outdoor trips as perceived by leaders. Leisure Studies, 26(2), 193-212.

Robillard Jr., D. (2000). Toward a definition of deaning. New Directions for Community Colleges, 2000(109), 3.

Robison, G., Sugar, W., \& Miller, B. (2010). Fostering community college leaders: An examination of leadership development programs. Community College Journal of Research and Practice, 34(8), 605-623.

Romero, M. (2004). Who will lead our community colleges? Change, 36(6), 30-34.

Rosenthal, R. (1977). The PONS test: Measuring sensitivity to nonverbal cues. In P. McReynolds (Ed.), Advances in psychological assessment .San Francisco, CA: Jossey-Bass. 
Rosser, V. J., Johnsrud, L. K., \& Heck, R. H. (2003). Academic deans and directors: Assessing their effectiveness from individual and institutional perspective. Journal Of Higher Education, 74(1), 1-25.

Rost, J. C. (1991). Leadership for the twenty-first century. New York: Praeger.

Rost, J. C. (1993). Leadership development in the new millennium. The Journal of Leadership Studies, 91-110.

Russell, C. A. (2000). Community college academic deans: Leadership frames and stress. Iowa State University). ProQuest Dissertations and Theses, , 201-201 p. Retrieved from http://search.proquest.com/docview/304628364?accountid=2837. (304628364).

Rutherford, S. (2001). Any Difference? An Analysis of Gender and Divisional Management Styles in a Large Airline. Gender, Work \& Organization, 8(3), 326.

Salovey, P., Bedell, B., Detweiler, J. B., \& Mayer, J. D. (1999). Coping intelligently: Emotional intelligence and the coping process. In C. R. Snyder (Ed.), Coping: The psychology of what works (pp. 141-164). New York: Oxford University press.

Salovey, P., Mayer, J. D. (1990). Emotional intelligence. Imagination, Cognition and Personality, 9(3), 185-211.

Salovey, P., Mayer, J. D., Goldman, S. L., Turvey, C., \& Palfai, T. P. (1995). Emotional attention, clarity, and repair: Exploring emotional intelligence using the Trait Meta-Mood Scale. In J. W. Pennebaker (Ed.), Emotion, disclosure, and health (pp. 125-154). Washington, D.C.: American Psychological Association.

Schneider, B., \& Goldstein, H. W. (1985). The ASA-framework: An update. Personal Psychology, 48, 748-769. 
Schults, C. (2001). The critical impact of impending retirements of community college leadership. Washington D.C.: American Association of Community Colleges.

Sharpe, R. (2000, November 20). As leaders, women rule. Business Week, pp. 74-84.

Shoda, Y., Mischel, W., \& Peake, P. K. (1990). Predicting adolescent cognitive and selfregulatory competencies from preschool delay of gratification: Identifying diagnostic conditions. Developmental Psychology, 26(6), 978-986.

Shults, M. (2001). Professional development for presidents: A study of community college and technical college presidents in three states. Community College Review, 4, 35-42.

Simms, J. (2002). Is Britain being led astray?. Director , 55(6), 48.

Singh, A., \& Purohit, B. (2010). Leadership for Higher Education -- Role of a Dean. Academic Leadership (15337812), 8(4), 1.

Snarey, J. R., \& Vaillant, G. E. (1985). How lower- and working-class youth become middleclass adults: The association between ego defense mechanisms and upward social mobility. Child Development, 56(4), 899-910.

Snuggs, K. L. (2006). Leadership that inspires dedication: The relationship between the emotional intelligence of community college presidents and faculty and staff retention. East Carolina University). ProQuest Dissertations and Theses, , 206-206 p. Retrieved from http://search.proquest.com/docview/304937082?accountid=2837. (304937082).

Sternberg, R. J. (1997). Managerial intelligence: Why IQ isn't enough. Journal of Management, 23(3), 475-494.

Stogdill, R. M. (1948). Personal factors associated with leadership: A survey of the literature. Journal of Psychology, 25, 35-71. 
Stogdill, R. M. (1974). Handbook of leadership: A survey of theory and research. New York: Free Press.

Strathe, M., \& Wilson, V. (2006). Academic leadership: The pathway to and from. New Directions for Higher Education, (134), 5-13.

Sullivan, P. (2006). Diversity, leadership, and community college: A case study. Community College Journal of Research and Practice, 30(5), 383-400.

Suzuki, L. A., \& Valencia, R. R. (1997). Race-ethnicity and measured intelligence. American Psychologist , 52(10), 1103-114. doi:10.1037/0003-066X.52.10.1103

Sypawka, W. (2008). A study of division deans' in the north carolina community college system self perceived leadership style based on bolman and deal's four frame theory. East Carolina University). ProQuest Dissertations and Theses, , 116. Retrieved from http://search.proquest.com/docview/304380763?accountid=2837. (304380763).

Sypawka, W., Mallett, W., \& McFadden, C. (2010). Leadership Styles of Community College Academic Deans. Community College Enterprise, 16(1), 63-73.

Tichy, N. M., \& DeVanna, M. (1986). The Transformational Leader. Training \& Development Journal, 40(7), 26. Retrieved from EBSCOhost.

Thomas, R. M. (2007). The emotional intelligence of chief development officers in public higher education institutions of the mid atlantic region and organizational climate perceptions of their development teams. West Virginia University). ProQuest Dissertations and Theses, , 117. Retrieved from http://search.proquest.com/docview/304813002?accountid=2837. (304813002).

Ullman, E. (2010). Learning for today's leader: The changing state of community college training programs. Community College Journal, 80(6), 20-22. 
Van der Zee, K. I., Thijs, M., \& Schakel, L. (2002). The relationship of emotional intelligence with academic intelligence and the big five. European Journal of Personality, 16, 103125.

Van der Zee, K., \& Wabeke, R. (2004). Is trait emotional intelligence simply or more than just a trait? European Journal of Personality, 18, 243-263.

Vaughan, G. B. (1995). The community college story: A tale of American Innovation. Washington, DC: American Association of Community Colleges.

Vesterinen, S., Isola, A., \& Paasivaara, L. (2009). Leadership styles of Finnish nurse managers and factors influencing it. Journal of Nursing Management, 17(4), 503-509.

Walker, K. L., \& ERIC Clearinghouse for Community Colleges, L. A. (2000). Facing challenges: Identifying the role of the community college dean. ERIC Digest.

Warner, R. M. (2008). Applied statistics: From bivariate through multivariate techniques. Thousand Oaks, CA: Sage Publications.

Watts, G., \& Hammons, J. (2002). Leadership Development for the Next Generation. New Directions for Community Colleges, 2002(120), 59-66.

Wechsler, D. (1940). Nonintellective factors in general intelligence. Psychological Bulletin, 37, 444-445.

Wechsler, D. (1958). The measurement and appraisal of adult intelligence (4th ed.). Baltimore, MD: The Williams \& Wilkins Company.

Weinberger, L. A. (2004, March). An examination of the relationship between emotional intelligence and leadership style. Paper presented at the Academy of Human Resource Development International Conference (AHRD) Austin, TX.

Weisinger, H. (1998). Emotional intelligence at work. San Francisco, CA: Jossey-Bass 
Publishers.

Weissberg, R. (2007). Oh to be rid of administrative wimps! Academic Questions, 20(2), 146149.

Weisman, I. M., \& Vaughan, G. B. (2002). The community college presidency 2001 (Research Brief Leadership Series No. 2, AACC-RB-02-1). Washington, D.C.: American Association of Community Colleges.

Weisman, I. M., \& Vaughan, G. B. (2007). The community college presidency: 2006 (Research Brief Leadership Series). Washington, D.C.: American Association of Community Colleges.

Wenrich, J., \& Reid, B. (2003). It's not the race I signed up for, but it's the race I'm in: The role of community college presidents. New Directions for Community Colleges, 2003(124), $27-32$.

Whitsett, G. (2007). Perceptions of leadership styles of department Chairs. College Student Journal, 41(2), 274-286.

Wolverton, M., Montez, J., Guillory, R., \& Gmelch, W. H. (2001). Deans, affective commitment and optimizing the work environment so they stay. Retrieved October 8, 2012, from http://www.eriche.org/ASHEpapers/Search/Wolverton et $\%$ al.affective

Wong, C. S., Law, K. S., \& Wong, P. M. (2004). Development and validation of a forced choice emotional intelligence for Chinese respondents in Hong Kong. Asia Pacific Journal of Management, 21(4), 535-559.

Yoder, D. M. (2003). Organizational climate and emotional intelligence: An appreciative inquiry into a "leaderful" community college. The University of Texas at Austin). 
ProQuest Dissertations and Theses, , 99-99 p. Retrieved from http://search.proquest.com/docview/305295122? accountid=2837. (305295122).

Yukl, G. A. (1981). Leadership in organizations. Englewood Cliffs, NJ: Prentice-Hall Inc.

Yukl, G. A. (1999). An evaluation of conceptual weakness in transformational and charismatic leadership theories. Leadership Quarterly, 10, 285-305 
Appendices A, B, C, D, E, F, G, H, I 


\section{Appendix A: Mayer-Salovey-Caruso Emotional Intelligence Test (MSCEIT) - Request to}

\section{use instrument}

From: Irene Maundu [mailto:Irene.Maundu@mail.wvu.edu]

Sent: Friday, March 04, 2011 2:31 PM

To: Tyrone Williams

Cc: \#R\&D

Subject: Permission to Use Mayer-Salovey-Caruso Emotional Intelligence Test (MSCEIT)

To Whom it may Concern:

Dear Sir/Madam,

RE: Permission to use MSCEIT Instrument

My name is Irene Maundu and I am a student at West Virginia University. I am currently pursuing a doctorate in Educational Leadership Studies. My Dissertation topic is : What is the relationship between the Leadership styles and the Emotional and Social intelligence of community college deans?

I am at the proposal phase of dissertation and intend to use the MSCEIT instrument (online) to measure the emotional intelligence of community college deans.

Please advise me on the cost of the questionnaire, accessibility, and conditions that regard its use. Any assistance will be highly appreciated.

Thank you.

Irene K. Maundu

Ed. D Leadership Studies

West Virginia University 


\section{Appendix B: Mayer-Salovey-Caruso Emotional Intelligence Test (MSCEIT) - Permission}

\section{to use instrument}

Hello Irene K. Maundu,

Congratulations! You have been approved for a Student Research Discount on the MSCEIT for your study entitled 'Nature of the Emotional Intelligence of Community College Deans' under the supervision of Adriane Williams.

This discount grants you 30\% off of related product orders over $\$ 50$ (before shipping) as well as access to scored datasets for a fee of \$6 (\$7 CAN) per administration online.

Conditions

1) Your discount expires one year from today. If you require a discount beyond the expiry date please re-apply at that point.

2) Please bear in mind that scored datasets are to be used for the collection of data only and cannot be used to provide feedback to respondents. If you are intending to provide feedback please ensure that you order one of our available reports. Your 30\% discount will apply to the report cost.

3) It is mandatory that you are in possession of the Users/Technical Manual while making use of this assessment. Please ensure that you order a copy if you do not already have one.

4) You will have to purchase scoring before online setup is complete, please call 1.800.456.3003 to make your initial purchase.

5) Your research is important to us, as agreed upon in your application please remember to send a report of your results to: researchsummaries@mhs.com following the completion of your study.

4. Read the Terms and Conditions of Use and click I accept if you agree.

5. Change your password as instructed.

Once again, welcome to MHS Scoring Organizer. Please don't hesitate to contact us with any questions, comments, or suggestions. 
Appendix C: MAYER-SALOVEY-CARUSO EMOTIONAL INTELLIGENCE

(MSCEIT) ASSESSMENT - ONLINE VERSION

The following assessment questions are examples from the MSCEIT assessment s. More information on the MSCEIT can be found at www.mhs.com. 


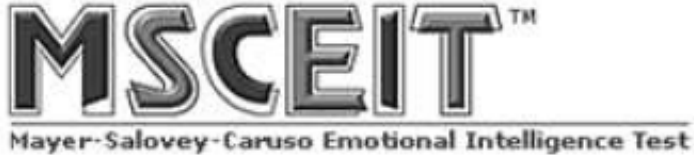

TERMS AND CONDITIONS OF USE. PERMITTED ACCESS

You have been authorized and provided a password and ID number to enter this website for the purpose of completing the MSCEIT instrument (the "Instrument"). You understand that participation in completing the Instrument is entirely voluntary and if you wish to withdraw from completing the Instrument, you may do so at any time without explanation.

The information requested of you on this website will be provided to the Administrator by MHS for the purposes of scoring, analyzing, and interpreting the Instrument's results. You acknowledge that MHS has no control or influence over the Administrator's use of the Instrument's results or your information (including a ny personal information such as your name, age, responses to items, scores, and other similar data) or the reports generated after you complete the Instrument.

INFORMATION PRIVACY

MHS is committed to protecting the privacy and security of the information transmitted on this website and it employs technology that secures the information and prevents unauthorized access, use, or disclosure. MHS employs an adva nced security system, Secure Socket Layers (SSL) encryption technology to protect the transmission of information on this website.

You acknowledge that the internet is not an absolutely secure medium, and the privacy of your information, communications, and visits to this website cannot be guaranteed.

MHS reserves the right to store de-personalized and aggregated data in its database indefinitely for research and statistical pur poses by MHS, its affiliates, subsidiaries, licensees, successors, assigns, suppliers, and a dvertisers.

YOUR RESPONSIBLITIES

You agree not to provide the passw ord given to you by the Administrator to any other pers on for any reason whatsoever. You agree that you are responsible for providing accurate and complete information when completing the Instrument. You agree to use and access the website in a manner that will not disrupt, corrupt, or otherwise damage the website. Accordingly, this website shall not be used in a manner that is prohibited by law. Use of this website is subject to your compliance with all applicable laws and regulations in your location.

If you are the parent or guardian of a child under the age of majority in your particular State or Province who is required by an Administrator to complete the Instrument, you hereby provide consent for your child to participate in the administration process.

NO WARRANTY ON CONTENTS, INFORMATION, OR MATERIALS

The information included in this website does not constitute, and shall not be considered, the advice, recommendation, ass essment, or endorsement of MHS. MHS shall not be liable for any claims based on the use of the Instrument. The Instrument and other contents of this website are provided on an "As Is" basis only. Tothe extent permitted by law, any statutory or implied warranty of merchantability or fitness for a particular purpose are completely denied and disclaimed.

MHS COPYRIGHT, LOGOS, AND TRADEMARKS

MHS is the copyright owner of this website and all of the contents of this website. These rights are protected by Canadian intellectual property right laws, international treaty provisions, and other applicable national laws. No portion of this we bsite, including the Instrument's information, text, images, audio, orvideo, may be copied, modified, or used in any manner without MHS' prior written permission. Any name, logo, trademark, or service mark contained and accessed by this website is owned or licensed by MHS and may not be used in any manner without MHS' prior written permission. Unauthorized use of all or part of this website or the Instrument is strictly prohibited and may result in the violation of MHS' trademarks, privacy, copyrights, and publicity rights. GOVERNING LAW

This agreement shall be governed by the laws of the Province of Ontario.

By clicking "I Accept" below, you are indicating that you understand and agree to the Terms and Conditions of Use of this website.

If you agree to the terms and conditions, click "I Accept" to continue

I Accept

I Decline

Copyright (s) 2002 Multi-Health Systems Inc. All rights reserved, 


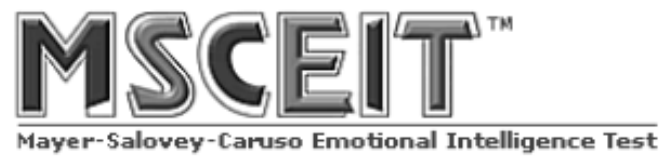

\section{Welcome to MSCEIT}

MSCEIT contains eight different sections. Each section has its own instructions. Try to answer every question. If you are unsure of the answer, make your best guess.

What is MSCEIT? Mayer-Salovey-Caruso Emotional Intelligence Test (MSCEIT) uses an ability approach to Emotional Intelligence that defines emotional intelligence as the ability to understand your own and others ${ }^{\circ}$ emotions and to use emotions to think more effectively. MSCEIT measures four separate components of emotional intelligence: accurately identifying emotions in people and objects, being able to generate an emotion and solve problems with that emotion, understanding the causes of emotions, and selecting strategies that result in positive outcomes.

You may find some of the questions on this test to be different from questions on other tests you have taken. Some parts of the test may not appear to be directly relevant to the work that you do. Some of the items will seem strange or unusual. The subtle skills measured by MSCEIT are best measured indirectly. The components of MSCEIT were chosen because they provide a stable measure of these emotional abilities. 


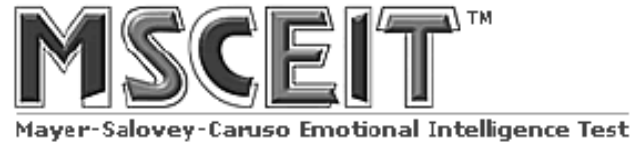

\section{Important!}

Please ensure you have set aside 30-45 minutes to complete MSCEIT Online. If you exit the test, all your data will be lost. You must complete the test in one sitting.

To take the test you must know how to:

\section{Scroll}

There may be more information in a window than is displayed on your screen. The scroll bar allows you to move the page up and down so that you can see all of the content. Try scrolling this page up and down by clicking and dragging the grey scroll bar on the right of this page.

\section{Click in the bubbles}

You will make your selections by clicking in bubbles that look like this $\odot$. To answer a question, click the center of the bubble once. A black dot appears in the bubble you clicked. Give it a try:

\begin{tabular}{|l|l|l|l|l|l|l|}
\hline No happiness & 1 & $\mathbf{2}$ & $\mathbf{3}_{3}$ & $\mathbf{O}_{\mathbf{4}}$ & $\mathbf{0}$ & $\begin{array}{l}\text { Extreme } \\
\text { happiness }\end{array}$ \\
\hline
\end{tabular}

Once you are comfortable scrolling and clicking, click Start MSCEIT below. Remember that if you exit MSCEIT without completing the test or by closing your browser, all your data will be lost and you will have to start the test again.

\section{Start MSCEIT}

Copyright @ 2002 Multi-Health Systems Inc. All rights reserved. 
Mayer-Salovey-Caruso Emotional Intelligence Test

INSTRUCTIONS: Select the best alternative for each of these questions.

1. Marjorie felt more and more ashamed, and began to feel worthless. She then felt

\begin{tabular}{|c|l|}
\hline 1 & a. overwhelmed \\
\hline 2 & b. depressed \\
\hline 3 & c. ashamed \\
\hline 4 & d. self-conscious \\
\hline 5 & e. jittery \\
\hline
\end{tabular}

2. Kenji felt content as he thought of his life, and the more he thought about the good things he had done and the joy his acts had brought to others, the more he felt

\begin{tabular}{|c|l|}
\hline 1 & a. surprised \\
\hline 2 & b. depressed \\
\hline 3 & c. acceptance \\
\hline 4 & d. happiness \\
\hline 5 & e. amazement \\
\hline
\end{tabular}

\section{$<<$ Previous Item}

Next Item $>>$ 


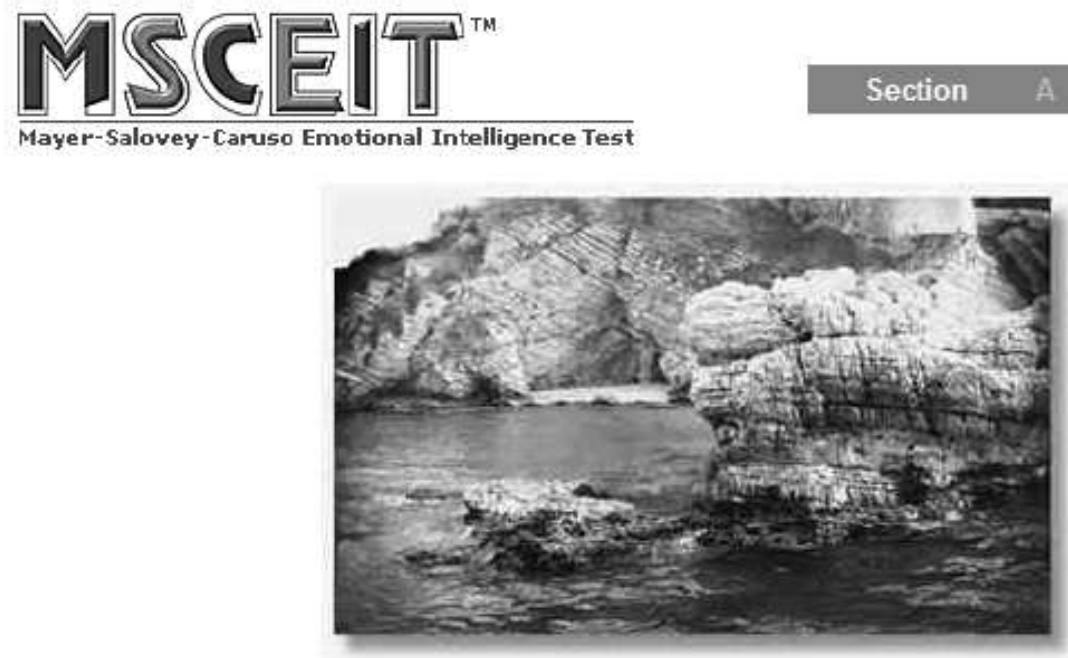

INSTRUCIIONS: How much is each feeling below expressed by this picture? (Please select a response for each item.)

1.

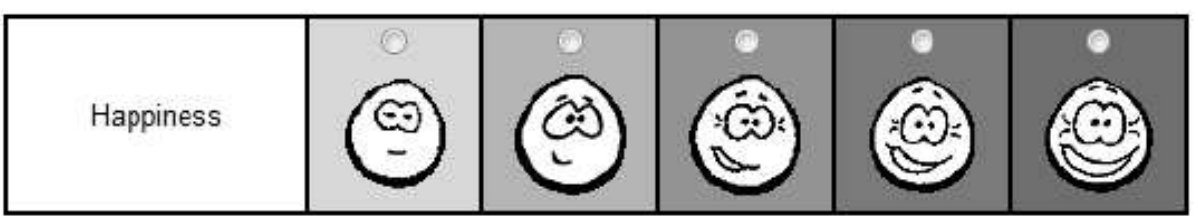

2

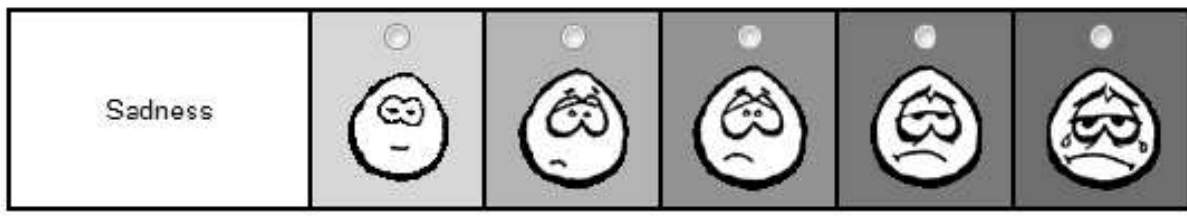

\section{$<<$ Previous Item Next Item $\gg>$}

Copyright $@ 2002$ Multi-Health Systems Inc. All rights reserved: 


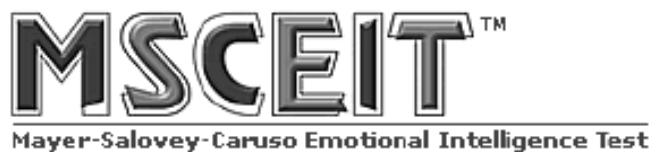

INSTRUCTIONS: For each item below, you are asked to imagine feeling a certain way. Answer as best as you can, even if you are unable to imagine the feeling

1. Imagine feeling guilty that you forgot to visit a close friend who has a serious illness. In the middle of the day, you realize you completely forgot to visit your friend at the hospital. How much is the feeling of guilt like each of the following?

\begin{tabular}{|c|c|c|c|c|c|c|c|c|c|}
\hline \multirow[b]{2}{*}{ a. cold } & \multicolumn{2}{|c|}{ Not Alike } & & & & & & & $\begin{array}{l}\text { Very } \\
\text { Much } \\
\text { Alike }\end{array}$ \\
\hline & ○ & 1 & 0 & 2 & 0 & 3 & 0 & 4 & 05 \\
\hline b. blue & 0 & 1 & 0 & 2 & 0 & 3 & 0 & 4 & - 5 \\
\hline c. sweet & 0 & 1 & 0 & 2 & 0 & 3 & 0 & 4 & . 5 \\
\hline
\end{tabular}

2. Imagine feeling content on a wonderful day, with terrific news about your job and family. How much is the feeling of contentment like each of the following sensations?
a. warm
b. purple
1
2
3
4
5
c. salty
1
(1) 2
( 3
405
1
( 2
( 3
- 4 ○ 5

\section{$<<$ Previous Item}

Next Item $>>$ 


\section{Appendix D: Dean's Cover Letter}

Subject: Emotional Intelligence and Deans Research Study

May 2012

Dear Community College Dean:

I am a graduate student in the Higher Education and Leadership Studies Doctoral program at West Virginia University. I am writing to solicit your participation in a dissertation research study the emotional intelligence of community college deans.

In fulfillment of the requirements of my doctoral degree, I am conducting a study on the nature of the emotional intelligence of community college deans and selected demographics, under the direction of my dissertation committee chair, Dr. Adriane Williams. The findings from this research will be essential in understanding the role of emotional intelligence in leadership. The results of the study may also be useful for training programs.

Enclosed is the MSCEIT questionnaire link for emotional intelligence. The questionnaire will take approximately 45 minutes to complete.

Your questionnaires will be identified by a code for follow up purposes only. Your results will be submitted electronically to me once you complete the questionnaires. The survey results will only be reported as aggregate data, and names of participants and institutions will remain anonymous in the final research report. You must be 18 years of age or older to participate. Participation is completely voluntary. You may skip any question that you do not wish to answer and you may discontinue at any time. West Virginia University's Institutional Review Board acknowledgement of this project is on file.

Survey completion is voluntary, although your participation will enhance the quality of the study. If you have any questions or comments, please contact me through email at Irene.maundu@mail.wvu.edu , or by telephone at 515-729-7408.

Please respond to the questionnaires by $1^{\text {st }}$ Sept, 2011.

Thank you in advance for your time and consideration.

Sincerely,

Irene Maundu

Doctoral Candidate

Educational Leadership

West Virginia University

Dr. Adrian Williams

Assistant Professor

C\& I/Social \& Cultural foundations

West Virginia University 


\section{Appendix E: Dean's Reminder}

From:

To:

Date:

Subject: Emotional Intelligence and Leadership Styles Research Study

May, 2012

Dear Community College Dean:

This is a courtesy reminder of the MSCEIT questionnaire that was send to you about two weeks ago. If you have already responded to the electronic survey, thank you. If you haven't had time to complete, I will appreciate your feedback, which is very important to the completion of this study.

If you have any questions regarding the study, please contact me through email at Irene.maundu@mail.wvu.edu , or by telephone at 515-729-7408. You can also contact my dissertation chair, Dr. Adrian Williams at, Adriane.Williams@mail.wvu.edu Thank you in advance for your time and consideration.

Sincerely, Irene Maundu Doctoral Candidate Educational Leadership West Virginia University 


\section{Appendix F: Demographic follow up Questions}

\section{Demographics}

1. What is the size of your institution?

$\Gamma$ Small

$\ulcorner$ Medium

$\Gamma$ Large

2. Number of years as a Dean

$\ulcorner 0-4$

$\ulcorner\quad 5-10$

$\ulcorner$ 10plus

3. Check one that represents your level of education

$\Gamma$ Bachelor's degree

$\ulcorner$ Master's degree

$\ulcorner$ Doctoral degree 


\section{Appendix G: Approval to use Table 4.1 from the MSCEIT Manual}

Hello Irene,

Thank you for sending back the Permissions application.

MHS is pleased to grant you permission reproduce Table 4.1- Guidelines for Interpreting MSCEIT Scores from the MSCEIT Manual for your dissertation research.

I hope that this e-mail is sufficient for you to proceed.

Thank you,

Betty 
Appendix H: Permission to use Table 4.1 from the MSCEIT Manual - Request to use

table

From: Irene Maundu [mailto:Irene.Maundu@mail.wvu.edu]

Sent: Friday, January 18, 2013 2:30 PM

To: Holly Hatfield

Cc: Beverly Pascua

Subject: Permission to use table for interpreting MSCEIT Scores

To Whom it may Concern:

Dear Sir/Madam,

\section{RE: Permission to use Table 4.1 from the MSCEIT Manual}

My name is Irene Maundu and I am a doctoral candidate at West Virginia University. I already purchased the MSCEIT instrument for my dissertation study and i am in the process of writing and presenting my findings.

My customer number is $\mathbf{1 8 0 6 0 9 .}$

I kindly request your permission to use table 4.1 on Guidelines for Interpreting MSCEIT Scores (page 18 of the user's manual).

Your response will be highly appreciated.

Thank you.

Irene K. Maundu, Doctoral candidate

Ed. D Leadership Studies

West Virginia University 


\section{Appendix I: Scatter Plots}

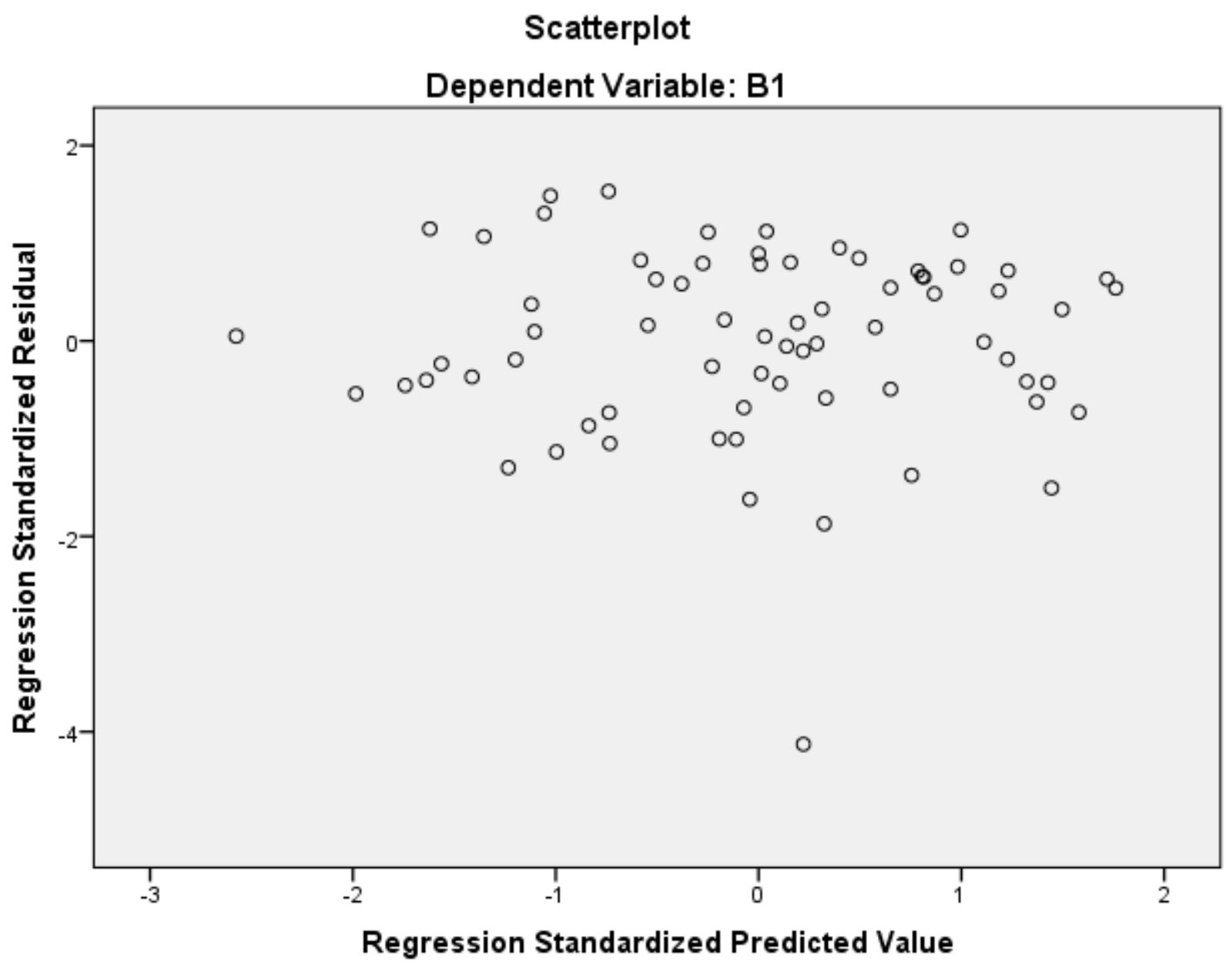




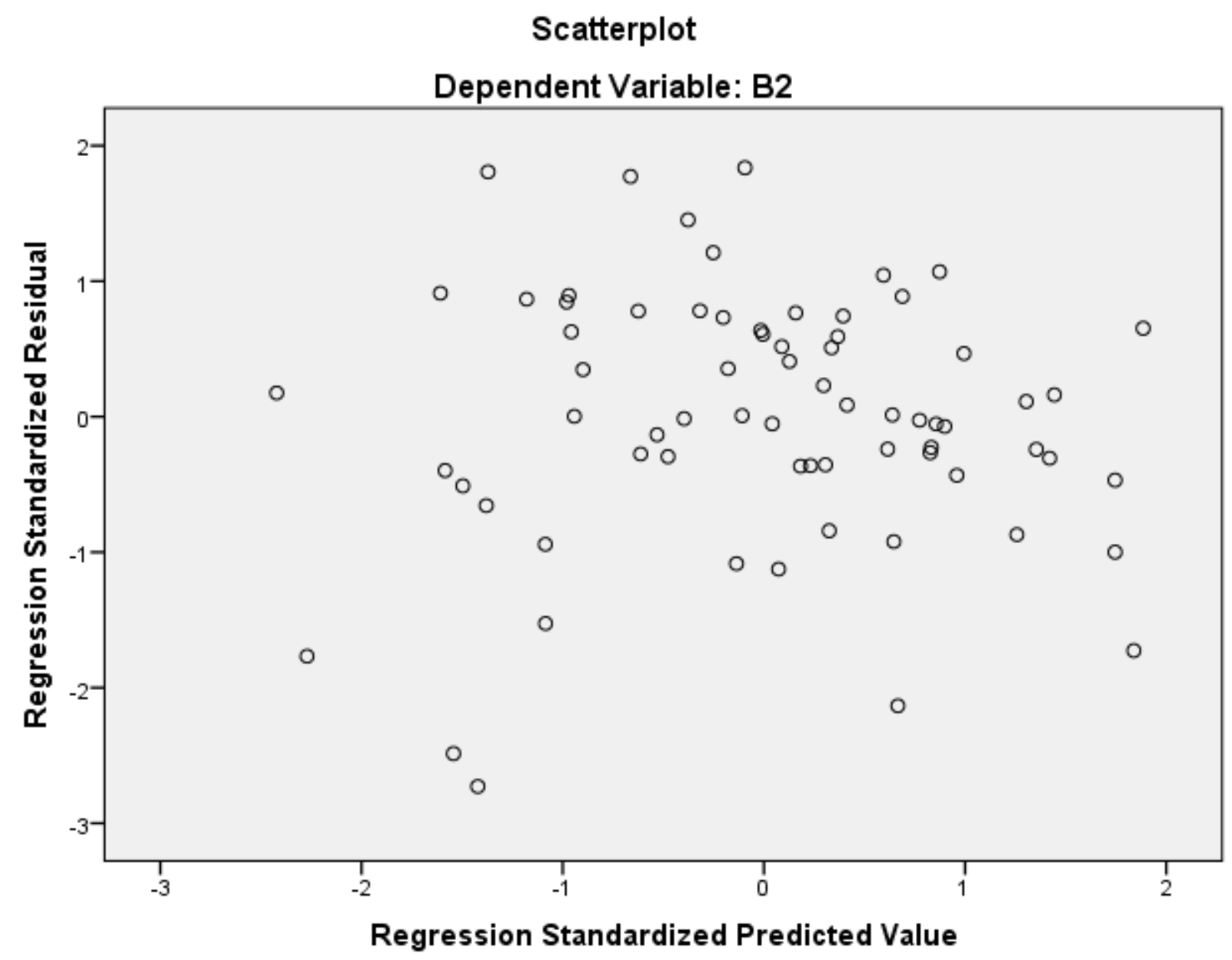




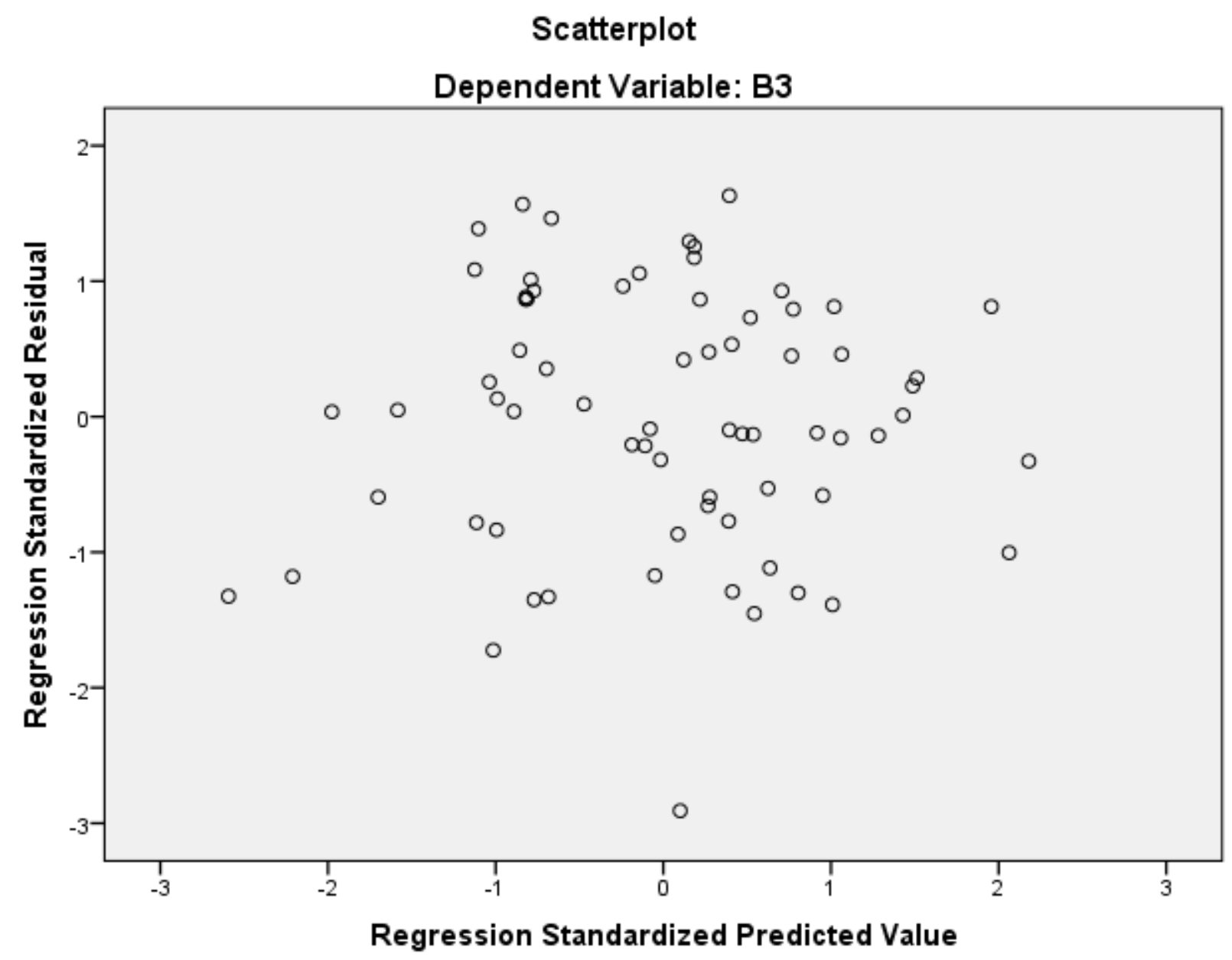




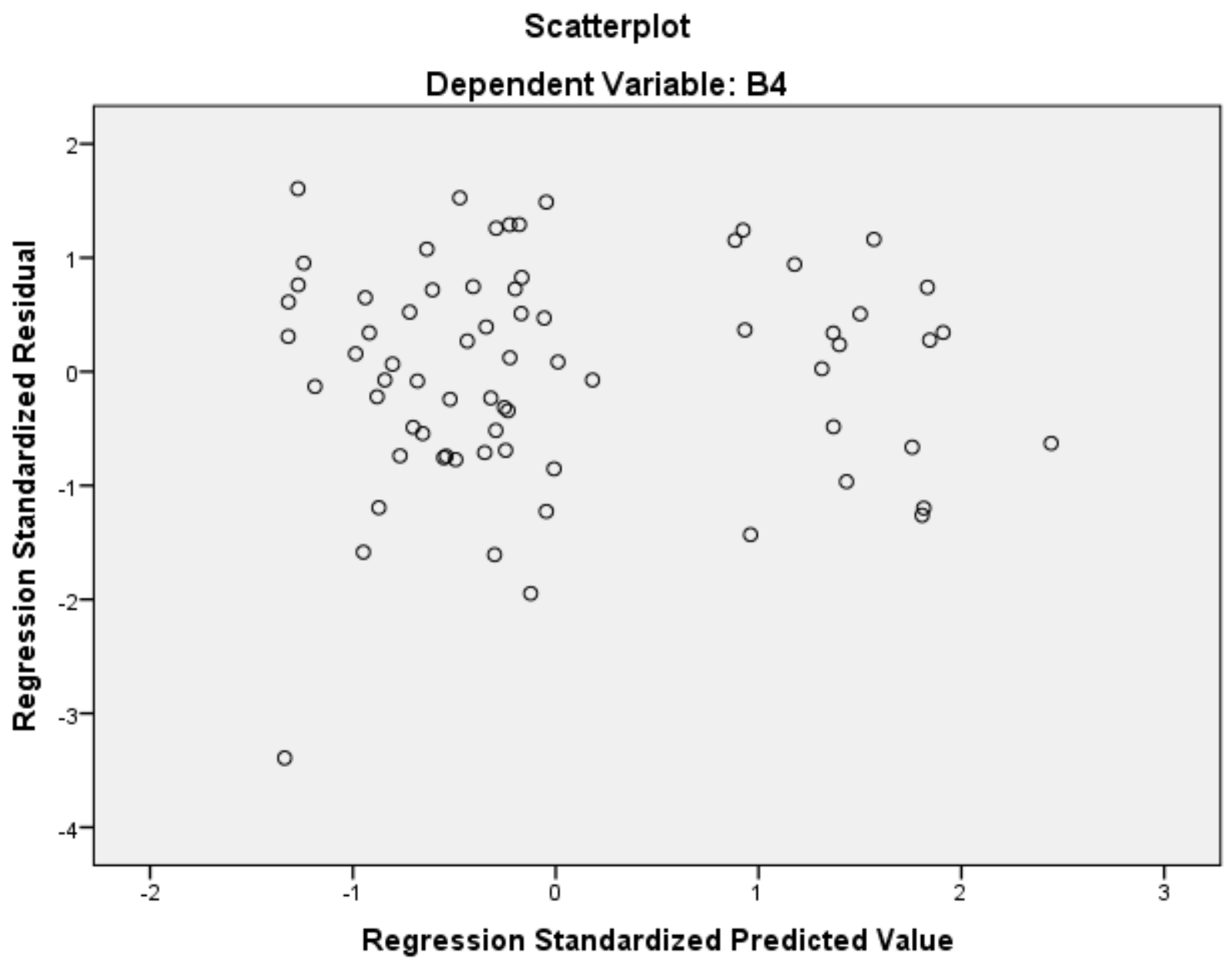




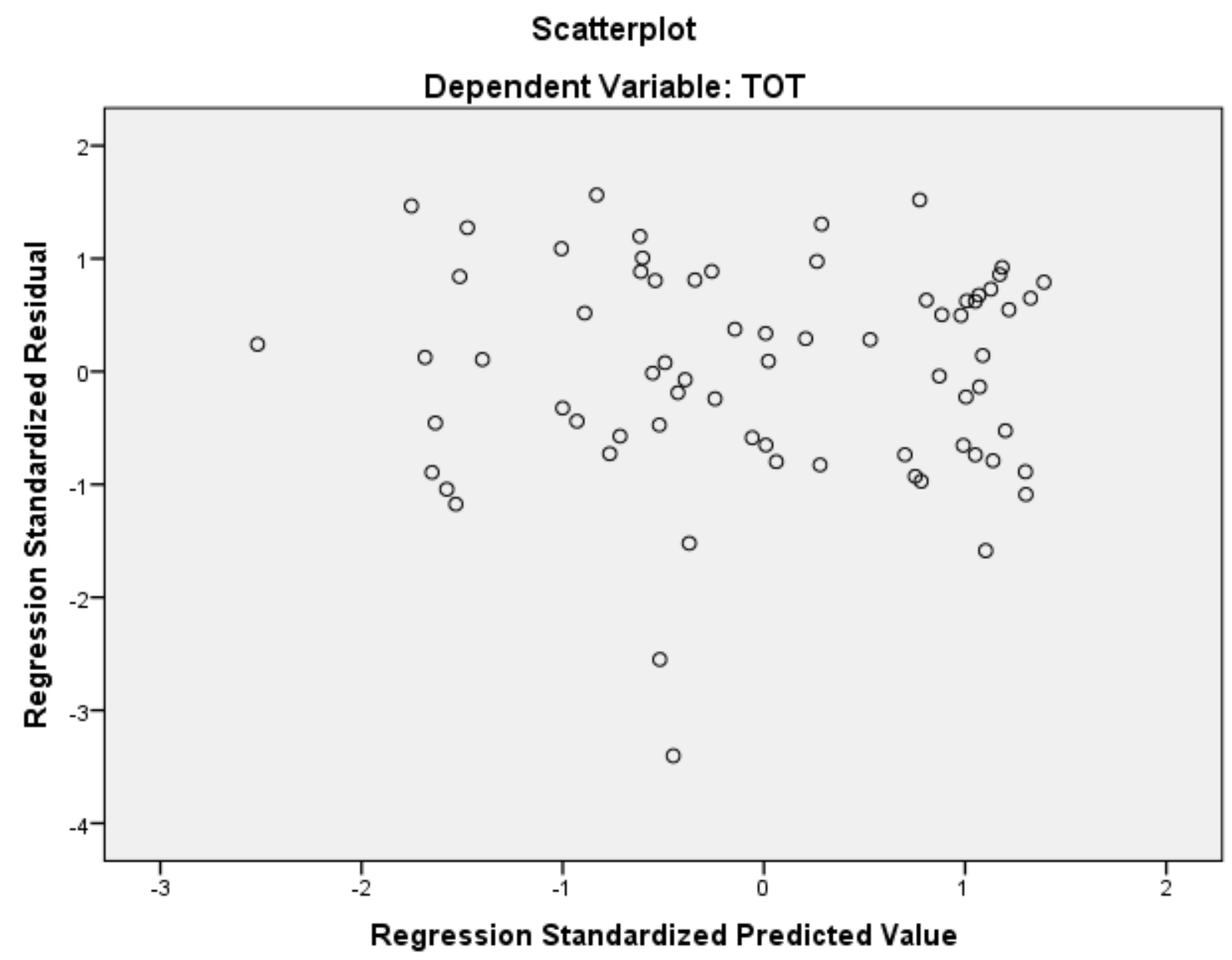

